Portland State University

PDXScholar

Fall 12-1-2014

\title{
The Power of Reflective Professional Development in Changing Elementary School Teachers' Instructional Practices
}

Carolina Christmann Cavedon

Portland State University

Follow this and additional works at: https://pdxscholar.library.pdx.edu/open_access_etds

Part of the Educational Methods Commons, and the Teacher Education and Professional Development Commons

Let us know how access to this document benefits you.

\section{Recommended Citation}

Cavedon, Carolina Christmann, "The Power of Reflective Professional Development in Changing Elementary School Teachers' Instructional Practices" (2014). Dissertations and Theses. Paper 2075. https://doi.org/10.15760/etd.2074

This Thesis is brought to you for free and open access. It has been accepted for inclusion in Dissertations and Theses by an authorized administrator of PDXScholar. Please contact us if we can make this document more accessible: pdxscholar@pdx.edu. 
The Power of Reflective Professional Development in Changing Elementary School

Teachers' Instructional Practices

by

Carolina Christmann Cavedon

A thesis submitted in partial fulfillment of the

requirements for the degree of

Master of Science in Teaching

in

General Science

Thesis Committee:

William Becker, Chair

Emily Saxton

Nicole Rigelman

Portland State University

2014 
(C) 2014 Carolina Christmann Cavedon 


\begin{abstract}
With the new goal of K-12 education being to prepare students to be college and career ready at the end of high school, education needs to start changing at the elementary school level. The literature suggests that teachers need reflective professional development (PD) to effectively teach to the new standards and to demonstrate change to their current instructional practices. This mixed-method multiple-case study investigated the impacts of a reflective professional development (PD) in changing elementary school teachers' instructional practices.
\end{abstract}

Teachers Instructional Portfolios (TIPs) were scored with a TIP rubric based on best practices in teaching mathematics problem-solving and science inquiry. The TIPs were also analyzed with a qualitative coding scheme. Case descriptions were written and all the collected data were used to explain the impacts of the reflective PD on changes in teachers' instructional practices.

While we found no predictive patterns in relation to teachers changing their classroom practices based on the reflective PD, we claim that teachers' desire to change might contribute to improvements in instruction. We also observed that teachers' selfassessment scores tend to be higher than the actual TIP scores corroborating with the literature on the usage of self-assessment to evaluate teachers' instructional practices. 


\section{Dedication}

I would like to dedicate this thesis in memory of my father, who I know, is very proud of my accomplishments. Especially, I would like to dedicate my work to my daughters: Laura and Bianca. You are the love of my life! 
Table of Contents

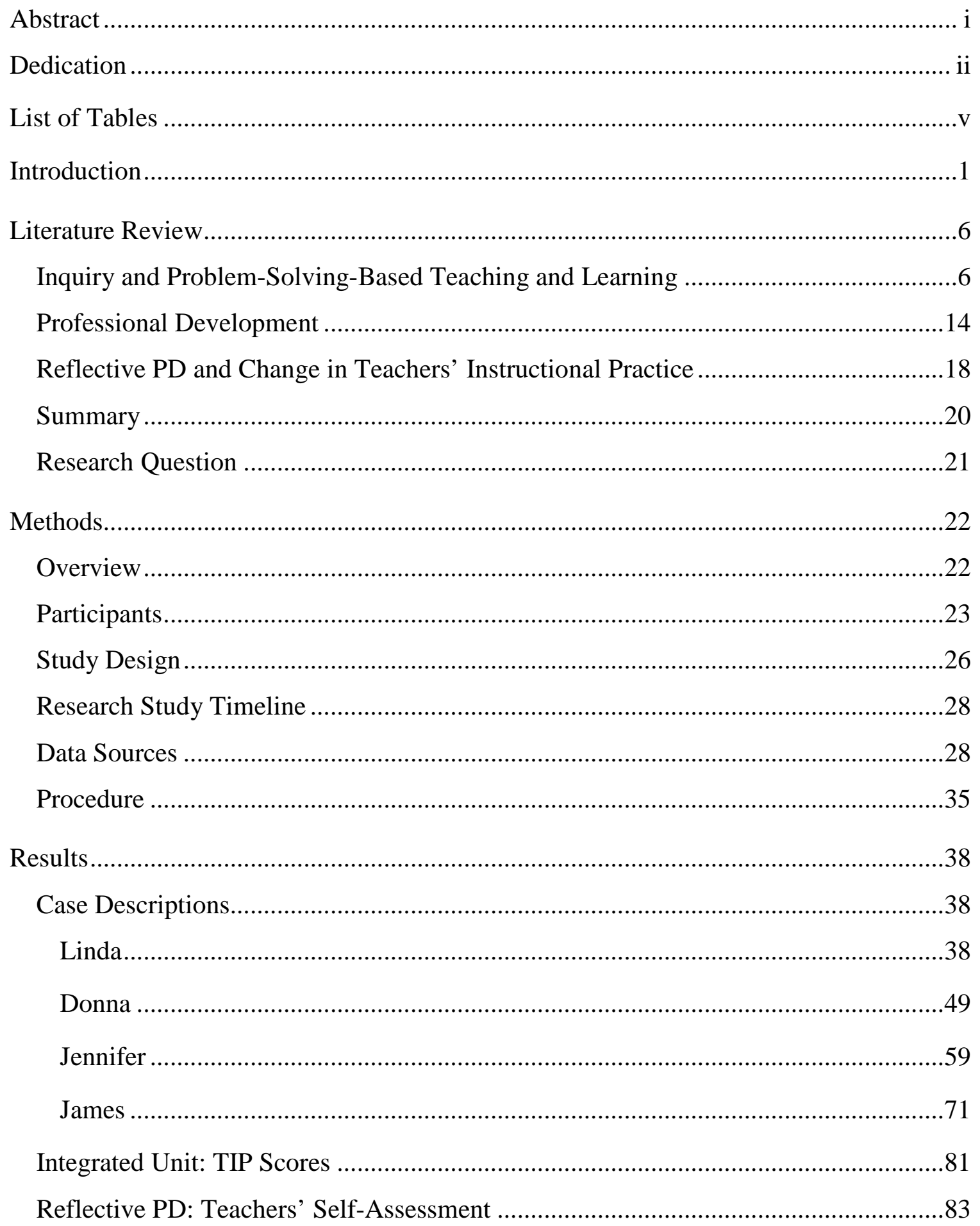


Reflective PD: Questions Posed by the Researchers ..............................................8 84

Reflective PD: Audio of Reflective Conversations with Researchers .........................88

Reflective PD: Teachers' Written Reflection .........................................................90

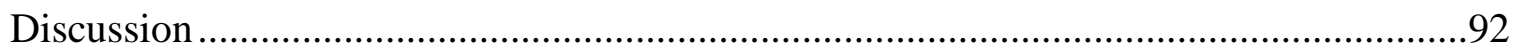

Trends Found in the First Implementation of the Integrated Units ...........................92

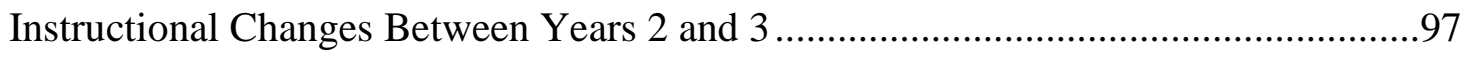

Data Sources: Explaining Teachers' Instructional Changes ..................................97

Case Descriptions: Teachers' Desire to Change Instructional Practices .................103

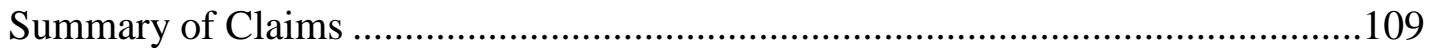

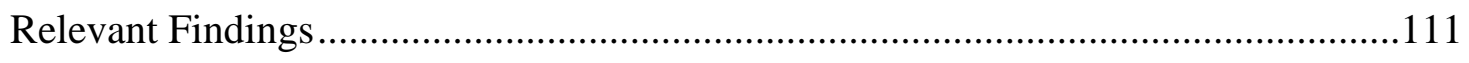

Desire to Change Instruction versus Importance of Changing Instruction..............111

The Specific Case of Content and Cognitive Skills for Science..............................114

Comparison Between TIP Scores and Self-Assessment Scores ...........................116

External Factors that Could Have Contributed to Teachers' Instructional Change.118

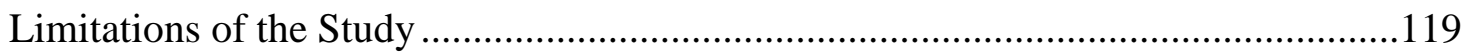

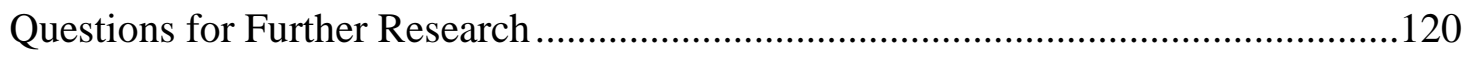

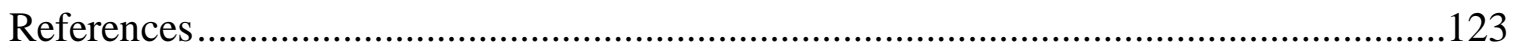

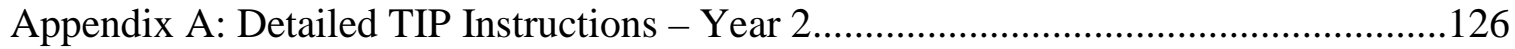

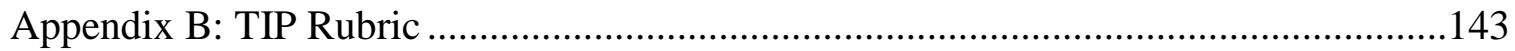

Appendix C: Teacher Self-Assessment Rubric - Science ............................................145

Appendix D: Reflection Day Agenda and Questions that Guided Teachers'

Written Reflections 
List of Tables

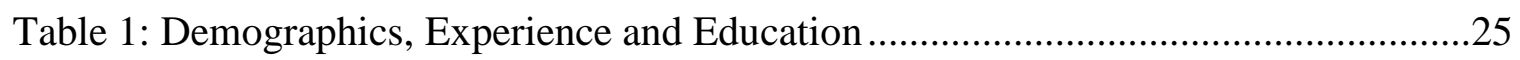

Table 2: Courses Taken by Each Teacher.....................................................................26

Table 3: Integrated Unit Information for Participating Teachers ...................................27

Table 4: Professional Development Timeline...........................................................29

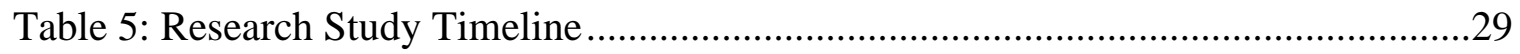

Table 6: Audio Coding Scheme Based on the TIP Rubric Categories .............................34

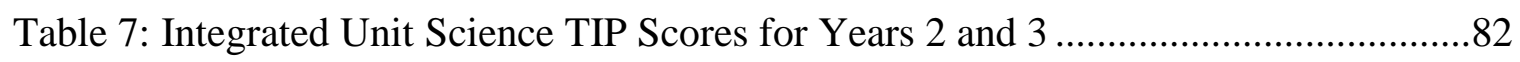

Table 8: Integrated Unit Mathematics TIP Scores for Years 2 and 3 ............................83

Table 9: Teachers' Self-Assessment Instructional Vision: Science ...............................85

Table 10: Teachers' Self-Assessment Instructional Vision: Mathematics .......................86

Table 11: Frequency of Science Researchers’ Posed Questions .....................................87

Table 12: Frequency of Mathematics Researchers' Posed Questions ............................87

Table 13: Frequency of Teachers' Audio Code (Science) ............................................89

Table 14: Frequency of Teachers' Audio Code (Mathematics) ......................................89

Table 15: Frequency of Teachers' Written Reflection ..............................................91 


\section{Introduction}

The new approach to K-12 education in the United State is urgent in preparing students to be college and career ready. Our modern society is expecting students who finish high school to be ready to enter the workforce and perform high-level tasks, which increasingly demand strong background knowledge in fields such as science, technology, engineering, and mathematics (STEM). In addition, students who follow the college path will need to possess critical-thinking, problem-solving and analytical skills to be successful in freshman-level college courses and throughout their undergraduate programs (CCSSI, 2014; NRC, 2012).

Schools are being held accountable for making the necessary changes so students possess the new skills our society is requiring. However, for that to be accomplished, teachers will need to learn how to teach these new skills that are key to college and career readiness (CCR). To better facilitate students' learning and support their efforts to accomplish the goals of the " $21^{\text {st }}$ century education", teachers need to be well-prepared and ready to foster students' autonomy in being proficient in STEM content as well as in the use of higher-order thinking skills (HOTS) (NRC, 2012).

When addressing the specific skills necessary to be CCR, new instructional practices need to be in place. For inquiry-based science and inquiry-oriented mathematics, authority over content needs to be shifted away from teachers so they can act as facilitators and supporters of students' scientific learning and sense making of 
mathematics (Anderson, 2002; Hiebert et al., 1997). Conceptual understanding and HOTS both need to be targeted when planning and implementing units of study as well as multiple opportunities for students to construct meaning, apply content and practice HOTS need to be provided so students can be active learners and further develop their understanding about the world (Anderson, 2002; Hiebert et al., 1997; Minner et al., 2010; Stein et al. 2009). Black and Wiliam (1998) reinforce the importance of the use not only of summative but also formative assessments with feedback from teachers so students' misconceptions are addressed and assessment data is used to improve instruction.

In order to succeed in implementing these instructional practices, which contribute to students being CCR at the end of high school, change needs to start at the elementary school level. Dougherty (2013) points out four reasons to explain why early learning is important in order for students to be college and career ready at the end of high school: (1) learning takes time, (2) learning is cumulative, (3) student interests often develop at an early age, and (4) empirical evidence shows the difficulty of catching students up in middle and high school (p. 2). However, it is very difficult to start teaching for STEM content and HOTS in the early stages of learning as suggested by Dougherty (2013), because (1) teachers haven't experienced that kind of instruction themselves and (2) typical elementary school instruction is characterized by rote memorization, factbased instruction over higher order thinking (Gulamhussein, 2013, Linn et al., 2006; Schoenfeld, 1988). For this reason, it is recommended to provide professional development for elementary school teachers so they receive the necessary support to 
implement the essential instructional practices to prepare young students to be ready for middle and high school (Dougherty, 2013).

Considering professional development one of the answers to addressing teachers' inexperience with CCR instructional practices that will target the new goals of the $21^{\text {st }}$ century education, Ingvarson et al. (2005) argue "professional development for teachers is now recognized as a vital component of policies to enhance the quality of teaching and learning in our schools" (p. 2). Nevertheless, not every kind of professional development can promote teachers' understanding and ability to implement these new instructional practices. Gulamhussein (2013) suggests that the "real issue isn't that teachers aren't provided professional development, but that the typical offerings are ineffective at changing teachers' practice or student learning" (p. 1). Specific professional development needs to be planned and delivered to foster change and better implementation of teachers' instructional practices.

Guskey (2002) emphasizes that there is need for professional development to provide teachers with extra time to practice the new skills being acquired, to ensure that teachers will receive feedback on student learning progress, and to provide follow-up and support during the process. Adding to Guskey's points regarding professional development, Ingvarson et al. (2005) points to the need for a content focus, with active learning, and collaborative examination of student work for effective professional learning to happen. Summarizing the characteristics of successful professional development, Elmore and Burney (1997) state: 
it focuses on concrete classroom applications of general ideas; it exposes teachers to actual practice rather than to descriptions of practice; it offers opportunities for observation, critique, and reflection; it provides opportunities for group support and collaboration; and it involves deliberate evaluation and feedback by skilled practitioners with expertise about good teaching. (p. 263).

It is clear that effective professional development needs to include the characteristics proposed by the above authors: collaboration between teachers, feedback from experts, follow up, and opportunities for teachers to reflect on their own practice to have an impact on teachers' instructional practices.

From all the characteristics already cited, reflection is reported to "be the key to teacher learning and development" (Shulman \& Shulman, 2004, p. 264). Harnett (2012) points out the importance of teachers taking the time to reflect on their own actions to enhance their own professional practice. Contributing to that, Ferraro (2000) states, that for teachers, the primary benefit of reflective practice is an understanding of their own teaching and learning. Harnett (2012) argues, "if professional development is to bring about lasting change it must involve the teachers concerned in analyzing, critiquing, reflecting upon, and improving their own classroom practice" (p. 382). Reflective professional development seems to be an effective opportunity for teachers to implement new instructional practices, reflect about their implementation and change their practice based upon what they have reflected on.

Parise and Spillane (2010) suggest "there is great faith among school reformers and education researchers that augmenting the learning opportunities of practicing teachers will enhance teacher performance and lead to improved student outcomes" (p. 
324). Even though teachers' professional development is extremely important to accomplish the goals of $21^{\text {st }}$ century education, it does not make sense to provide teachers with opportunities to experience professional development without studying whether it is actually contributing to changes in teachers' instructional practices. Guskey (2002) reinforces that "in the absence of evidence of positive change in students' learning, [...] significant change in the attitudes and beliefs of teachers is unlikely" (p. 386). In consideration to Guskey's assertion, Gulamhussein (2013) illustrates how teachers' and students' change can represent a Catch-22:

to internalize a practice and change their beliefs, teachers must see success with their students, but student success is very hard to come by initially, as learning new skills takes several attempts to master. Crafting effective professional development means confronting this reality and building a significant amount of support for teachers during the critical implementation phase in one's actual classroom. (p. 12).

For this reason, before we can even investigate students' learning as a result of professional development, we need to investigate whether it is changing teachers' instructional practices.

The purpose of this mixed-methods, multiple-case study is to investigate the power of reflective professional development in changing elementary school teachers' instructional practices. Teachers Instructional Portfolios (TIP) about mathematics and science integrated units from first and second implementation were analyzed from eight elementary school teachers. Both quantitative and qualitative analyses were conducted using a rubric (Saxton \& Rigelman, unpublished) and researchers-developed coding schemes to characterize the changes in teachers' instructional practices. 


\section{Literature Review}

The literature review for this study is focused on understanding effective instructional techniques for science and mathematics teaching and learning and how those strategies can be fostered in professional development (PD) to create change in teacher's instructional practices. A first section, entitled Inquiry and Problem-Solving-

Based Teaching and Learning, reviews methods that are widely accepted as effective in science and mathematics teaching. Two research papers and a review of the Framework for K-12 Science Education provide an overview of inquiry-based learning and two other papers inform about mathematics problem-solving education. Those five references are used as the theoretical foundation for this research. A second section, entitled Professional Development, describes effective characteristics of professional development in general and also presents examples of successful PD programs. Finally, the last section, entitled Reflective Professional Development and Change in Teachers' Instructional Practice, presents two articles about the importance of reflective professional development to achieve change in teachers' instructional practices.

\section{Inquiry and Problem-Solving-Based Teaching and Learning}

Anderson (2002) presents an overview of inquiry in science education (starting with the National Science Education Standards document), including multiple meanings of the term, and the value of inquiry as an instructional practice. According to the author and his review of the National Science Education Standards (NSES), the term inquiry 
refers to the scientific inquiry that motivates scientists to research; it also is used as the "heart of learning", as an active learning process in which students are engaged. Finally, Anderson states inquiry as a teaching methodology, more specifically a science teaching methodology, citing the NSES: inquiry "refers to the activities of students in which they develop knowledge and understandings of scientific ideas, as well as understanding of how scientists study the natural world" (p. 2). When it comes to science education research results, Anderson analyzes a wide range of recent and older studies that demonstrate a positive impact of inquiry teaching on student's skills, attitudes towards science and cognitive achievement. At the same time, Anderson states more research is under way to better demonstrate all the positive impacts of science inquiry in students' learning. In fact, more research is necessary because there is resistance from parents, teachers, policy makers that are "not convinced that these objectives are as important as more specific knowledge of vocabulary and facts" (p. 6).

Later, the author analyzes the question of whether teachers are capable of implementing inquiry learning for their students and he reports that research so far was positive "under the right circumstances" (p. 7). He also highlights that it is important to understand the difficulty of doing so. Teachers need to learn "how to teach constructively, acquire new assessment competencies, learn new teaching roles, learn how to put students in new roles and foster new forms of student work" (p. 8) which can conflict with their beliefs and the methods they developed in their prior experiences and trainings. Finally, Anderson emphasizes that collaboration is a "powerful stimulus for the 
reflection" (p. 9); this observation applies to students that collaborate with each other and their teachers in reaching their own conclusions but also teachers relationships with other teachers, which can be helpful to overcome difficulties in training good teachers and “change beliefs, values and understandings" (p. 9).

Building on Anderson's work, Minner et al. (2010) synthesize research results from 1984 to 2002 in Inquiry-Based Science Instruction. They define inquiry learning similarly to Anderson (2002): "Learners are engaged by scientifically orientated questions; learners give priority to evidence (...), learners formulate explanations (...), learners evaluate their explanations (...), learners communicate and justify their proposed explanations" (Minner et a., 2010, p. 476). A total of 138 studies were considered and $51 \%$ of those report positive impacts of inquiry science instruction, which does not represent a statistically significant association of inquiry to increased conceptual learning. However, Minner et al. (2010) emphasize that "subsequent model refinement indicated that the amount of active thinking, and emphasis on drawing conclusions from data, were in some instance significant predictors of the increased likelihood of student understanding of science content" (p. 493).

Finally, the authors highlight that of all comparative studies, more than half had significant statistical evidence of a benefit, especially the ones involving hands-on activities and "emphasis on student responsibility" (p. 493). While this data is not "overwhelmingly positive" (p. 493), it demonstrates a trend that "instruction within the investigation cycle has been associated with improved student learning" (p. 493). 
The Framework for K-12 Science Education: Practices, Crosscutting Concepts, and Core Ideas (2012) adds to the above conversation about engaging students in scientific inquiry by acknowledging that it requires coordination of both content and higher order thinking skills. The authors state, "engaging in the practices of science helps students understand how scientific knowledge develops; such direct involvement gives them an appreciation of the wide range of approaches that are used to investigate, model, and explain the world" (p. 42). In addition, including scientific inquiry in teaching and learning can foster students' curiosity, motivate them to learn, and deepen their understanding of the work of scientists and engineers.

To better include science inquiry and engineering design in the classrooms, the framework suggests the implementation of eight practices: (1) asking questions (for science) and defining problems (for engineering), (2) developing and using models, (3) planning and carrying out investigations, (4) analyzing and interpreting data, (5) using mathematics and computational thinking, (6) constructing explanations (for science) and designing solutions (for engineering), (7) engaging in argument from evidence, and (8) obtaining, evaluating, and communicating information. It is not expected of students to develop new scientific theory, but to use theory-based models to argue, build explanations and demonstrate understanding of scientific viewpoints. In summary, the framework argues, "students' opportunities to immerse themselves in these practices [the 8 practices cited above] and to explore why they are central to science and engineering 
are critical to appreciating the skill of the expert and the nature of his or her enterprise" (p. 47).

Addressing mathematics education, Hiebert et al. (1997) state that it is crucial that students learn mathematics with understanding. The authors identify that students "need problem-solving methods that can be adapted to new situations, and they need the knowhow to develop new methods for new kinds of problems" (p. 1). Hiebert et al. also suggest a framework for thinking about classrooms and the practice of mathematics. They emphasize that the framework can lead teachers to reflect on their practice and to identify possible changes in their mathematics instructional practices. Their framework has five dimensions: “(1) the nature of the learning tasks, (2) the role of the teacher, (3) the social culture of the classroom, (4) the kind of mathematical tools that are available, and (5) the accessibility of mathematics for every student" (p. 2).

With Hiebert et al.'s (1997) framework as a background for teachers' reflection, teachers can keep students engaged in mathematics by providing opportunities for students to understand math since they begin to practice it. The authors advocate that student learning with understanding means to learn "skills so they are remembered, can be applied when they are needed, and can be adjusted to solve new problems" (p. 6). Three characteristics are proposed for tasks to foster students' learning mathematics with understanding: (1) the subject of the task needs to be problematic for students, (2) the task needs to be based on students' background knowledge, and (3) the task should engage students in thinking about important mathematics concepts and skills. In 
summary, mathematical tasks should be viewed as "opportunities to explore mathematics and come up with reasonable methods for solution" (p. 8).

Stein et al. (2009) analyzed mathematics instructional tasks in terms of their cognitive demands. Citing the Professional Standards for Teaching Mathematics, the authors state that

opportunities for student learning are not created simply by putting students into groups, by placing manipulatives in front of them, or by handing them a calculator. Rather, it is the level and kind of thinking in which students engage that determines what they will learn. (p. 11).

Students are led to distinct opportunities depending on the level of cognitive demand the mathematical instructional task they are supposed to do requires. Since teachers are the ones selecting the tasks to be used in their classrooms, they need to learn how to differentiate each task based on the level of cognitive demand. Stein et al. exemplify close relationship between the learning goals and the selected task by arguing "if a teacher wants students to learn how to justify or explain their solution processes, she should select a task that is deep and rich enough to afford such opportunities" (p. 12).

Next, the authors characterize the cognitive demand of mathematical tasks in four levels. The first two levels are low in cognitive demand: (1) memorization and (2) procedures without connections to understanding, meaning and concepts. The next two levels are considered high in cognitive demand: (3) procedures with connections to understanding, meaning, or concepts and (4) doing mathematics. Stein et al. (2009) assert that not all mathematical tasks should engage students in challenging cognitive demand 
activities. Lower-level cognitive demands tasks are important to "improve students performance on tests that consist of low-level items and may lead to greater efficiency of time and effort in solving routine aspects of problems that are embedded in more complex tasks" (Stein et al., 2009, p. 15).

When analyzing mathematical tasks, it is important to look beyond the surface of the task to be able to understand what kind of thinking it requires. Stein et al. (2009) suggest that when designing a mathematics task, the teacher should consider the learning goals of student performance as well as the appropriate level of challenge for their students' cognitive ability. Finally, the authors urge teachers to provide students with opportunities to "engage with tasks that lead to deeper, more generative understanding regarding the nature of mathematical processes, concepts, and relationships" (p. 15).

Black and Wiliam (1998) present their conclusions about formative assessment based on an extensive literature review they had published prior to 1998. The authors state that an assessment becomes formative when "the evidence is actually used to adapt the teaching to meet student needs" (p. 140). Black and Wiliam emphasize the importance of formative assessment to raise achievement overall, indicating the need to include feedback on students' work, and to actively involve students in their own learning. The authors state that "feedback to any pupil should be about the particular qualities of his or her work, with advice on what he or she can do to improve, and should avoid comparisons with other pupils" (p. 143). Feedback on students' work is one of the 
instructional practices that the authors believe needs significant improvement in order to be successful as an assessment practice.

The authors found out in their literature review that the way formative assessment is being used in the classroom is not appropriate and that it needs to be better developed to increase its impact on student learning. One way suggested by Black and Wiliam to improve formative assessment is to provide students with genuine opportunities for them to self-assess. The authors argue "opportunities for pupils to express their understanding should be designed into any piece of teaching, for this will initiate the interaction through which formative assessment aids learning" (p. 143). They conclude their review by stating that formative assessment is an important component of classroom practice and when it is well implemented, it can raise standards of achievement.

In summary, the Inquiry-Based and Problem-Solving Teaching and Learning section presents a review of effective practices in science and mathematics teaching that are the foundation of this research study. For science, it highlights the importance of scientific inquiry, students' collaboration and active engagement, and opportunities for content and higher order thinking skills to be taught, practiced and applied together. With the framework for science education, the eight science inquiry and engineer design instructional practices are presented and a justification for its implementation is provided. For mathematics, it emphasizes the nature of the problem-solving task and the importance of learning mathematics with understanding. Formative assessment is also seen as an instructional practice that needs improvement but when well developed can 
contribute to raise standards of achievement. All those characteristics of effective teaching and learning are considered in this study in hopes to observe changes in teachers' instructional practices when participating in a reflective professional development opportunity.

\section{Professional Development}

Guskey (2002) presents a model of teacher change based on professional development (PD). The author starts by defining PD programs as "systematic efforts to bring about change in the classroom practices of teachers, in their attitudes and beliefs, and in the learning outcomes of students" (p. 381). Then, some reasons for PD to fail are exposed: (1) not taking into consideration what motivates educators to engage in PD, and (2) not considering the "process by which change in teachers typically occurs" (p.382). Guskey notes that teachers indicate their own success in teaching based on students' performance. Considering that, Guskey points out "what attracts teachers to professional development, therefore, is their belief that it will expand their knowledge and skills, contribute to their own growth, and enhance their effectiveness with students" (p. 382).

A model of teacher change is proposed in view of professional development that first wants to change teachers' beliefs and skill sets to then impact students' learning outcomes. According to Guskey's alternative model, “significant change in teachers' attitudes and beliefs occurs primarily after they gain evidence of improvements in student learning" (p. 383) In support of this model, the author presents a variety of studies where 
teachers only became committed to a new practice after they had observed the impact of it in their students. Further, Guskey describes a similar model proposed 100 years ago to illustrate the relationship between behavioral response and emotion. Finally, he identifies three principles that should guide program developers when planning PD to ensure success: "(1) recognize that change is a gradual and difficult process for teachers; (2) ensure that teachers receive regular feedback on student learning progress; and (3) provide continued follow-up, support and pressure" (p. 388). At the end Guskey concludes, "careful attention to the order of change events described in this model is likely not only to facilitate change-making, but also to contribute to the endurance of change" (p. 389). It is important to understand that the process for teachers to change instructional practice through professional development is complex and follows a general pattern where teachers first change their classroom practice, then a change in student learning outcomes occurs, and finally teachers' beliefs and attitudes are changed.

In another study, Ingvarson, Meiers, and Beavis (2005) examined the "effects of structural and process features of professional development programs on teacher's knowledge, practice and efficacy" (p. 2). The authors combined data from four studies to report their results from 3250 teachers. Those teachers participated in more than 80 different professional development opportunities and completed a common survey instrument, providing a possibility for a cross-program analysis. Teachers were surveyed at least three months after participating on the PDs and that caused a response rate average of 50\%. The authors developed a framework to evaluate the effectiveness of PD 
programs based on four impacts resulting for trainings: knowledge, practice, student learning, and teacher efficacy. Further, they created an instrument (4-point scale) to measure the research-based critical features of PD: content focus, follow up, active learning, feedback, and collaborative examination of student work.

Ingvarson et al. argued that "the quality of impact of a program should not only be measured in terms of whether it meets the developers' objectives, but also in terms of the extent to which the program moves teachers' practices towards those associated with research-based standards for effective teaching" (p. 10). In summary, they found that the "opportunities to learn" (content focus, active learning, follow-up, collaborative examination of student work, and feedback on practice) had the largest effect on PD program outcomes as measured by teacher report. The authors suggest that one of the most significant findings from their study was "how rarely designers built in opportunities for feedback and coaching in the workplace, despite research on their centrality to learning new and complex skills" (p. 18). They also concluded that the impact of the PD on teachers' efficacy was related to the impact of teachers' instructional practices on their students' learning outcomes.

Elmore and Burney (1999) documented, described and analyzed an attempt to "use professional development to mobilize knowledge in the service of systemwide instructional improvement" (p. 264). The authors chose to report on the Community School District 2 (CSD) in New York because this district had a unique systematic way of implementing PD. CSD professional development plan had been implemented for 8 
years when Elmore and Burney wrote their report and the district's main goal was to improve teaching and learning in the schools.

Elmore and Burney describe the five major categories used to create the CSD professional development model. The first of those categories include a professional development laboratory where visiting teachers spent 3-4 weeks observing and practicing in resident teachers' classrooms. The second category was the investment in hiring instructional consultants who worked directly with the teachers at each school site. Peer network and visits to other school sites were the third category and fostered the contact of teachers and principals with exemplary practices. In addition to those 3 categories, the district also offered off-site training during the summer and school year to promote content-focused training over a long term. The fifth category was oversight and principal visits to review the performance of the schools as well as to provide opportunities for district staff to know a lot more about the schools.

Elmore and Burney suggest that this PD model worked because it implemented strategies to succeed. It did not try to "change all dimensions of teaching practice at once, but that it sets in motion a process for making changes in teaching practices, and it creates the expectation that these changes will reach deeply and broadly in the system" (p. 281). Finally, the authors report the main characteristics of successful PD as:

it focused on concrete classroom applications of general ideas; it exposes teachers to actual practice rather than to descriptions of practice; it offers opportunities for observation, critique and reflection; it provides opportunities for group support and collaboration; and it involves deliberate evaluation and feedback by skilled practitioners with expertise about good teaching. (p. 263). 
In summary, the section about Professional Development provided a definition of professional development as well as an alternative PD model for teacher change (Guskey, 2002). Further all studies in some way emphasize that for teachers' instructional practices to change, it is necessary to have evidence of student learning improvement. Examples of successful PD implemented were described and analyze (Elmore and Burney, 1999; Ingvarson, et al., 2005) as well as the characteristics of successful PD were shared (Elmore and Burney, 1999; Guskey, 2002; Ingvarson et al., 2005) serving as a foundation for this research study.

\section{Reflective PD and Change in Teachers' Instructional Practice}

Ferraro (2000) wrote a short review of the importance of reflective practice in education. She uses the definition proposed by Schon (1996) to state "reflective practice involves thoughtfully considering one's own experiences in applying knowledge to practice while being coached by professionals in discipline" (p. 2). Further, the author reinforces the importance of building a unique background for reflection that should be specific to every teacher and teacher's own experiences.

Next, Ferraro (2000) argues, "critical reflection upon experience continues to be an effective technique for professional development" (p. 3). Moreover, effective teaching practice has also been linked to "inquiry, reflection, and continuous professional growth" (p. 5). Finally, the author emphasizes that reflective practice has a benefit to teachers' 
deeper understanding of their own teaching style, improving their effectiveness as teachers.

Harnett (2012) investigated the effects of teachers' reflection on their own practice. As Ferraro, Harnett (2012) also reinforced the need for teachers to reflect critically to enhance their professional practice. The author implemented an action research project with two elementary school teachers that had a reflection day where the researcher asked probing questions to encourage those two teachers to reflect on their lessons.

The author claims that there was a discrepancy between what teachers believed they were doing in the classrooms and what they were really doing. Harnett (2012) also asserts that when teachers engage in reflective opportunities, they are "pulled out" of the "automatic pilot" mode to be become grounded in deep understanding of their own teaching and learning (p. 379). In addition, the author supports the idea that "unless teachers are assisted to develop their reflective skills to the point where they are able to critique and monitor their own behavior in the classroom, such routinised [sic] and unreflective practice will be unlikely to change" (p. 382). Finally, Harnett urges for professional development to include teachers' analysis, critique and reflection upon improving their own instructional practices.

In summary, the section about Reflective Professional Development and Change in Teachers' Instructional Practice presents a definition of reflective practice and its 
importance to teachers' education programs. This section emphasized the necessity of professional development to include opportunities for teachers to reflect on their own teaching to be able to change their instructional practices.

\section{Summary}

Inquiry and problem-solving-based teaching and learning is widely recognized to be a collection of successful teaching practices, especially when applied to science and mathematics. In comparison with a traditional format where students receive knowledge from the teachers, the inquiry and problem-solving-based teaching stimulates students to provide their own conclusions by being challenged with questions that can be answered with hands-on activities and by practicing higher order thinking skills. One problem that arises with the implementation of inquiry and problem-solving-based teaching is the need to support and educate teachers so they can acquire new instructional practices.

To support teachers' implementation of inquiry and problem-solving-based strategies, the next section of this literature review reviewed three papers about professional development. The articles provide examples of successful PD programs (Ingvarson et al., 2005; Elmore and Burney, 1999) and presented a PD model of teacher change (Guskey, 2002). The studies also highlighted that the success of PD programs depend upon teachers' change in instructional practices that will have positive effects on students' learning. All three-research articles emphasize the characteristics of successful 
PD (collaboration between teachers, feedback on teachers' practice, follow up and reflection) and serve as a foundation for this study.

Finally, the last two articles, in the last section, are specifically about reflective PD and its relevance to teachers changing their instructional practices. Both papers suggest ways to implement reflection in professional development, providing examples

of successful experiences. However, there is not a significant amount of research articles specific about the impacts of reflective professional development in changing teachers' instructional practices, indicating that more research in this field is necessary.

All the research studies summarized in this literature review contribute to the knowledge that serves as a foundation to this thesis investigation. Understanding the factors that contribute to change in teachers' instructional practices within inquiry and problem-solving-based learning will support the findings of this study about a reflective professional development experience.

\section{Research Question}

This study investigates the impact of reflective professional development in changing elementary school teachers' instructional practices by using a mixed-methods approach to better understand teachers' practices. 


\section{Methods}

\section{Overview}

The goal of this multiple-case study was to investigate the influence of reflective professional development on teachers' instructional practices, by conducting an in-depth investigation of selected cases.

This research investigated eight elementary school teachers that submitted Teacher Instructional Portfolios (TIP) for a professional development workshop (described below). This study used a mixed-methods approach to analyze and accomplish its goal. First, the TIP for each teacher was scored using the TIP rubric developed by Saxton and Rigelman (unpublished) based on best instructional practices. Next, reflective questions posed by the researchers about each TIP were coded following the TIP rubric categories. The qualitative code was used to score teacher's written reflections and the audio from each reflective professional development session. Finally, a detailed case description was written for 4 out of the 8 teachers who participated in this study.

Rigelman and Saxton developed a three-year long professional development program about integration of science and mathematics to elementary school teachers. This three-year long research project and professional development collected data from around 20 elementary school teachers. It was entitled Connect2MATH and Connect2SCIENCE: Proficiency and Inquiry-Based Teaching in Math and Science. This thesis is based on a reflective PD day that was part of this three-year long PD project. 
The main instrument used for this research was the Teacher Instructional Portfolio (TIP). Saxton and Rigelman collected TIPs from elementary school teachers from grades third to fifth about an integrated math and science unit. The TIPs had three main sections: knowledge, skills and experience (KSE) outcomes, assessment, and pedagogical strategy reflections. The Data Sources section of this thesis presents a detail description of the TIP as well as other data sources used in this study.

\section{Participants}

Context. The participants of this study were eight elementary school teachers of grades three through five. They participated in the three-year long professional development (PD) project provided by Portland State University's Center for Science Education in conjunction with school districts from the Portland metropolitan area. The first sessions of the PD that are relevant to this research study happened during the summer of 2011 (content courses and Connect2INTEGRATION). After that, the teachers had an opportunity to implement mathematics and science integrated units in the following school year (2011-2012). By spring 2012, teachers turned in their TIPs and participated in the reflective session of the PD. During the summer, teachers took content courses once again. Those teachers had a chance to modify their planned integrated units during the following school year based on their reflections during the PD. By spring 2013, they had implemented a revised version of the same integrated unit, turned in their TIPs for year three (second implementation on the integrated units) and also participated in the last reflective session of the PD relevant to this study, even though their units were 
not the focus of the discussion. Those teachers were invited to participate in the research and all voluntarily agreed to participate. The selection criteria for these educators to participate in the grant was based on the fact that they were considered leaders in their schools, as well as in the professional development program and had at least three years of teaching experience.

Number of cases. From the eighteen lead teachers who agreed to participate in the three-year long PD project, only eight were able to revise and teach their integrated units a second time. Some of the teachers were assigned to a different grade level or switched to a different school, and therefore not able to take part in this study. The eight teachers submitted all the requested materials from their integrated mathematics and science unit and continued to participate in PD the following spring conforming to the expected criteria to be included in this research.

Teacher demographics. All teachers who agreed to be involved in this investigation provided their consent to the researchers to use their unit materials as well as other data sources for the purpose of this research. Further, they completed the Survey of Enacted Curriculum (SEC) providing information about their own demographics, education, and teaching experience. This information is summarized in Table 1. 
Table 1

Demographics, Experience and Education of Participating Teachers from SEC

\begin{tabular}{|l|c|c|c|c|c|}
\hline Teacher & Gender & Ethnicity & $\begin{array}{c}\text { Teaching } \\
\text { Experience (years) }\end{array}$ & $\begin{array}{c}\text { Years Teaching at } \\
\text { Current School }\end{array}$ & $\begin{array}{c}\text { Highest } \\
\text { Degree }\end{array}$ \\
\hline Mary & F & $\begin{array}{c}\text { American } \\
\text { Indian/ Alaskan } \\
\text { Native }\end{array}$ & $3-5$ & Less than 1 & BA or BS \\
\hline Linda & F & White & $6-8$ & $3-5$ & MA or MS \\
\hline Jennifer & F & White & More than 15 & More than 15 & MA or MS \\
\hline Susan & F & $\begin{array}{c}\text { Black/African } \\
\text { American }\end{array}$ & $1-2$ & $1-2$ & MA or MS \\
\hline Nancy & F & White & $9-11$ & $3-5$ & MA or MS \\
\hline James & M & White & $9-11$ & $9-11$ & MA or MS \\
\hline Laura & F & White & $9-11$ & $9-11$ & MA or MS \\
\hline Donna & F & White & More than 15 & More than 15 & BA or BS \\
\hline
\end{tabular}

Courses Taken by Participants. All teachers who participated in this study took courses during the summer of 2011 and 2012 to support their content knowledge. Also, in the summer of 2011, all educators were involved in a course called Connect2INTEGRATION where they developed their mathematics and science integrated units. Table 2 provides information about the courses taken by each teacher. 
Table 2

Courses Taken by Each Teacher During the Summer of 2011 and Summer of 2012

\begin{tabular}{|l|l|l|}
\hline Teacher & \multicolumn{1}{|c|}{ Courses Taken in the Summer 2011 } & \multicolumn{1}{|c|}{ Courses Taken in the Summer 2012 } \\
\hline Mary & $\begin{array}{l}\text { Connect2Integration, and } \\
\text { Connect2Science: Earth Space }\end{array}$ & Connect2Science: Physical Science \\
\hline Linda & $\begin{array}{l}\text { Connect2Integration, and } \\
\text { Connect2Science: Physical Science }\end{array}$ & $\begin{array}{l}\text { Connect2Math: Geometry, } \\
\text { Connect2Math: Measurement, and } \\
\text { Connect2Science: Earth Space }\end{array}$ \\
\hline Jennifer & $\begin{array}{l}\text { Connect2Integration, and Connect2Math: } \\
\text { Fractions }\end{array}$ & $\begin{array}{l}\text { Connect2Science: Earth Space, and } \\
\text { Connect2Science: Physical Science }\end{array}$ \\
\hline Susan & $\begin{array}{l}\text { Connect2Integration, and } \\
\text { Connect2Science: Earth Space }\end{array}$ & $\begin{array}{l}\text { Connect2Math: Geometry, } \\
\text { Connect2Math: Measurement, and } \\
\text { Connect2Math: Whole Number }\end{array}$ \\
\hline James & $\begin{array}{l}\text { Connect2Integration, and } \\
\text { Connect2Science: Physical Science } \\
\text { Connect2Integration, and }\end{array}$ & $\begin{array}{l}\text { Connect2Math: Whole Number, and } \\
\text { Connect2Science: Physical Science }\end{array}$ \\
\hline Laura & $\begin{array}{l}\text { Connect2Integration, and } \\
\text { Connect2Science: Physical Science }\end{array}$ & $\begin{array}{l}\text { Connect2Math: Whole Number, and } \\
\text { Connect2Science: Earth Space }\end{array}$ \\
\hline Donna & $\begin{array}{l}\text { Connect2Integration, and } \\
\text { Connect2Science: Physical Science }\end{array}$ & $\begin{array}{l}\text { Connect2Math: Whole Number, and } \\
\text { Connect2Science: Earth Space }\end{array}$ \\
\hline $\begin{array}{l}\text { Connect2Math: Geometry, } \\
\text { Connect2Math: Measurement, and }\end{array}$ \\
\hline
\end{tabular}

\section{Study Design}

This mixed-methods case study assessed the Teachers Instructional Portfolios using the TIP rubric, a qualitative coding scheme focused on the three categories presented on the TIP rubric, questions posed by the researchers on the TIPs, audio from the reflective professional development section coded with the qualitative coding scheme, written reflections from the reflective data day, self-assessment and result in a holistic case description of each of the four teachers who were studied in-depth. Table 3 presents 
a summary of grade level, unit topic and teachers who developed the unit together as well as some science and math big ideas addressed by the units.

Table 3

Integrated Unit Information for Participating Teachers

\begin{tabular}{|c|c|c|c|c|}
\hline Classroom & Grade Level & Unit Title & Science Content & Math Content \\
\hline Linda & $4^{\text {th }}$ grade & $\begin{array}{l}\text { The Changing } \\
\text { Earth }\end{array}$ & $\begin{array}{l}\text { Property of Earth } \\
\text { materials, and Earth's } \\
\text { slow and rapid changes }\end{array}$ & $\begin{array}{l}\text { Numerical data to } \\
\text { describe objects, } \\
\text { Perimeter and Area of } \\
\text { two dimensional } \\
\text { shapes }\end{array}$ \\
\hline Donna & $4^{\text {th }}$ grade & $\begin{array}{l}\text { The Changing } \\
\text { Earth }\end{array}$ & $\begin{array}{l}\text { Property of Earth } \\
\text { materials, and Earth's } \\
\text { slow and rapid changes }\end{array}$ & $\begin{array}{l}\text { Numerical data to } \\
\text { describe objects, } \\
\text { Perimeter and Area of } \\
\text { two dimensional } \\
\text { shapes }\end{array}$ \\
\hline Jennifer & $5^{\text {th }}$ grade & $\begin{array}{l}\text { Rockets: A } \\
\text { Study of } \\
\text { Newton's } \\
\text { Laws }\end{array}$ & $\begin{array}{l}\text { Force and Motion, } \\
\text { Rockets, Friction, } \\
\text { Newton's Laws, and } \\
\text { Sun, Earth, Moon } \\
\text { System }\end{array}$ & $\begin{array}{l}\text { Measurement, place } \\
\text { value, represent data }\end{array}$ \\
\hline James & $5^{\text {th }}$ grade & $\begin{array}{l}\text { Newton goes } \\
\text { to the Moon } \\
\text { on a Rocket }\end{array}$ & $\begin{array}{l}\text { Sun-Earth-Moon system, } \\
\text { and Friction, Gravity and } \\
\text { Magnetic Forces }\end{array}$ & $\begin{array}{l}\text { Operation with multi- } \\
\text { digit and decimal } \\
\text { numbers, Converting } \\
\text { Measurement Units, } \\
\text { and Represent and } \\
\text { Interpret Data }\end{array}$ \\
\hline Mary & $5^{\text {th }}$ grade & $\begin{array}{l}\text { Sun, Earth, } \\
\text { Moon in our } \\
\text { Solar System }\end{array}$ & $\begin{array}{l}\text { Sun, Earth, Moon, } \\
\text { Gravity, Friction }\end{array}$ & $\begin{array}{l}\text { Operations with } \\
\text { Decimals Numbers, } \\
\text { Place Value }\end{array}$ \\
\hline Susan & $5^{\text {th }}$ grade & $\begin{array}{l}\text { Sun, Earth, } \\
\text { Moon System }\end{array}$ & $\begin{array}{l}\text { Shadow, Moon, } \\
\text { Day/Night, Earth }\end{array}$ & Scale \\
\hline Nancy* & $4^{\text {th }}$ grade & Earth Science & $\begin{array}{l}\text { Property of Earth } \\
\text { materials, and Earth's } \\
\text { slow and rapid changes }\end{array}$ & $\begin{array}{l}\text { Display and Organize } \\
\text { Data, Concepts of } \\
\text { Angles }\end{array}$ \\
\hline Laura* & $3^{\text {rd }}$ grade & $\begin{array}{l}\text { Force and } \\
\text { Motion }\end{array}$ & $\begin{array}{l}\text { Force, Gravity, Mass, } \\
\text { and Friction }\end{array}$ & $\begin{array}{l}\text { Measurement, and } \\
\text { Representing Data }\end{array}$ \\
\hline
\end{tabular}

* Nancy and Laura did not develop their units together but participated in the same reflective conversation. Shaded rows indicate that those two teachers worked together developing their units. 


\section{Research Study Timeline}

To better understand the timeline of this study, the author provides two tables. Table 4 presents the months when teachers participated in specific PD courses, including the Connect2INTEGRATION and the Connect2Science and Connect2Math content courses showed in Table 2. It also specifies when the units were implemented and when the TIPs were given to the researchers. Further, it provides a reference to when the reflective PD happened.

Table 5 offers the study timeline itself, making available the months when the data was scored and analyzed for each data source and instrument, as well as when the results and discussion were written and this thesis defended. The objective of those two tables is to clarify when the data was collected and analyzed supplying the reader with a better understanding of the whole scope of this study.

\section{Data Sources}

This study used a TIP instrument as well as a variety of data sources to assess information about the impacts of professional development in teachers' instructional practices. Below a description of each data source is provided. 
TIP Instrument. The Teacher Instructional Portfolio was used as an instrument to measure the instructional practices implemented in teachers' integrated units. Each TIP consisted of three sections included in a binder: (a) Knowledge, Skills, and Experiences 
Table 4

Professional Development Timeline

\begin{tabular}{|c|c|c|c|c|c|c|c|}
\hline Summer 2011 & $\begin{array}{l}2011 \text {-2012 } \\
\text { School Year }\end{array}$ & $\begin{array}{l}\text { By March } 15^{\text {th }} \\
\text { of } 2012\end{array}$ & Spring 2012 & $\begin{array}{c}\text { Summer } \\
2012\end{array}$ & $\begin{array}{l}2012 \text {-2013 } \\
\text { School Year }\end{array}$ & $\begin{array}{l}\text { By March } \\
15^{\text {th }} \text { of } 2013\end{array}$ & Spring 2013 \\
\hline $\begin{array}{l}\text { Teachers took the } \\
\text { Connect } 2 \text { Integratio } \\
\mathrm{n} \text { course, and they } \\
\text { also took other } \\
\text { content courses. }\end{array}$ & $\begin{array}{l}\text { Teachers } \\
\text { implemented a } \\
\text { Mathematics } \\
\text { and Science } \\
\text { Integrated Unit } \\
\text { in their } \\
\text { classrooms }\end{array}$ & $\begin{array}{l}\text { Teachers } \\
\text { documented } \\
\text { their integrated } \\
\text { unit by } \\
\text { completing a } \\
\text { TIP }\end{array}$ & $\begin{array}{l}\text { Teachers } \\
\text { participated } \\
\text { in the } \\
\text { Reflective } \\
\text { Professional } \\
\text { Development }\end{array}$ & $\begin{array}{l}\text { Teachers } \\
\text { took } \\
\text { content } \\
\text { courses } \\
\text { related to } \\
\text { their } \\
\text { content } \\
\text { knowledge. }\end{array}$ & $\begin{array}{l}\text { Teachers } \\
\text { implemented a } \\
\text { revised } \\
\text { Mathematics } \\
\text { and Science } \\
\text { Integrated Unit } \\
\text { in their } \\
\text { classrooms }\end{array}$ & $\begin{array}{l}\text { Teachers } \\
\text { documented } \\
\text { their } \\
\text { integrated } \\
\text { unit by } \\
\text { completing a } \\
\text { TIP }\end{array}$ & $\begin{array}{l}\text { Teachers participated in } \\
\text { the Reflective } \\
\text { Professional } \\
\text { Development, even } \\
\text { though they were not } \\
\text { the main focus of this } \\
\text { second session of the } \\
\text { PD }\end{array}$ \\
\hline
\end{tabular}

\section{Table 5}

\section{Research Study Timeline}

\begin{tabular}{|l|l|l|l|}
\hline \multicolumn{1}{|c|}{ Summer 2013 } & \multicolumn{1}{|c|}{ Fall 2013 - Winter 2014 } & \multicolumn{1}{c|}{ Spring 2014 } & Summer 2014 \\
\hline $\begin{array}{l}\text { Saxton and Rigelman trained graduate research assistants } \\
\text { on how to score the TIPs using the TIP rubric. After the } \\
\text { initial training, researchers and graduate assistants scored } \\
\text { the TIPs using the TIP rubric. Consensus discussions } \\
\text { happened to provide a final score for each category. }\end{array}$ & $\begin{array}{l}\text { Researchers developed a coding scheme and } \\
\text { scored the audio from the reflective } \\
\text { conversations as well as scored the questions } \\
\text { posed by the researchers on the TIPs and } \\
\text { teachers' reflections }\end{array}$ & $\begin{array}{l}\text { Researchers analyzed } \\
\text { all data and wrote the } \\
\text { results and } \\
\text { discussion, finalizing } \\
\text { the thesis }\end{array}$ & $\begin{array}{l}\text { Thesis' } \\
\text { defense }\end{array}$ \\
\hline
\end{tabular}


Outcomes, (b) Assessments, and (c) Pedagogical Strategies. The directions given on the TIP instrument were stated as the following:

This portfolio should document the implementation of the integrated unit you developed during the Connect2Integration course. We ask you to review your instructional portfolio after the implementation of your unit. Please make sure to include an updated calendar, planning template and your completed reflections in your final instructional portfolio. (Saxton \& Rigelman, unpublished)

More detailed instructions were also provided to each section (see Appendix A for the detailed instructions). In addition, the TIP binder included all the materials the teachers provided as part of their units as well as high, medium and low students' work samples.

The TIP rubric, also part of this instrument and developed by Saxton and Rigelman, (unpublished), was used to quantitatively score the TIPs into three main categories: classroom roles, content and cognitive skills, and assessment for learning. Those categories were identified from a literature review as best instructional practices for inquiry-based science and problem-solving mathematics instruction. The first category (Classroom Roles) encompasses three bullets: (1) the role of the teacher as a facilitator of student learning pushing students to develop their higher order thinking skills, (2) students engagement in problem solving and inquiry to deepen their conceptual knowledge, and (3) students as active participants in their own learning. The second category (Content and Cognitive Skills) includes two bullets: (1) content and cognitive skills are used simultaneously in the activities implemented by the unit, and (2) the unit provides multiple opportunities for students to construct meaning, apply content knowledge and practice higher order thinking skills. Finally, the third category 
(Assessment for Learning) covers three bullets: (1) unit frequently assesses students prior, during and after the lessons with the use of formative and summative assessments tied to the learning goals, (2) students have opportunities to self-assess and monitor their learning progress, and (3) assessments are appropriate to students in terms of cognitive demand as well as are structured to provide evidence of students' performance. A scale from zero to four was used to score each category. Appendix B presents the TIP rubric.

Saxton and Rigelman are evaluating the TIP rubric for validity and reliability. To use this instrument in this study, Saxton and Rigelman trained three graduate research assistants to interpret the three categories of the rubric. Next, the five raters practiced scoring TIPs independently and then met to compare and discuss the scores and understandings. After several practice sessions, each rater independently scored the TIPs for this study. Each TIP was scored by at least three different raters. Because inter-rater reliability was not acquired by the raters, a consensus (agree-upon) score was used for all categories in the rubric for the data analysis of this study.

TIP Reflective Questions Posed by the Researchers. Saxton and Rigelman marked artifacts in each Teacher Instructional Portfolio and wrote questions to go with each artifact with the intention of bring teachers' attention to specific instructional practices. Those questions were used during the reflective professional development session to guide the conversation between teachers and researchers and to stimulate teachers' reflection about specific instructional practices. Later, each question was coded as being 
related to a bullet level of the TIP rubric categories. The frequency of questions for each bullet level was noted and is presented in the result section of this thesis.

\section{Audio Recording of Reflective Professional Development Session. Saxton and}

Rigelman had a guided conversation with two to three teachers at a time about their units. They combined teachers from the same school and grade level who designed an integrated unit together, when possible. The questions placed on each teacher's instructional portfolio guided the conversation that was designed to offer specific professional development targeted to teachers' individual needs as well as specific instructional practices. Those conversations were recorded and later analyzed using a qualitative coding scheme based on a similar approach as the one suggested by Weston et al., 2001.

Weston et al. (2001) created a code by using their research questions as a frame of reference, further developing it into different categories. To address validity and reliability of their code, they had meetings to discuss the codes until agreement was established. The authors stated "reliability was our way of establishing a shared interpretive validity" (p. 394). They also attached "codes to words and phrases within episodes to facilitate retrieval" (p. 393) and marked the time when each phenomenon began and ended.

This research study's coding scheme was based on the TIP rubric categories: shift from teacher-centered to student-centered instruction, integration of higher order thinking into mathematics and science content practices, and assessment data that informed 
practice (summative and formative assessments, as well as self-assessment and alignment with content standards) (Saxton \& Rigelman, unpublished). Table 6 provides a description of each category of the coding scheme used. At least two coders always coded the audio from the reflective PD sessions, and met to discuss and agree on the final code. Further, detailed notes were taken with transcribed quotes from the teachers' conversations as well as a time marker was used to identify the beginning and end of a specific topic in each discussion. From the eight teachers who participated in this study, four of them had their audio coded to do a more in-depth analysis: Linda, and Donna; Jennifer, and James. We chose these four teachers because they provided the best-case scenario in relation to external variables like teaching in the same school, teaching the same grade level and collaborating to develop the integrated unit.

Teacher Self-Assessment. At the beginning of each reflective professional development session, teachers were asked to complete a rubric called Teacher SelfAssessment Instructional Vision (Appendix C) where they provided a self-assessment themselves based on student role, instructional practices, and assessment instructional characteristics in their integrated unit. This rubric was closely aligned with the instructional practices in the TIP rubric phrased slightly differently to function as a selfassessment. They scored themselves selecting one of four statements that were described; representing a progression of the instructional practice. This self-assessment rubric has not been validated yet. Mary and Susan did not self-assessed for year 3 because their reflective PD session could not happen before the end of the school year for scheduling reasons. 
Table 6

Audio Coding Scheme Based on the TIP Rubric Categories

\begin{tabular}{|l|l|}
\hline \multicolumn{1}{|c|}{ Bullet Level Category } & \multicolumn{1}{c|}{ Description } \\
\hline Classroom Roles (CR) - Bullet 1 & $\begin{array}{l}\text { Teacher as the content authority versus teachers as } \\
\text { the content facilitator. }\end{array}$ \\
\hline Classroom Roles (CR) - Bullet 2 & $\begin{array}{l}\text { How the science inquiry, engineer design or } \\
\text { mathematics problem solving was structure. }\end{array}$ \\
\hline Classroom Roles (CR) - Bullet 3 & $\begin{array}{l}\text { Students actively engaged in learning (minds-on) } \\
\text { versus students being passive. }\end{array}$ \\
\hline $\begin{array}{l}\text { Content and Cognitive Skills (CCS) - } \\
\text { Bullet 1 }\end{array}$ & $\begin{array}{l}\text { The unit lessons target both content and cognitive } \\
\text { skills. }\end{array}$ \\
\hline $\begin{array}{l}\text { Content and Cognitive Skills (CCS) - } \\
\text { Bullet 2 }\end{array}$ & $\begin{array}{l}\text { The unit provides multiple and diverse } \\
\text { opportunities for students to experience both } \\
\text { content and cognitive skills. }\end{array}$ \\
\hline $\begin{array}{l}\text { Assessment for Learning (AL) - } \\
\text { Bullet 1 }\end{array}$ & $\begin{array}{l}\text { Frequency and intention of the assessments aligned } \\
\text { with the learning goals. }\end{array}$ \\
\hline $\begin{array}{l}\text { Assessment for Learning (AL) - } \\
\text { Bullet 2 }\end{array}$ & $\begin{array}{l}\text { Self-assessment, peer and teacher feedback for } \\
\text { students to monitor their own learning. }\end{array}$ \\
\hline $\begin{array}{l}\text { Assessment for Learning (AL) - } \\
\text { Bullet 3 }\end{array}$ & $\begin{array}{l}\text { Assessments are aligned with learning goals, are } \\
\text { cognitive development appropriate, and generate } \\
\text { evidence of learning. }\end{array}$ \\
\hline Extra Codes & $\begin{array}{l}\text { For example: logistics, integration, science and } \\
\text { mathematics curriculum. }\end{array}$ \\
\hline
\end{tabular}

Teacher's Written Reflection. At the end of the reflective professional

development session, teachers were asked to write down a reflection about what was

most significant from the reflective professional development they participated in. The

main idea was to provide an opportunity for teachers to think about their integrated units

and reflect on what needed to be changed before the next implementation. As a guide, the

teachers had questions proposed by the researcher. Those questions were separated into

two categories: (1) Implication for Classroom Practice: "What are the implications of this

data for student learning and achievement?", "What are the implications of this data for

teaching and assessment?", "Based on the interpretations of the data, what steps could be

taken next?", "What strategies might be most effective?", "What else would you like to 
see happen?", "What kinds of assignments or assessments could provide this information?", "What does this conversation make you think about in term of your own practice?", "What does this conversation make you think about teaching and learning in general?", "Are there implications for equity?" and (2) Implications for your Professional Learning Community (PLC) next year: "What are the implications of this data for the goals of your PLC next year?" Like the TIP questions posed by the researchers, those reflections were later coded having the audio coding scheme and the TIP rubric bullet level categories as a foundation (Table 6). The frequency of each bullet level was noted and it is presented in the result section of this thesis (see Appendix D for the detailed questions posed by the researchers).

\section{Procedure}

Teacher Instructional Portfolios were collected from eight elementary school teachers that taught in schools located in the Portland metropolitan area, Oregon. The units were implemented during the 2011-2012 and 2012-2013 school years and the TIP was provided to the researches prior to spring break of each year. The professional development integration course (Connect2Integration) took place in the summer of 2011 when teachers designed their integrated units. The teachers taught third, fourth and fifth grade classrooms and the mathematics and science units covered topics related to the Sun-Earth-Moon system, Newton's laws, force and motion, Earth materials and its changes, measurement, decimal numbers, area and perimeter, place value, scale and data analysis (Table 3). 
First, each TIP from the first year of implementation of the units (Year 2) was scored by at least three raters using the TIP rubric (Saxton \& Rigelman, unpublished). Also, detailed notes were taken about what was observed in each TIP related to studentcentered instruction, higher order thinking skills and content, and assessment practices. Bullet level scores were also recorded. Next, the same procedure took place using the same rubric to score TIPs implemented the following year (Year 3). All scores were discussed and reviewed until agreement was reached on a final score for each TIP rubric category between the researchers. Then, the author of this study analyzed the notes presented for each TIP to provide qualitative support to the scores as well as to better describe any possible changes that had happened.

After that, the questions posed by the researchers in the TIPs and teachers' written reflections were coded using a code scheme developed for this study similar to the TIP rubric categories for each teacher who participated in this study. Later, teachers' selfassessment scores were analyzed for each TIP rubric category and a composite score was generated. Audio from the reflective professional development session was coded by at least two raters following a coding system based on the Weston et al. (2001) model. Subsequently, the case descriptions of the four teachers were written based on the TIP's notes from all researchers, TIP's scores, questions posed by the researchers and teachers' written reflections as well as self-assessment, qualitative code from reflective PD and demographics. 
The results of this study were organized into tables as well as case descriptions. The qualitative codes, quantitative scores and the case descriptions were used to characterize the influence of the reflective professional development on teachers' instructional practices, as well as to describe and analyze how teachers change their instructional practices based on the reflective PD, and to identify impacts that reflective PD had on teachers' implementation of their integrated mathematics and science unit. 


\section{Results}

\section{Case Descriptions}

To accomplish the goal of this thesis, a case description was written for each teacher based on all the data analyzed which includes: demographics, courses taken, integrated unit overview, description of the first and second year of implementation of the integrated unit, teachers' self-assessments, questions posed by the researchers, audio of reflective conversation with the researchers, and teachers' written reflections. The objective of those case descriptions is to present a chronological and holistic view of each teacher, the unit implemented and the pedagogical strategies used to illustrate possible changes in the teachers' practices over time. Those four case descriptions are provided below.

\section{$\underline{\text { Linda }}$}

Demographics. Linda is a white, female teacher that had 6-8 years of teaching experience when she started participating in the larger three-year professional development (PD) project. She had been teaching in the school were she implemented her unit for at least 35 years. Linda held a master's degree when she started the PD project and was licensed to teach multiple subjects at the elementary school level (Table 1).

Courses taken in the summer of 2011. Linda took the Connect2Integration course, as did all the other participants on this study. She also chose to take the Connect2Science: Physical Science class (Table 2). 
Integrated unit overview. Linda developed a science and mathematics unit to be taught to her $4^{\text {th }}$ grade classroom. She planned her unit in collaboration with Donna and they entitled their unit: "The Changing Earth". The main science content addressed by the unit was: properties of Earth materials and Earth's slow and rapid changes. The main mathematics content was: numerical data to describe objects, and perimeter and area of two-dimensional shapes. Linda's unit was mainly about the Earth layers, rock formation and types, weathering and erosion, volcanoes and lava flow and finding area of irregular shapes (Table 3).

Integrated unit: first year of implementation. Linda originally planned her unit with eight lessons plus a summative work sample. However, she did not have time to implement all lessons. Her Teacher Instructional Portfolio (TIP) demonstrated that she implemented six lessons about the following topics: rock cycle, weathering and erosion with data collection (two lessons), earth layers, area of irregular shapes, and volcanoes. She also had a science inquiry and problem-solving work sample that was done in groups. For assessment, Linda implemented one formative assessment ("Is it a rock?" probe), one vocabulary/concept quiz, one journal reflection with possibilities for students to selfassess, a work sample prompt and one summative test that had questions related to science and mathematics content. As for the pedagogical strategies Linda used in her unit, she stated that she most frequently used hands-on investigations, "think-pair-share" and "I do, we do, you do" strategies as well as journal reflections. 
Considering classroom roles for science (a category from the TIP rubric), even though Linda had a variety of activities planned where students were active, the main source of knowledge for students to check the accuracy of their learning was often centered on a content authority such as flipcharts or PowerPoint presentations. When considering the science inquiry, students participated in two opportunities: the first inquiry being scaffolded and structured for students to follow procedures and use a template (i.e. "Will the area and perimeter of the lava flow change with multiple eruptions?"), and the second inquiry being more open-ended (i.e "Will lava with salt, red food coloring, baking soda and vinegar create the greatest land change?" - inquiry question proposed in a high student work sample). Even though there were a variety of activities for students to be engaged in hands-on experiences, most of the time those tasks were implemented in a way that learners had to follow procedures instead of contributing their own ideas (i.e. Crayon Rock Cycle activity where students followed procedures to model the process that creates each rock type, but did not discussed it).

For the content and cognitive skills TIP rubric category, Linda planned her unit to include both content and higher-order thinking skills (HOTS). However, the lessons overemphasized content over HOTS and students did not have multiple opportunities to construct meaning or apply content. When there was an opportunity for HOTS to be practiced, it was translated into lower level observations and descriptions without providing chances for higher-order thinking skills (for example during the Earth layers activity where students colored and described the characteristics of each layer without discussing the content.). For the assessment for learning TIP rubric category, Linda had 
planned on using a variety of summative and formative assessments, including opportunities for students to self-assess. When the unit was implemented, however, there was a lack of assessment for some content areas, for example the Earth layers topic was only assessed formatively. Further, some assessments were not challenging enough and even did not have appropriate cognitive demand for $4^{\text {th }}$ grade students, requiring them to memorize vocabulary and definitions (Table 7).

Considering classroom roles for mathematics (a category from the TIP rubric), Linda was the main source of knowledge when she taught students a procedure to calculate the area of irregular shapes and learners used only this strategy to solve other problems. As for problem-solving, students had to determine the area of a lava flow by following specific procedures predetermined by Linda. This unit for mathematics targeted only content and did not offer multiple opportunities for students to apply content, construct meaning or practice higher-order thinking skills. This integrated unit only presented one mathematics lesson. During this lesson, students were assessed prior, during and after the instruction but did not have a chance to self-assess. Further, the assessments were mostly aligned with the learning goals. Nevertheless, some learning goals were not assessed based on the instructional approach, causing students to miss opportunities to develop other strategies to find the area of irregular shapes and to practice higher-order thinking skills (i.e. the learning target of "Develop non-traditional strategies to calculate area and perimeter" was not assessed) (Table 8). 
Reflective PD: teacher's self-assessment (year 2). In the beginning of the first reflective professional development session relevant to this study, Linda self-assessed using a selfassessment rubric tied to the TIP rubric bullet categories (Appendix C).

For science, she rated herself a score of 3 out 4 on all categories except teacher versus student centrality. Her self-assessment score for teacher versus student centrality indicated that students relied on her, the text or more capable peers to provide the correct answers or to verify their observations and conclusions. Her self-assessment score for cognitive demand demonstrated her appraisal that her students frequently contributed their own ideas or applied skills previously learned when participating in scientific investigations. Finally, Linda's preconceptions and misconceptions self-assessment score indicated her students' conceptions were assessed prior or during lessons and that their misconceptions were addressed through discussion of concepts (Table 9).

Linda rated her mathematics practice with self-assessment scores ranging from 2 to 4. Most of her self-scores were 3, though. For cognitive demand, she rated herself a score of 3 , which indicated that her students were primarily engaged in mathematics tasks they already knew how to complete and periodically engaged in more challenging tasks. Linda scored herself a 2 on preconceptions and misconceptions indicating her appraisal that her students' conceptions were assessed and their misconceptions were only partially addressed through direct instruction (Table 10).

Reflective PD: questions posed by the researchers. After self-assessing, Linda participated in separate discussions with the researchers that targeted instructional 
practices in science and mathematics components of her integrated unit. The discussions were guided by questions posed by the researchers; each question was associated with a specific artifact in her instructional portfolio.

For science, the one question addressed the instructional practice about the centeredness of her classroom. The question was specific about the "Slide, Collide and Divide" activity and how it was implemented because Linda's TIP showed evidence of teacher authority being prioritized over student discovery. In addition, another question was about the reason why Linda decided not to include a second part (groundcover) of the weathering and erosion investigation related to the science inquiry work sample and how that impacted students' understanding of content (a missed chance to provide multiple opportunities for students to construct meaning and apply content). Further, the other two questions were related to assessment. One of the questions was about how she used the information from a probe ("Imagine you are watching a volcano") to change her instruction. The other one was framed like this: "Can you share how the "erosion learning targets' guided your planning and implementation of this portion of your unit?" and it was coded by the researchers as assessment for learning bullet 3 of the TIP rubric category as an example of misalignment between the learning targets of Linda's unit about erosion and the materials/activities provided in her TIP (Table 11).

For mathematics, the inquiries she received from the researchers were focused on how students used the feedback Linda provided on one of the activities to inform their subsequent work. Additionally, the other two questions were about students' participation 
in hands-on activities and how those activities supported their understanding of the content and problem-solving tasks (Table 12).

Reflective PD: audio of reflective conversation with researchers. After Linda selfassessed, Donna and Linda had a discussion with the researchers to reflect on their units with the questions posed by the researchers (to both teachers) as a guide.

For science, most of their discussions were about the classroom role category from the TIP rubric. They spent a significant amount of time discussing everything students needed to accomplish to demonstrate their understanding of the content and higher-order thinking skills and how fun it was for learners to engage in the activities they had planned. Donna noted that the English language learners needed to participate in a variety of activities to be able to share their understanding. She added that students needed to make sense of their own learning. Donna stated that she and Linda used two strategies to facilitate sense making: (a) “... the kids have to say the whole thing; they can't just give us a partial answer. That is part of our language goals. So, when they are orally engaged in class, ..., they need to recycle the question, and have a complete thought." and (b) “... we [Donna and Linda] don't care if the answer is right or wrong. ...We just want them [the students] to be able to share their understanding." Linda stated that the hands-on experiments were supportive to students "visualizing and conceptualizing" to be able to understand the science processes being studied.

Further Donna also emphasized that one thing that was important in $4^{\text {th }}$ grade was that the teachers "wanted them [the students] to be able to share their understanding." In 
addition, both teachers discussed changing the way the science inquiry was implemented so it would be "less painful" and not so overwhelming for the students. To scaffold instruction, Donna suggested next year doing the first science inquiry (lava flow) as a teacher demonstration, asking students if they have questions about it prior to releasing control over the next inquiry. There was also discussion about how some of the tasks, even if not planned that way, provided multiple opportunities for students to apply content and construct meaning addressing both content and higher-order thinking skills. For example, Linda shared "the activity [crayon to simulate rock formation] just kind of lent itself to that really nicely [addressing content and higher-order thinking]. ... It was fortuitous that it just happened that way." When discussing her assessment instructional practices, Linda highlighted the importance of addressing students' misconceptions by stating "it [the probe] pointed out misconceptions that the kids had, as far as what rocks were, and ... how we needed to fix those misconceptions, or at least explore them with the kids. For me, this was the most helpful benefit of it" (Table 13).

For mathematics, the discussions were also partly focused on classroom roles, especially on how Linda and Donna were planning on letting go of their authority over content so students could be more active and engaged. Donna pointed out that they modeled and scaffolded instruction for students. She stated "I modeled it [finding the area of a rectangle activity] the first time instead of them [students] doing it by themselves." Linda added that they could have given the students a variety of shapes or asked them to draw different shapes and then asked students to figure it out strategies to find the area of their shapes. She said that the hands-on practice was a strategy that students really liked: 
"And they loved this [referring to working with different shapes activity]. I don't know why it was but this was just so fun for them [students]. They just really loved learning this, and then applying it right away. They really enjoyed that [moving the pieces around]." Linda and Donna also talked about the strategies they used to assess students' mathematical knowledge. They revealed in the discussion that some of those assessments were merely application of procedures Linda and Donna taught the students how to do it. For example, Donna said, "I just gave my kids a quick shape and they had to apply their strategy and quickly find the area. They had to apply it and that was an example of quick application of skills as an exit ticket" (Table 14).

Reflective PD: teacher's written reflection. At the end of the reflective professional development session, Linda wrote a reflection about her unit and what was discussed throughout the day, following a guide provided by the researchers (Appendix D). She demonstrated interest in changing the activities and worksheets implemented in the first year to support students' understanding of the concepts and to deepen their scientific reasoning. She wrote the following: “Through extension activities I'd like to challenge students to test out their strategies in multiple scenarios and to justify their hypotheses with deeper scientific understanding." Further, in relation to the content and cognitive skills instructional practice, Linda emphasized her desire to provide students more opportunities to demonstrate all their work in the data sheets (Table 15).

Integrated unit changes: second year of implementation. For the second year of implementing her integrated unit, Linda made some changes to her practices. 
Comparing year 2 science to year 3, Linda was still the main source of knowledge but this time she was able to release her authority over content so students would have more input sometimes during instruction; for example, when she used the strategy "I do, We do, You do". Students seemed to have opportunities to contribute their own ideas and to connect with previous knowledge. Another change was evident in Linda's assessment practices. She was able to assess students' misconceptions about rocks and volcanoes more frequently and the assessments used were more developmentally appropriate to $4^{\text {th }}$ grade students as well as better aligned with the learning goals, even though some concepts still were not well-assessed (i.e. weathering and erosion, and layers of the Earth) (Table 7).

For the mathematics component of the unit, the changes were once again related to student participation. The students were sometimes able to discuss and contribute their own ideas to decide which strategy they would like to apply to the problem-solving task (i.e. finding the area of the lava flow). In the second year of implementing this unit, the assessments were selected intentionally and were mostly aligned with the learning goals even though there were still missed opportunities to assess; for example, the topic related to the concept that rectangles with same area can have different perimeters was not assessed (Table 8).

Reflective PD: teacher's last self-assessment (year 3). At the beginning of the last reflective professional development session, Linda self-assessed her practice one more time. 
For science, she rated herself scores of 4 out 4 , that represented a change from year 2 to year 3, on all the following categories: diversity of group size, cognitive demand, cooperative learning and equity in student interaction, discourse, and preconceptions and misconceptions. Linda rated herself a score of a 3 out of 4 on teacher versus student centrality, which also represented a positive change from year 2 . This indicates that Linda considered that her students relied mainly on themselves, participated in challenging activities that promoted higher-order thinking and sense making. Further, Linda chose scores where learners' productive discourse provided opportunities to construct their own ideas based on interactions with others. She self-assessed her practice as if she had assessed students' knowledge prior and during instruction, using purposely selected activities (Table 9).

For mathematics, she rated herself a score of 4 out of 4 on deep conceptual understanding through investigation, cognitive demand and cooperative learning and equity in student interaction (all changes from year 2). In addition, she scored her practice a score of a 3 out of 4 on preconceptions and misconceptions (another change from year 2). Her self-assessment scores indicated her rating that students engaged in problemsolving as a way to learn mathematics, with activities that were regularly cognitively challenging and provided opportunities for the use of multiple abilities. Further, based on her self-assessment scores, Linda considered that she was able to assess students' knowledge prior and during instruction by exploring and discussing the concepts behind students' misconceptions (Table 10). 
In summary for science, Linda increased her self-assessment scores identifying her instruction as more student-centered, with more opportunities for all students to cooperate, to engaged in cognitive challenging activities, to participate in productive discourse, and with assessments to address students' misconceptions. For mathematics, the changes in Linda's self-assessment scores encompassed practices that involved students engaging in problem-solving as a way to learn mathematics, engaging in cognitively challenging activities, engaging in activities that provide opportunities for multiple abilities, and assessing students' misconceptions prior and during instruction.

\section{$\underline{\text { Donna }}$}

Demographics. Donna is a white, female teacher that had more than 15 years of teaching experience when she started participating in the larger three-year PD project. She had been teaching in the school were she implemented her unit for more than 15 years. Donna held a bachelor's degree when she started the PD and was licensed to teach multiple subjects at the elementary school level (Table 1). Donna and Linda taught at the same school and grade-level and worked together in developing their integrated units.

Courses taken in the summer of 2011. Donna took the Connect2Integration course. As Linda also did, she also took the Connect2Science: Physical Science class (Table 2).

Integrated unit overview. Donna planned her unit in collaboration with Linda. Their units at the planning level were exactly the same (refer to Linda's unit overview in the above section for specifics about their unit). In summary, “The Changing Earth" unit addressed 
rock formation and types, weathering and erosion, volcanoes and lava flow and finding area of irregular shapes (Table 3).

Integrated unit: first year of implementation. Donna originally planned her unit with eight lessons including a summative work sample. However, she did not have time to implement all lessons, having to exclude the lesson on Earthquakes and one of her summative activities entitled Emergency Plan. Her Teacher Instructional Portfolio demonstrated that she implemented six lessons, the same ones as Linda.

Donna also had a science inquiry and problem-solving work sample that was done in groups. She used a variety of assessments throughout her unit: one formative assessment ("Is it a rock?" probe), journal writing about the different types of rocks and the rock cycle, a Venn diagram about physical and chemical weathering, one vocabulary/concepts quiz, data collection worksheet about erosion and landforms, a worksheet about volcanoes, layers of the Earth coloring and identification worksheet, one journal reflection with possibilities for students to self-assess, two scaffolded science inquiry activities that led to a work sample prompt (i.e.: surface flow of volcanoes) and one summative test that had questions about the science and mathematics content taught. As for the pedagogical strategies Donna used in her unit, she stated that most frequently (around $40 \%$ of her teaching time) she used hands-on experiments, models and tools. She also indicated she used strategies like "think-pair-share", "I do, we do, you do" and scaffolding around $25 \%$ of the time. 
Considering classroom roles for science, even though Donna had a variety of activities planned where students were active 'doing something', the locus of authority for content knowledge was videos, flowcharts and lectures presented by Donna. When considering the use of science inquiry in her unit, students participated in three opportunities: the first two being scaffolded and structured for students to follow procedures and use a template (i.e. "Will the area and perimeter of the lava flow change with multiple eruptions?"), and the third one being more open-ended so students could decide what their question would be (i.e. "Will the height, area and perimeter of the volcano change if we added mentos to the lava chamber?"), following the "I do, We do, You do" strategy of gradual release. Even though there were a variety of activities for students to be engaged in hands-on experiences, most of the time those tasks were implemented in a way that learners had to follow procedures instead of contributing their own ideas. That represented evidence of students lacking opportunities to make connections and construct meaning as they were participating on activities that were highly scripted (for example, high and medium students' work sample had almost the same words in their answers indicating a lack of students' own ideas).

For content and cognitive skills TIP rubric category, Donna planned her unit to include both content and higher-order thinking skills. However, the lessons overemphasized content over HOTS. Students occasionally did have an opportunity to practice developing a hypothesis and/or a conclusion, but the majority of the activities were content focused. Students had a few opportunities to construct meaning, apply content and practice using higher-order thinking skills. Nevertheless, most of their 
journal entries showed evidence that they were copying directly from the teacher (i.e. high and medium student sample entries were identical) characterizing an instructional practice that is based on rote memorization.

For assessment for learning TIP rubric category, Donna had planned on using a variety of summative and formative assessments, including opportunities for students to self-assess. She used assessments prior, during and after lessons and most of the learning goals were assessed at some point in the unit. On the other hand, the opportunities for students to self-assess did not include feedback from the teacher and there was no evidence of modification of instruction based on assessment data. Some assessments were not developmentally appropriate for $4^{\text {th }}$ grade students, requiring them to memorize vocabulary and definitions and the summative test did not include higher-order thinking skills (Table 7).

Considering classroom roles category from the TIP rubric for mathematics, there was only one math lesson on this unit. For this lesson, Donna started with a writing prompt asking students to complete the following sentence: "To calculate the square area of a rectangle you". She also used a "Think, Pair, Share" strategy. However, after that, the lesson was very teacher centered as Donna taught students a procedure to calculate the area of irregular shapes and students only used this strategy to solve other problems, not really thinking for themselves. As for the problem-solving task, students had to determine the area of a lava flow by following specific procedures predetermined by Donna during the math lesson and then applied this approach during the science inquiry. 
The mathematics in this unit targeted only content and it offered inconsistent opportunities for students to apply content and construct meaning at the same time.

Despite the limited scope of mathematics covered in this unit, students were assessed prior, during and after the instruction with the use of a quick write (already described), an exit ticket and a few times where they had to figure out the area of irregular shapes. Nevertheless, learners did not have a chance to self-assess. The assessments that were used mostly aligned with the learning goals. However, not all goals were assessed and/or taught causing a lack of evidence of this unit being representative of the learning progression for mathematics (Table 8).

Reflective PD: teacher's self-assessment (year 2). Donna rated the first implementation of her unit with a self-assessment rubric tied to the TIP rubric bullet categories (Appendix C).

For science, Donna rated herself at scores of a 3 with the exception of deep conceptual understanding through investigation and diversity of group size, which received scores of a 4 . Her self-assessment scores indicated her appraisal that her classroom practice was more student-centered, with inquiry as a meant for students to gain deep conceptual understanding. She self-assessed her practice as if her students were mostly active contributing their own ideas or apply previously learned skills to new context. Donna also indicated that her students' conceptions were assessed prior to or during instruction and their misconceptions were addressed through exploration and discussion of the concept (Table 9). 
Most of Donna's self-assessment scores for mathematics were of a 3. However, she did score her practice a 2 on cooperative learning and equity in student interaction, appraising that her students occasionally had opportunities to engage in tasks that had more than one approach. In addition, her self-assessment scores indicated that she consistently mediated classroom interactions even though students participated in productive discourse. Finally, Donna also rated her practice with a score of a 3 in cognitive demand, demonstrating that her students primarily engaged in tasks they knew how to accomplish and had opportunities to periodically complete more challenging tasks (Table 10).

Reflective PD: questions posed by the researchers. After self-assessing, Donna participated in separate discussions with the researchers that targeted instructional practices in science and mathematics components of her integrated unit. The discussions were guided by questions posed by the researchers that were tied to specific artifacts in her instructional portfolio.

For science, she received a question that addressed how she implemented the science inquiry, focusing on the how a preliminary activity supported students' development of content tied to higher-order thinking skills. In addition, Donna and the researchers discussed the crayon rock cycle activity to identify how the activity took place and verify if it provided multiple opportunities for students to apply content and higher-order thinking skills. Considering science assessment, Donna was questioned about the "What is a rock?" probe by Paige Keeley that she used with her students. The 
researchers were interested in knowing how Donna used the information she got from this specific formative assessment. She was asked about what changes in her instruction, if any, resulted from the information this probe provided her. Further, the researchers also questioned Donna if the students received feedback on the assessments (Table 11).

When considering mathematics, two questions were about the implementation of content and higher-order thinking skills in Donna's unit. One query was about examples where Donna planned and implemented activities to provide opportunities for students to use higher-order thinking skills (i.e., "Would you please give an example or two of places where you intended for students to have opportunities to conjecture, justify, or generalize? How did that work out? Are there any tweaks or enhancements that you would make for next time?"). The other one was about how data was entered in a table and provided to students possibly fostering mistakes when it was time to analyze it. Adding to that, the researchers questioned Donna about extra opportunities for learners to practice how to find the area of irregular shapes prior to having to do it in an isolated activity. Finally, Donna and the researchers discussed that the "Weathering and Erosion" activity could have been an assessment of students background knowledge about measuring height and circumference (Table 12).

Reflective PD: audio of reflective conversation with researchers. As described above, Donna and Linda had a conversation with the researchers about their integrated units. Their reflective discussion was described in detail in Linda's case description. For science, the conversation focused on how important it was for students to make sense of 
their learning by participating on hands-on activities while being minds-on. For mathematics, the discussion concentrated on teachers modeling instruction before students had an opportunity to engage in hands-on activities. The discussion also revealed that the math assessments were pure application of procedures taught by the teachers (Tables 13 and 14).

Reflective PD: teacher's written reflection. Following a guide provided by the researchers, Donna wrote a reflection about her unit and the discussion she had with Linda and the researchers (Appendix D). She emphasized the importance to teach science vocabulary to access students' understanding. Donna also stated she "would like to see a greater understanding of the 'why' behind the science in the students' processing." No specific comment was made about the mathematics component of her unit (Table 15).

Integrated unit changes: second year of implementation. For the second year of implementing her integrated unit, Donna made some changes to her practices. Compared to the first year of implementation, Donna was able to release some of her control over the science content to students so they had an opportunity to engage in observations and discussions prior to her providing the answers or confirming their ideas. In addition to that, Donna also implemented the three science inquiries in a way that students participated in "I do, We do, You do" strategy being able, on the third inquiry, to do it by themselves.

Even though on the second implementation of the unit Donna gave students more opportunities to participate in hands-on activities, there is not much evidence on Donna's 
TIP that students were really understanding what they were doing, meaning that they were not minds-on when being in charge for their learning. This time around, Donna's unit targeted both content and cognitive skills and during the second implementation there were some opportunities for both to happen in the same activities. Another change was that Donna was able to implement some prompts for students to self-assess. In this implementation of the unit, there was evidence of feedback from the teacher and peers on students' work. However, some of the learning goals were not met and the preassessment failed to generate evidence of students' thinking since even the high students left most questions blank (Table 7).

For the mathematics component of the unit, once again there was evidence of only one math lesson being taught with a few opportunities for students to measure in other lessons. For the second year of implementation, there was a positive change related to assessment. In this implementation of the unit, all learning goals were assessed and students' knowledge was assessed prior, during and after implementing the mathematics lesson. Based on the Donna's pedagogical strategies reflection from her year 3 TIP, it appears that she first elicited students' ideas and then the class agreed on a procedure to the find the area of irregular shapes. This represented another positive change from year 2 to year 3, where the teacher provided opportunities for students to work together collaborating with their own ideas to the whole group discussion (Table 8). 
Reflective PD: teacher's last self-assessment (year 3). At the beginning of the last reflective professional development session, Linda self-assessed her practice one more time.

For science, she rated herself scores of 4 out 4 , that represented a change from year 2 to year 3, on all the following categories: diversity of group size, cognitive demand, cooperative learning and equity in student interaction, discourse, and preconceptions and misconceptions. Linda rated herself a score of a 3 out of 4 on teacher versus student centrality, which also represented a change from year 2 . This indicates that Linda considered that her students relied mainly on themselves, participated in challenging activities that promoted higher-order thinking and sense making. Further, Linda chose scores where learners' productive discourse provided opportunities to construct their own ideas based on interactions with others. Her self-assessment scored also indicated that she had assessed students' knowledge prior and during instruction using purposely selected activities (Table 9).

For mathematics, she rated herself a score of 4 out of 4 on deep conceptual understanding through investigation, cognitive demand and cooperative learning and equity in student interaction (all positive changes from year 2). In addition, she scored her practice a score of a 3 out of 4 on preconceptions and misconceptions (another change from year 2). Her self-assessment scores indicated her rating that students engaged in problem-solving as a way to learn mathematics, with activities that were regularly cognitively challenging and provided opportunities for the use of multiple abilities. 
Further, based on her self-assessment scores, Linda considered that she was able to assess students' knowledge prior and during instruction by exploring and discussing the concepts behind students' misconceptions (Table 10).

In summary for science, Linda increased her self-assessment scores identifying her instruction as more student-centered, with more opportunities for all students to cooperate, to engaged in cognitive challenging activities, to participate in productive discourse, and with assessments to address students' misconceptions. For mathematics, the changes in Linda's self-assessment scores encompassed practices that involved students engaging in problem-solving as a way to learn mathematics, engaging in cognitively challenging activities, engaging in activities that provide opportunities for multiple abilities, and assessing students' misconceptions prior and during instruction.

\section{$\underline{\text { Jennifer }}$}

Demographics. Jennifer is a white, female teacher that had more than 15 years of teaching experience when she started participating in the larger professional development project. She had been teaching in the school were she implemented her unit for more than 15 years. Jennifer held a master's degree when she started the PD project and was licensed to teach multiple subjects at the elementary school level (Table 1).

Courses taken in the summer of 2011. Jennifer took the Connect2Integration course. She also chose to participate on the Connect2Math: Fractions class (Table 2). 
Integrated unit overview. Jennifer developed a science and mathematics unit to be taught to her $5^{\text {th }}$ grade classroom. She planned her unit in collaboration with James and entitled her unit: "Rockets: A Study of Newton's Laws". The main science content addressed by Jennifer's unit was: force and motion, rockets, friction, Newton's Laws, and Sun, Earth, and Moon system. The main mathematics content was: measurement, place value, and data representation. Jennifer front-loaded the science content during her literacy block and then students had an opportunity to participate in hands-on activities about rockets to exemplify Newton's Laws. Overall, this unit used rockets as the context for students to apply Newton's Laws of motion and to represent and interpret data (Table 3).

Integrated unit: first year of implementation. Jennifer planned her unit to be six weeks long. However, because her student-teacher had to teach his work sample, Jennifer's unit had to be taught in two separate parts (before and after the Spring break). Her TIP demonstrated that she implemented the following lessons: literacy blocks about force and friction, a pictorial history of rockets timeline, a guided inquiry about potential and kinetic energy, a "How rockets work?" activity, an experiment about inertia, a science inquiry using the Newton Car activity, Pop Can Hero Engine activity about Newton's Third Law, and Pop Rockets engineering design that included a math problem-solving activity for students to calculate mean, median, mode, maximum and minimum range.

Jennifer planned and implemented two science inquiries and engineering design activities: Pop Can Hero Engine and then Pop Rockets. She also included a mathematical problem-solving task that was connected with the science context for the unit. For 
assessments, Jennifer had planned on assessing students' prior, during and after the unit. However, as she mentioned on her unit plan, she did not have the time to truly implement all her assessments. She provided examples of students work for the following assessments: a rocket timeline, force and motion book, Pop Can Hero Engine, engineering design and math problem-solving. As for Jennifer's pedagogical strategies, she indicated she used whole class, small partner group and individual work $95 \%$ of the time, followed by gradual released during the science inquiry and problem-solving (direct, then guided and finally independent work).

For science, when addressing the classroom role TIP rubric category, students relied on texts and their teacher as the main source of content knowledge, especially in the beginning of this unit. Later, when students had an opportunity to engaged in handson activities, those were more explanatory than exploratory. As for the science inquiries and the engineering design, Jennifer scaffolded instruction to prepare students to do the final ED by themselves. The whole unit was highly structured with students participating in activities by following procedures and occasionally contributing with their own ideas.

For the content and cognitive skills TIP rubric category, even though this unit targeted both content and higher-order thinking skills, most of the questions which addressed higher-order thinking were skipped by the students or not assigned by the teacher, evidencing the lack of multiple opportunities for students to practice higher-order thinking skills. The unit sometimes failed to generate evidence of the performance criteria for students to meet the unit goals. Even though their conceptions were 
sometimes assessed in the unit. Further, there were infrequent opportunities for students to self-assess when considering all learning goals and Jennifer infrequently provided written feedback on students' work; higher-order thinking skills were not assessed in this unit (Table 7).

Considering the classroom roles for mathematics TIP rubric category, Jennifer did not provide any math lesson plan. The only mathematics activity provided for this unit was the problem-solving task. Even though there was evidence that the teacher differentiated the task for students and that the math content from the problem-solving was in some way related to the science context of the unit, it still failed to be aligned with the learning goals originally identified for math. Jennifer designed a basic version of problem-solving task, a regular version and a challenging version of the task for students to choose from based on how comfortable each student felt with the activities. As for content and cognitive skills category, Jennifer's unit targeted only content and did not provide multiple opportunities for students to construct meaning, apply content and practice HOTS. Regarding assessment for learning, with only the math problem-solving, this unit provided infrequent opportunities for students to be assessed and it did not include any self-assessment for mathematics (Table 8).

Reflective PD: teacher's self-assessment (year 2). In the beginning of the first reflective professional development session relevant to this study, Jennifer self-assessed her practice. 
For science, she rated herself a score of 3 out 4 on all categories except cooperative learning and equity in student interaction (score of 4). Jennifer, through her self-assessment scores, characterized her science practice as if her students' learning opportunities included individual, partner, small and whole group that were not always selected based on a particular task. Further, her scores indicated that her students were mostly active participants in activities that they contributed their own ideas, and were asked to reflect on group process and interactions. Students' conceptions were assessed prior or during lessons and had periodic opportunities to reflect on their own observations (Table 9).

Jennifer rated herself at a score of a 3 on all categories of the self-assessment rubric for mathematics. Those scores supported her appraisal that her students primarily engaged in tasks that had multiple entry points and that they knew how to accomplish, having opportunities to work individually, in small groups and as a whole class (Table $10)$.

Reflective PD: questions posed by the researchers. After self-assessing, Jennifer participated in separate discussions with the researchers that targeted instructional practices in science and mathematics components of her integrated unit. The discussions were guided by questions posed by the researchers; each question was associated with a specific artifact in her instructional portfolio. For science, one of the questions addressed the templates Jennifer used during the engineering design portion of the unit. Her templates were different from James' templates (they collaborated to plan their integrated 
units) and the researcher thought it could lead to a productive conversation for the teachers to reflect on the advantages and disadvantages of each template.

The other two science questions concentrated on providing multiple opportunities for students to apply content, construct meaning and practice higher-order thinking skills. One was about Jennifer's choice to cut out the Sun, Earth and Moon relationship content from her unit because of lack of time to teach it, and the impacts it may have caused in her unit overall. The other one was about a specific activity called the "Hero Engine" and how it represented multiple opportunities for students to apply content and practice higher-order thinking skills (Table 11).

For mathematics, two of the questions posed by the researchers were focused on the structure of her problem-solving activity. One was about the two distinct versions of the problem-solving task and how Jennifer determined which student engaged in which version of the tasks. The second one was about the scaffolding students received to complete their problem-solving task and if learners had a chance to decide if they wanted to use the provided template or not. In addition to those two inquiries, another question was framed like this: "You have identified quite a number of math standards that connected to your unit. Would you briefly describe the math storyline of your unit and how you see it connected to the science concepts?" The researchers were wondering if students had multiple opportunities to apply content, practice higher-order thinking skills and construct meaning related to all those standards (Table 12). 
Reflective PD: audio of reflective conversation with researchers. Jennifer and James' reflective discussion about their units' implementation were based on the questions posed by the researchers (above as well as in James' session). For science, the main topics of the discussion were about (1) assessment (both teachers stated not having enough time to assess students' learning) and (2) not providing multiple opportunities for students to apply content, construct meaning and practice higher-order thinking skills. James stated the need to have more formative assessments to assess content and HOTS and that part of the problem was not having time to stop to "check back and assess their [students] knowledge". James also pointed to the need to provide more opportunities for students to reflect on their learning (maybe using an exit ticket, for example, as suggested by James) and come back together and review. He stated “... [Students need] more opportunities to stop and reflect on what they are doing."

The teachers also discussed about students' self-assessment and how some of the activities did not work well for all students. For example, James commented that only students who had an intrinsic motivation were able to go back and review their materials to be able to answer one of the questions he posed ("What science concepts did you learn from doing our Sun, Moon, Earth, Force and Rocket unit?”). James also added a comment about the importance of having a rubric on the worksheets that are used as assessments so students know what they are expected to do and can reflect on their learning; otherwise the assessments fail to make expectations clear and fail to generate evidence of students' performance. He planned on adding rubrics to his assessments the next year he implemented his unit. Jennifer added to the discussion by highlighting the 
limitations of using a template: “...when you use a template, you're limiting their [students] thinking and their [students] ability to do beyond."

The next significant topic of their conversation was about classroom roles. Jennifer described how she implemented the Hero Engine activity by stating that she modeled for students; then they made predictions and, in groups, students followed her procedures to complete the guided inquiry. James added to the conversation by explaining how he implemented the engineering design and how he was planning on being more explicit next time he implemented this project: “...be more explicit about making those connections between each activity you do and linking them [activities] a little bit more thoughtfully and thoroughly."

When James and Jennifer were discussing about the Hero Engine activity she said that it was a demonstration of content (Newton's Third Law) but that HOTS were not practiced. In addition to that, Jennifer explained how next year she would like to do a demo of each Newton's law so students who did not understand the content from the book read (literacy block) would have an opportunity to grasp the concepts through her explicit demonstrations. By stating what she would like to do in the future, Jennifer indicated that she did not provide multiple opportunities for students to construct meaning and apply content when she implemented her unit. She stated, "The change I am planning on making next year is to do a real explicit demo of each of the laws. And, I didn't do that." Further, she added that she did not like the books she used very much but that she liked it "from the stand point of [students] getting some of the vocabulary into 
their thinking." Her comment added to the discussion of integrating science and literacy and how her students mastered science vocabulary (Table 13).

For mathematics, Jennifer and James discussion focused on classroom roles, especially on the problem-solving task. Jennifer described the problem-solving activity and her design of three different versions where students could choose which one they would like to work on: "A real basic one, a regular on grade level one and a challenge one [talking about the three versions of the problem-solving task]... I shared all three with the class and said I'd like you to choose the one you think you can do the best on to show your understanding of this concept." In addition, Jennifer shared that students thought they were expected to use the template she provided to be able to complete the problem-solving activity and that she did not provide opportunities for students to solve the mathematical problem without using the template: "I think they believed they were expected to use it [the template]. I didn't think beyond that." James added to the conversation about the problem-solving by saying he had not had a chance to really select a task and to reflect on it: "These problem solvers were kind of like, um, I need to do a problem-solving... So it wasn't very thoughtful and there was not a lot of time to reflect on it and talk about it... I wish...next year be more mindful and talk about it, ... I feel that they [students] needed more practice [prior to doing the problem-solving]." Further, James stated that by the 'nature of the day' when the task was implemented, the problemsolving task failed to generate evidence of students' learning. Students did not know what to do or how to complete the problem-solving task without guidance from James. 
Jennifer also talked about the connections between all the math standards she listed on her unit overview compared to what she was really able to accomplish in her unit. She stated "Let me say up front that I realized very quickly into the rocket unit that I did not have the natural math connections within the unit that I thought I had. I think that these [mathematics standards] ended up being more the background knowledge the kids were going to need to be able to help them with some of the activities that we did. I would take some of these out [of the unit overview] at this point." During James and Jennifer's math discussion there was a significant amount of time spent on talking about mathematics and science integration and how relevant it was to front-load the math content to be able to better address the science portion of the unit (Table 14).

Reflective PD: teacher's written reflection. At the end of the reflective professional development session, Jennifer also wrote a reflection about her unit and what was discussed throughout the day. She emphasized the importance to teach content as well as HOTS (organizing data, for example). She explained in detail what changes she planned on doing to her unit to better integrate the mathematical content into her rocket unit: (1) during the puff rocket activity, provide opportunities for students to find the area of their fins, collect data, and discuss about the effects of fins' area related to distance the rockets can fly; (2) during the pop rocket activity, provide opportunities for students to practice the skill of finding surface area. Jennifer stated that she just "would like to have them [the students] practice the skills [measuring surface area]" (Table 15). 
Integrated unit changes: second year of implementation. For the second year of implementing her integrated unit, Jennifer made a few changes to her practices. Compared to the first year, Jennifer's practices were almost the same when addressing the science components of her unit. The main difference was that she selected a variety of assessments including a pre-test, several formative assessments, a post-test and science inquiries and most of those assessments were in alignment with the unit learning goals. However, she did use a pre and post-test designed by another teacher so that may have cause the lack of alignment on those tests. Even though Jennifer had expressed interest in using demos to demonstrate each Newton's law in the second year of implementing her unit, she did not (Table 7).

For mathematics, the significant difference between the two implementations of her unit was related to the classroom roles category from the TIP rubric. Considering that Jennifer did not provide a lesson in year 2 and for that reason researchers could not score her TIP, in the second implementation, there was evidence that students were mainly copying information from the teacher and sometimes following procedures to complete tasks without thinking for themselves. Further, there was no evidence that HOTS were applied or practiced in this unit as it continued targeting only content. As for assessments, on the second year of implementation, there was an addition of a pre and post-test, as well as the continued use of the problem-solving tasks compared to not having a pre and post in the first implementation. Jennifer stated in her written reflection that she would like to better integrate the math content into her rocket unit. There was no evidence, 
however, that she was better able to integrate math into science in the second year of implementing her unit (Table 8).

Reflective PD: teacher's last self-assessment (year 3). At the beginning of the last reflective professional development session, Jennifer self-assessed her practice one more time.

Half of her science self-assessment scores changed from a score of 3 to a score of 4 in year 3 on the following categories: diversity of group size, cognitive demand, preconceptions and misconceptions, and student reflection/self-assessment. Jennifer indicated that in the second implementation of her unit her students were engaged in challenging activities of their own design, working individually, in small groups and as a whole class for sense making. Jennifer considered that she purposely selected activities to assess learners' knowledge prior and during instruction; students also had opportunities to self-asses that went beyond checklists. In contrast, comparing year 2 to year 3 , she rated herself as if her students were only sometimes engaged in tasks that provided opportunities for learners with different abilities to contribute, lowering her selfassessment score from a 4 to a 3 on cooperative learning and equity in student interaction (Table 9).

For mathematics, Jennifer's scores related to instructional characteristics (diversity of group size, cognitive demand, and cooperative learning and equity in student interaction) changed from a 3 to a 4 from year 2 to year 3 . Her appraisal about her instruction for year 3 was as if her students became regularly engaged in cognitively 
challenging activities and those tasks provided opportunities for learners with different abilities to contribute. Further, students worked individually, with a partner (or small group) and summarized to the whole class for sense making (Table 10).

In summary, Jennifer self-assessment scores indicated that she improved her science practice related to student's diversity of group size, cognitive demand, and assessment. She decreased her science practice related to cooperating learning (Table 9). For mathematics, she rated herself a 4 on diversity of group size, cognitive demand and cooperative learning and equity in student interaction (Table 10).

\section{$\underline{\text { James }}$}

Demographics. James is a white, male teacher who had 9-11 years of teaching experience when he started participating in the larger PD project. He had been teaching in the school (same one as Jennifer) where he implemented his unit for 9-11 years. James held a master's degree when he started the PD project and was licensed to teach multiple subjects at the elementary school level (Table 1).

Courses taken in the summer of 2011. James, as all the other teachers from this study, took the Connect2Integration course. Differing from Jennifer, who worked with James on developing the integrated unit, he opted to take the Connect2Science: Through Nature, a life science focused class (Table 2).

Integrated unit overview. James developed his $5^{\text {th }}$ grade unit in collaboration with Jennifer. He entitled his unit "Newton goes to the Moon on a Rocket". The main science 
content addressed by his unit was: Sun-Earth-Moon system, friction, gravity and magnetic forces. In addition, the mathematical content was: operation with multi-digit and decimal numbers, converting measurement units, and representation and interpretation of data (Table 3). James' unit was focused on science content and some higher-order thinking skills and did not provide enough opportunities for students to learn mathematics. Overall, his unit was about Newton's Laws and how to interpret and represent data using rockets as a context to apply the content knowledge being learned.

Integrated unit: first year of implementation. James planned and implemented a sevenweek long unit that included around 33 lessons. His lessons were taught following this sequence: force and motion vocabulary (using booklets), two lessons about Newton's Second Law (car modeling), Newton's Third Law, experiment with inertia (Newton's First Law), Earth, Moon and Sun relationship and relative size, Moon's eclipses, rockets and the Sun, flight stability, science inquiry, three lessons on engineering design, three lessons about rockets that included altitude and trigonometry, two lessons on problemsolving, and finally, a couple of lessons on Project X-51 using measurement and operations.

James had two distinct versions of his problem-solving task, as well as three to five scaffold science inquiries that led to the final engineering design project (Project X51). There were a variety of formative and summative assessments in James' unit even though he decided to not use some of the formative assessments he had initially planned to implement. As for the pedagogical strategies James used in his unit, he wrote that $85 \%$ 
of the time he used hands-on experiments, $80 \%$ collaboration, $75 \%$ of high interest level activities and $50 \%$ of written analysis.

Considering the classroom roles category from the TIP rubric for science, James' unit was divided into at least two parts. The first part (around 10 days/lessons) was very teacher centered with the use of books and vocabulary to teach content. The second portion where James implemented the SI and ED showed more of modeling and scaffolding instruction to get to a point where James released his content authority position to students. As for the SI and ED, James started with a predetermined format where students were following his procedures. Then, he used scaffolded instruction to finally release the predetermined format during the last ED. Considering this unit as a whole, students followed procedures during most of the activities and were not really minds-on when participating in hands-on experiments.

Even though James planned his unit to target content and HOTS, taking into consideration the way he implemented his lessons, content and HOTS were almost certainly not applied or practiced in the same activities (i.e. when students drew conclusions, they did not refer to content to explain their thoughts). Overall, James' unit did not provide enough opportunities for students to develop deep content understanding or to practice HOTS.

Students' conceptions were frequently assessed prior, during and after instruction with the use of intentional formative and summative assessments. However, some of the formative assessments planned were not implemented by James. Students received 
feedback in the form of a grade in their papers, but students did not had an opportunity to reflect on the meaning of their grade or to discuss with James what their grade was about (i.e. what did they miss to not receive a full grade?). Most of the assessments were aligned with the learning goals planned for this unit. Nevertheless, the last rocket assessment provided questions that did not relate with the unit's learning goals (for example, this assessment had a question about students' favorite part of the unit and the reasons behind their choice) (Table 7).

Addressing classroom roles for mathematics, since there was only one lesson plan explicitly presented in James' unit, it appeared that students mainly relied on their teacher as the content authority (i.e. James defined the word trigonometry and used it to demonstrate how to calculate the altitude of a rocket flight.) The problem-solving task ('In his haste to finish the rocket project, Bobo decided to copy Shadrack's results from his rocket launch. He recorded that the rocket went $72 \mathrm{ft}$. high and the launch angle was $58^{\circ}$. He did not record the baseline (how far the altitude tracker was away from the launcher) though. How far away from the launcher was the tracker?") was developed for students to follow a predetermined strategy and it was not a cohesive part of the unit, limiting the opportunities for deep content understanding.

Most of the time, during the problem-solving task, students were following procedures they already knew how to accomplish. The unit was planned to provide multiple opportunities for students to practice HOT and construct meaning. However, the way it was implemented it only targeted content missing opportunities to connect to 
HOTS and it provided inconsistent occasions for students to apply the content they learned (i.e. math worksheet with place value drills). The infrequently assessments provided in this unit were not linked to all learning goals (i.e. no evidence of the relationship between multiplication as the inverse of division being assessed). Further, instruction was not modified based on the assessments' results and there were no opportunities for students to self-assess. Most of the assessments failed to generate evidence of students' performance and some content like trigonometry, for example, were not developmentally appropriate to $5^{\text {th }}$ grade students (Table 8 ).

In summary, this unit was well planned but not very well implemented especially when considering the amount of literacy activities during the science component and the lack of mathematics emphasis. The texts used during instruction acted as the main source of content authority for both subject areas, and students were following procedures to be able to complete tasks without being really minds-on.

Reflective PD: teacher's self-assessment (year 2). During the beginning of the reflective PD day, James used a self-assessment rubric to self-assess his instruction (Appendix C).

For science, he rated himself a score of 3 out 4 on all categories except diversity of group size and discourse (score of a 4 on both these practices). With his selfassessment scores, James characterized his practice as more student-centered, with inquiry that had procedures for students to follow, and with students being mostly active, contributing their own ideas to the classroom investigations. James' students sometimes engaged in activities that provided opportunities for students with different abilities to 
contribute and students' conceptions were assessed prior and during lessons. Finally James scores demonstrated his appraisal that his students participated in productive discourse with each other (Table 9).

For mathematics, James rated himself a score of 3 out of 4 on all categories from the self-assessment rubric. A score of a 3 indicates that James characterized his classroom practice as if he occasionally had intervened to answer a question or focus students' attention on a contradiction, but students mainly relied on their own mathematical reasoning to determine the accuracy of their results. In addition, James indicated that his students engaged in problem-solving after having completed a similar task as a class. Finally, students had periodic opportunities to self-assess, reflect on feedback provided by James or peers, and monitored their progress towards the learning targets (Table 10).

Reflective PD: questions posed by the researchers. After self-assessing, James participated in separate discussions with the researchers that targeted instructional practices in science and mathematics components of his integrated unit. The discussions were guided by questions posed by the researchers; each question was associated with a specific artifact in his instructional portfolio.

For science, the researcher asked him about his observations regarding how his students performed on Project X-51 since learners did not mention some of the science concepts learned in the unit. Another question was about the impact of providing multiple opportunities for students to apply content and practice higher-order thinking skills during the rocket experiments. In addition, researchers posed a question about the need 
for more formative assessments to be used during weeks three and four of instruction building off of a note James wrote on his unit calendar that said, "Need more formative assessments". Finally, one last question related to science was about a specific question from the rocket assessment and if James was able to get the assessment data he was hoping for with the use of this broad question ("What science concepts did you learn from doing our sun, moon, earth, force and rocket unit?”) (Table 11).

For mathematics, the questions focused on how he could be more explicit in teaching using the math curriculum adopted by his district, as well as if students were able to see relationships between mass and force and how these affects the distance traveled by the car during the Newton Car Experiment. Further, another question was about a possible inclusion of a pre-assessment for mathematics addressing the student's background knowledge with thinking proportionally versus thinking additively. Finally, one question was about students' understanding about the procedures to find missing information in the work sample task. The researcher wondered if James knew if the numbers used in this task made sense to the students or not (Table 12).

Reflective PD: audio of reflective conversation with researchers. James and Jennifer discussed about their unit with the researchers having the researcher questions as a guide. Their conversation was already described in Jennifer's case description. For science, it focused on using direct instruction when addressing the classroom roles category of the TIP rubric. It also concentrated on assessments, especially on not having enough time to assess students' knowledge prior, during and after instruction. For content and cognitive 
skill the focus was on not proving multiple opportunities for students to construct meaning, apply content and practice HOTS (Table 13).

For mathematics, the conversation was mainly about the format of the problemsolving task (e.g. using a template and not giving opportunities for students to think by themselves), and James added that he did not put much attention on the problem-solving at all. There was also some time spent on discussing about science and mathematics integration and how they needed to front-load math content to better address the science concepts next time they teach this integrated unit (Table 14).

Reflective PD: teacher's written reflection. At the end of the reflective professional development session, James also wrote a reflection about his unit and what was discussed throughout the day, following a guide provided by the researchers (Appendix D). He addressed topics related to all TIP rubric categories with the exceptions of classroom roles related to student-centeredness of instruction. James wrote about specific details from his unit that he would like to address the following year, for example: collect data in groups and compile it as a class, use class data to discuss about math content, and emphasize students' understanding of the science skills being used when conducting each experiment from the unit. Considering assessment, James suggested having a metacognitive journal for students to self-assess, as well as creating and implementing pre and post-assessments that have application questions (Table 15).

Integrated unit changes: second year of implementation. For the second year of implementing his integrated unit, James made some changes to his practices. Compared 
to the first year, for science, James' unit was implemented to provide students with multiple opportunities to engage in activities where they had to be active, making sense of content and applying HOTS (i.e. lesson 4 where students analyzed class data related to an experiment about Newton's Second Law - the 'Newton's Car experiment'). In addition, students' knowledge and higher-order thinking skills were assessed prior, during and after the instruction with the use of formative and summative assessments (pre and post-test, a variety of formative assessments and a final project).

There were more opportunities for students to self-assess in this unit compared to the previous one. However, it is not clear how James used the information from those assessments to modify instruction. Most of the learning goals were assessed in this unit, though the pre-test failed to generate evidence of student learning because it was not developmentally appropriate for $5^{\text {th }}$ graders (i.e. the questions were very complex for $5^{\text {th }}$ graders, especially on the pre-test: "In the diagram below label the center of mass (COM) and the center of pressure (COP) and tell why one should be in front of the other.") (Table 7).

For mathematics, the second implementation of James' unit still evidenced a lack of math lessons. Considering the altitude tracker lesson, it looked like James explained how to use the tracking tool and then was able to let students brainstorm ways to measure altitude; a little bit more student centered than the first time this unit was implemented. The problem-solving task was not a cohesive part of the unit and there was no evidence that it was implemented. Once again, students were mainly following procedures to 
complete the few math activities. Even though the unit target content and HOTS, content was overemphasized and students had minimal opportunities to construct meaning and practice HOTS. Further, the assessments were not developmentally appropriate for $5^{\text {th }}$ graders, failing to generate evidence of student learning (i.e. finding the tangent of an angle in the pre- and post-assessments). There was no self-assessment (Table 8).

In summary, for science, James unit was better implemented with more opportunities for students to be the center of instruction as well as having assessments that were present throughout the unit (Table 9). In contrast, for mathematics, his unit was teacher-centered and the there was no evidence the problem-solving task was implemented. Also, the pre-test was too difficult for students and as a result it did not generate evidence of their learning (Table 8).

Reflective PD: teacher's last self-assessment (year 3). At the beginning of the last reflective professional development session, James self-assessed his practice one more time.

For science, the positive changes from year 2 to year 3 were related to studentcentered instruction, students most of the time engaging in inquiry as a mean to gain deep conceptual understanding and students engaging in challenging activities of their own design. His higher self-assessment scores also demonstrate his appraisal that balanced, open interaction in the group was achieved in year 3 in comparison with year 2 and that students' conception (both correct and incorrect) guided James' instructional decisions. James had a negative change in discourse, indicating that in year 3 his students 
participated in productive discourse but he consistently mediated the interactions (Table 9).

For mathematics, James only had negative changes when comparing his selfassessment scores from year 2 to year 3. James indicated that his students relied more on him as the main source of knowledge in year 3 when compared to year 2 . He also considered that learners participated in problem-solving task that followed a particular format. Further, based on his self-assessment scores for assessment, James indicated that his students occasionally had opportunities to self-assess and those chances were superficial when compared to year 2 (Table 10).

In summary, James improved his practice when considering classroom roles for science by releasing some of his authority over content. In addition, his appraisal was that students engaged in activities that were developmentally appropriate to $5^{\text {th }}$ graders, had opportunities to work cooperatively, and their preconceptions and misconceptions were addressed. For mathematics, the changes were negative and related to classroom roles and assessment. James considered his practice even more teacher-centered in year 3 and indicated that his students did not have opportunities to self-assess and/or to reflect on their learning on year 3 compared to year 2 (Tables 9 and 10).

\section{Integrated Unit: TIP Scores}

Teacher Instructional Portfolios were scored using a TIP rubric. The scores for each teacher on the three TIP rubric categories for science and mathematics are presented 
below (Table 7 and Table 8) and were used to try to accomplish the goal of this research study.

In summary, for science, the TIP scores indicate that most teachers scored a 2 on the three categories of the TIP rubric. A score of 2 characterizes teachers' instructional practices as being more teacher-centered, emphasizing content or higher-order cognitive skills at the expense of the other, and not always employing best practices in assessment (i.e. providing infrequent opportunities for students to self-assess and sometimes using formative assessments) (Table 7).

Table 7

Integrated Unit Science TIP Scores for Years 2 and 3 of the Research (Years 1 and 2 of Implementing the Unit, Respectively) for Each Teacher

\begin{tabular}{|l|c|c|c|c|c|c|}
\cline { 2 - 7 } \multicolumn{1}{c|}{} & \multicolumn{7}{c|}{ SCIENCE } \\
\cline { 2 - 7 } \multicolumn{1}{c|}{} & \multicolumn{2}{c|}{ Classroom Roles } & \multicolumn{2}{c|}{ Content and Cognitive Skills } & \multicolumn{2}{c|}{ Assessment for Learning } \\
\cline { 2 - 7 } \multicolumn{1}{c|}{} & YEAR 2 & YEAR 3 & YEAR 2 & YEAR 3 & YEAR 2 & YEAR 3 \\
\hline Linda & 2 & 3 & 2 & 2 & 2 & 2 \\
\hline Donna & 2 & 3 & 2 & 2 & 2 & 2 \\
\hline Jennifer & 2 & 2 & 2 & 2 & 2 & 2 \\
\hline James & 2 & 3 & 2 & 2 & 2 & 3 \\
\hline Mary & 2 & 2 & 1 & 1 & 2 & 2 \\
\hline Susan & 2 & 2 & 2 & 2 & 2 & 2 \\
\hline Nancy & 2 & 2 & 2 & 2 & 3 & 3 \\
\hline Laura & 2 & 2 & 2 & 2 & 2 & 2 \\
\hline
\end{tabular}

For mathematics, four of the eight TIPs scored a ' 2 ' in classroom roles showing that these classrooms emphasized teacher-centered instruction. Six of eight TIPs scored a 
' 1 ' in content and cognitive skills, demonstrating evidence in the TIP that either content or higher-order cognitive skills were targeted in the units. For assessment, three TIPs scored a ' 2 ' and three scored a ' 1 ' indicating that assessment is far from being intentional and frequently provided to students in these units (Table 8).

Table 8

Integrated Unit Mathematics TIP Scores for Years 2 and 3 of the Research (Years 1 and 2 of Implementing the Unit, Respectively) for Each Teacher

\begin{tabular}{|l|c|c|c|c|c|c|}
\cline { 2 - 7 } \multicolumn{1}{c|}{} & \multicolumn{7}{c|}{ MATHEMATICS } \\
\cline { 2 - 8 } \multicolumn{1}{c|}{} & \multicolumn{2}{c|}{ Classroom Roles } & \multicolumn{2}{c|}{ Content and Cognitive Skills } & Assessment for Learning \\
\cline { 2 - 7 } \multicolumn{1}{c|}{} & YEAR 2 & YEAR 3 & YEAR 2 & YEAR 3 & YEAR 2 & YEAR 3 \\
\hline Linda & 2 & 2 & 1 & 1 & 2 & 2 \\
\hline Donna & 2 & 2 & 1 & 1 & 1 & 2 \\
\hline Jennifer & 0 & 1 & 1 & 1 & 1 & 1 \\
\hline James & 2 & 1 & 1 & 1 & 1 & 1 \\
\hline Mary & 1 & 1 & 1 & 1 & 0 & 1 \\
\hline Susan & 1 & 1 & 0 & 1 & 0 & 1 \\
\hline Nancy & 2 & 2 & 2 & 1 & 2 & 2 \\
\hline Laura & 2 & 3 & 1 & 2 & 2 & 2 \\
\hline
\end{tabular}

\section{Reflective PD: Teachers' Self-Assessment}

Another relevant data source for this study was teacher's self-assessment. The main findings from the self-assessment were already reported in the case descriptions. In summary, for science, Linda, Donna, Jennifer and James self-assessed their practice higher in year 3 compared to Nancy and Laura who decreased their self-assessment score in year 3. For mathematics, Linda, Donna and Jennifer increased their self-assessments 
scores for year 3, and James, Nancy and Laura decreased it. With the exception of Susan, who self-assessed her mathematics cooperative learning and equity in student interaction practice with a one score, no other participant self-assessed his/her practice with a lower score than a two (Tables 9 and 10).

\section{Reflective PD: Questions Posed by the Researchers}

The questions posed by the researchers on teachers' instructional portfolios were coded using the TIP rubric categories as a guide. The frequency results are presented in the tables below. For science, Table 11 provides visual evidence that most questions concentrated on content and cognitive skills bullet 2 (unit providing multiple opportunities for students to construct meaning, apply content and practice higher-order thinking skills) and assessment for learning bullet 1 (students' knowledge being assessed prior, during and after instruction with an intentional selection of a variety of assessments) (Table 11). For mathematics, the questions target all three categories and bullet levels (Table 12). 
Table 9

Teachers' Self-Assessment Instructional Vision: Science ("Mary and Susan Did Not Self-Assess in Year 3)

\begin{tabular}{|c|c|c|c|c|c|c|c|c|c|c|c|c|c|c|c|c|c|}
\hline & & \multicolumn{16}{|c|}{ SCIENCE } \\
\hline & & \multicolumn{2}{|c|}{ Linda } & \multicolumn{2}{|c|}{ Donna } & \multicolumn{2}{|c|}{ Jennifer } & \multicolumn{2}{|c|}{ James } & \multicolumn{2}{|c|}{ Mary" } & \multicolumn{2}{|c|}{ Susan } & \multicolumn{2}{|c|}{ Nancy } & \multicolumn{2}{|c|}{ Laura } \\
\hline & & $\begin{array}{l}\text { YR } \\
2\end{array}$ & $\begin{array}{c}\text { YR } \\
3\end{array}$ & $\begin{array}{c}\text { YR } \\
2\end{array}$ & $\begin{array}{c}\text { YR } \\
3\end{array}$ & $\begin{array}{l}\text { YR } \\
2\end{array}$ & $\begin{array}{l}\text { YR } \\
3\end{array}$ & $\begin{array}{l}\text { YR } \\
2\end{array}$ & $\begin{array}{c}\text { YR } \\
3\end{array}$ & $\begin{array}{l}\mathrm{YR} \\
2\end{array}$ & $\begin{array}{l}\text { YR } \\
3\end{array}$ & $\begin{array}{l}\text { YR } \\
2\end{array}$ & $\begin{array}{l}\text { YR } \\
3\end{array}$ & $\begin{array}{l}\text { YR } \\
2\end{array}$ & $\begin{array}{l}\text { YR } \\
3\end{array}$ & $\begin{array}{l}\text { YR } \\
2\end{array}$ & $\begin{array}{c}\text { YR } \\
3\end{array}$ \\
\hline \multirow[t]{2}{*}{ Student Role } & $\begin{array}{c}\text { Category } 1 \\
\text { Teacher versus } \\
\text { Student Centrality }\end{array}$ & 2 & 3 & 3 & 3 & 3 & 3 & 3 & 3.5 & 4 & - & 2 & - & 2 & 2 & 2 & 2 \\
\hline & $\begin{array}{c}\text { Category } 2 \\
\text { Deep Conceptual } \\
\text { Understanding } \\
\text { through } \\
\text { Investigation }\end{array}$ & 3 & 3 & 4 & 3 & 3 & 3 & 3 & 3.5 & 3 & - & 3 & - & 3 & 3 & 3 & 3 \\
\hline \multirow[t]{4}{*}{$\begin{array}{l}\text { Instructional } \\
\text { Credits }\end{array}$} & $\begin{array}{c}\text { Category } 1 \\
\begin{array}{c}\text { Diversity of Group } \\
\text { Size }\end{array}\end{array}$ & 3 & 4 & 4 & 4 & 3 & 4 & 4 & 4 & 3 & - & 3 & - & 3 & 3 & 3 & 3 \\
\hline & $\frac{\text { Category } 2}{\text { Cognitive Demand }}$ & 3 & 4 & 3 & 4 & 3 & 4 & 3 & 4 & 3 & - & 3 & - & 3 & 2 & 3 & 3 \\
\hline & $\begin{array}{l}\text { Category } 3 \\
\text { Cooperative } \\
\text { learning; equity in } \\
\text { student interaction }\end{array}$ & 3 & 4 & 3 & 3 & 4 & 3 & 3 & 4 & 3 & - & 3 & - & 3 & 2 & 3 & 2 \\
\hline & $\frac{\text { Category } 4}{\text { Discourse }}$ & 3 & 4 & 3 & 4 & 3 & 3 & 4 & 3 & 3 & - & 2 & - & 3 & 3 & 2 & 3 \\
\hline \multirow[t]{2}{*}{$\begin{array}{c}\text { Assessment } \\
\text { Characteristics }\end{array}$} & $\begin{array}{l}\text { Category } 1 \\
\text { Preconceptions and } \\
\text { Misconceptions }\end{array}$ & 3 & 4 & 3 & 4 & 3 & 4 & 3 & 4 & 3 & - & 2 & - & 2 & 2 & 3 & 3 \\
\hline & $\begin{array}{l}\text { Category } 2 \\
\text { Student } \\
\text { reflection/self- } \\
\text { assessment }\end{array}$ & 3 & 3 & 3 & 3 & 3 & 4 & 3 & 3 & 3 & - & 3 & - & 2 & 2 & 3 & 2 \\
\hline
\end{tabular}


Table 10

Teachers' Self-Assessment Instructional Vision: Mathematics ("Mary and Susan Did Not Self-Assess in Year 3)

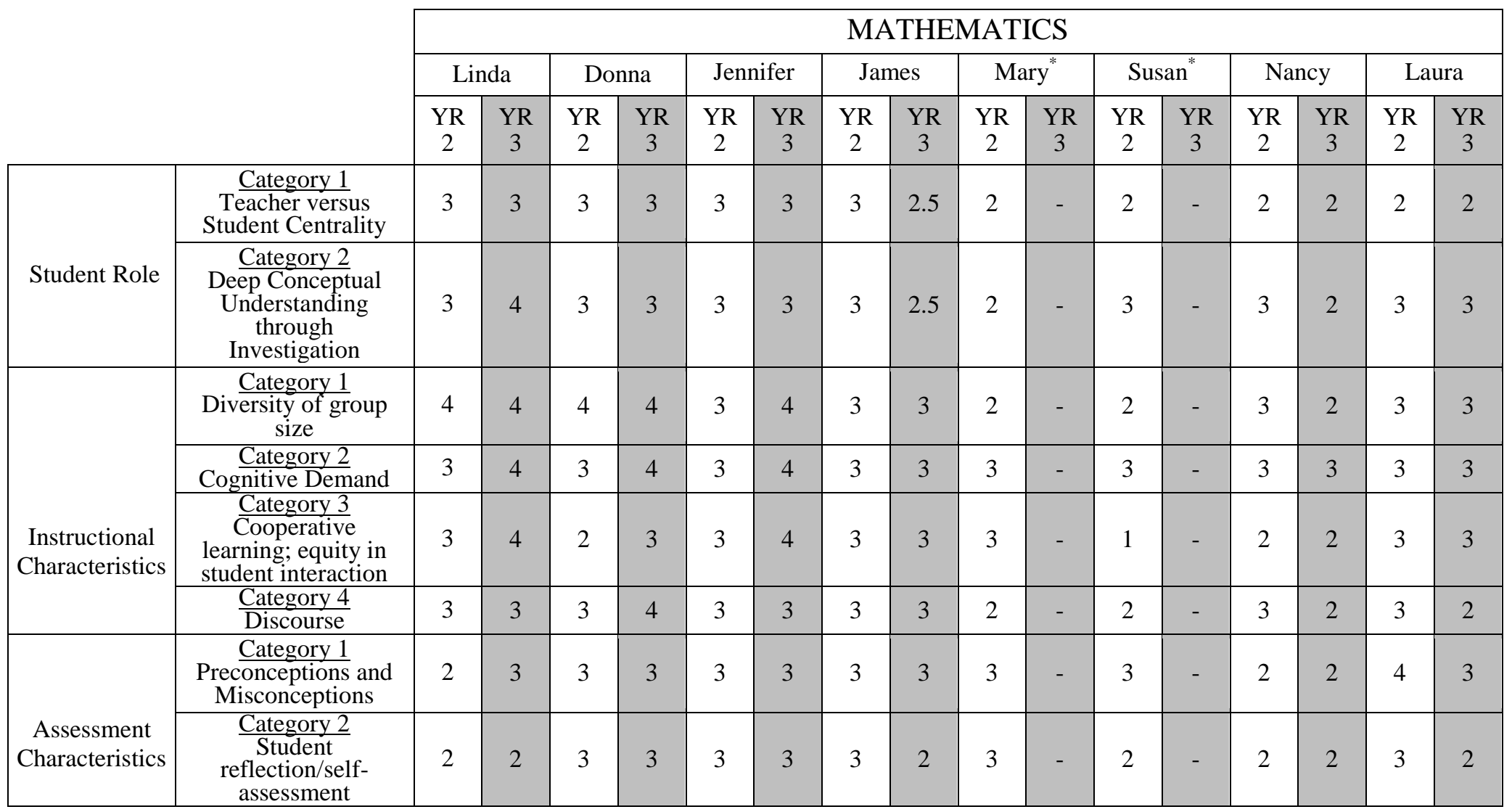


Table 11

Frequency of Science Researchers' Posed Questions Related to Each Bullet Level (BL) Category of the TIP Rubric for Each Teacher

\begin{tabular}{|l|c|c|c|c|c|c|c|c|}
\cline { 2 - 9 } \multicolumn{1}{c|}{} & \multicolumn{9}{|c|}{ SCIENCE } \\
\cline { 2 - 10 } \multicolumn{1}{c|}{} & \multicolumn{3}{|c|}{ CLASSROOM ROLES } & \multicolumn{3}{c|}{$\begin{array}{c}\text { CONTENT AND } \\
\text { COGNITIVE SKILLS }\end{array}$} & \multicolumn{4}{c|}{$\begin{array}{c}\text { ASSESSMENT FOR } \\
\text { LEARNING }\end{array}$} \\
\cline { 2 - 10 } Linda & BL 1 & BL 2 & BL 3 & BL 1 & BL 2 & BL 1 & BL 2 & BL 3 \\
\hline Donna & 0 & 0 & 0 & 0 & 1 & 1 & 0 & 1 \\
\hline Jennifer & 0 & 0 & 0 & 1 & 2 & 0 & 0 & 0 \\
\hline James & 0 & 0 & 0 & 1 & 1 & 1 & 0 & 1 \\
\hline Mary & 0 & 1 & 0 & 0 & 0 & 1 & 1 & 1 \\
\hline Susan & 0 & 0 & 0 & 0 & 1 & 2 & 0 & 0 \\
\hline Nancy & 0 & 0 & 0 & 0 & 1 & 2 & 0 & 0 \\
\hline Laura & 0 & 0 & 0 & 2 & 0 & 1 & 0 & 0 \\
\hline
\end{tabular}

Table 12

Frequency of Mathematics Researchers' Posed Questions Related to Each Bullet Level (BL) Category of the TIP Rubric for Each Teacher

\begin{tabular}{|l|c|c|c|c|c|c|c|c|}
\cline { 2 - 9 } \multicolumn{1}{c|}{} & \multicolumn{9}{c|}{ MATHEMATICS } \\
\cline { 2 - 10 } \multicolumn{1}{c|}{} & \multicolumn{3}{|c|}{ CLASSROOM ROLES } & \multicolumn{2}{c|}{$\begin{array}{c}\text { CONTENT AND } \\
\text { COGNITIVE SKILLS }\end{array}$} & \multicolumn{3}{c|}{$\begin{array}{c}\text { ASSESSMENT FOR } \\
\text { LEARNING }\end{array}$} \\
\cline { 2 - 10 } Linda & BL 1 & BL 2 & BL 3 & BL 1 & BL 2 & BL 1 & BL 2 & BL 3 \\
\hline Donna & 0 & 0 & 2 & 0 & 0 & 0 & 1 & 0 \\
\hline Jennifer & 0 & 2 & 0 & 0 & 1 & 0 & 0 & 0 \\
\hline James & 1 & 0 & 0 & 1 & 0 & 1 & 0 & 1 \\
\hline Mary & 1 & 0 & 0 & 2 & 0 & 0 & 0 & 0 \\
\hline Susan & 0 & 0 & 0 & 1 & 0 & 1 & 0 & 0 \\
\hline Nancy & 1 & 0 & 1 & 0 & 0 & 1 & 0 & 0 \\
\hline Laura & 0 & 0 & 0 & 1 & 0 & 2 & 0 & 0 \\
\hline
\end{tabular}




\section{Reflective PD: Audio of Reflective Conversation with Researchers}

Researchers used a coding system to code the audio from the conversations between teachers and researchers. This coding system was also based on the TIP rubric bullet level categories that summarize the instructional best practices to teach science and mathematics. The frequency of each category is presented in the tables below grouped by each pair of teachers. Extra codes were added based on the frequency that two additional topics (logistics and integration) appeared on teachers' discussions.

As already stated on the teachers' case descriptions, Linda and Donna conversation for science and mathematics focused on classroom roles and content and cognitive skills, as well as on assessment for learning. Jennifer and James discussions for science concentrated on assessment for learning and content and cognitive skills, as well as classroom roles. For mathematics, the discussion concentrated on classroom roles (Tables 13 and 14).

In summary, both conversations, for science and mathematics, concentrated more in classroom roles than the other two categories. Assessment for learning was the least discussed category for both content areas. As for the extra codes, logistics was addressed more during the science discussion than during mathematics discussion, and integration was discussed more during mathematics than science (Tables 13 and 14). 
Table 13

Frequency of Teachers' Audio Code of Reflective Professional Development Conversations with the Researchers Related to the TIP rubric Bullet Level (BL) Categories for Science

\begin{tabular}{|l|c|c|c|c|c|c|c|c|c|c|}
\cline { 2 - 11 } \multicolumn{1}{c|}{} & \multicolumn{9}{c|}{ SCIENCE } \\
\cline { 2 - 11 } & \multicolumn{3}{c|}{$\begin{array}{c}\text { CLASSROOM } \\
\text { ROLES }\end{array}$} & $\begin{array}{c}\text { CONTENT } \\
\text { AND } \\
\text { COGNITIVE } \\
\text { SKILLS }\end{array}$ & \multicolumn{2}{c|}{$\begin{array}{c}\text { ASSESSMENT FOR } \\
\text { LEARNING }\end{array}$} & \multicolumn{2}{c|}{ EXTRA CODES } \\
\cline { 2 - 11 } & BL 1 & BL 2 & BL 3 & BL 1 & BL 2 & BL 1 & BL 2 & BL 3 & Logistics & Integration \\
\hline $\begin{array}{l}\text { Linda } \\
\text { and } \\
\text { Donna }\end{array}$ & 3 & 3 & 4 & 2 & 3 & 3 & 1 & 0 & 2 & 0 \\
\hline $\begin{array}{l}\text { Jennifer } \\
\text { and } \\
\text { James }\end{array}$ & 3 & 0 & 2 & 1 & 3 & 1 & 3 & 2 & 1 & 1 \\
\hline
\end{tabular}

Table 14

Frequency of Teachers' Audio Code of Reflective Professional Development Conversations with the Researchers Related to the TIP Rubric Bullet Level (BL) Categories for Mathematics

\begin{tabular}{|l|c|c|c|c|c|c|c|c|c|c|}
\cline { 2 - 11 } \multicolumn{1}{c|}{} & \multicolumn{8}{c|}{ MATHEMATICS } \\
\cline { 2 - 11 } & \multicolumn{3}{c|}{$\begin{array}{c}\text { CLASSROOM } \\
\text { ROLES }\end{array}$} & $\begin{array}{c}\text { CONTENT } \\
\text { AND } \\
\text { COGNITIVE } \\
\text { SKILLS }\end{array}$ & \multicolumn{2}{c|}{$\begin{array}{c}\text { ASSESSMENT FOR } \\
\text { LEARNING }\end{array}$} & \multicolumn{2}{c|}{ EXTRA CODES } \\
\cline { 2 - 11 } \multicolumn{1}{c|}{} & BL1 & BL2 & BL3 & BL 1 & BL 2 & BL 1 & BL 2 & BL 3 & Logistics & Integration \\
\hline $\begin{array}{l}\text { Linda } \\
\text { and } \\
\text { Donna }\end{array}$ & 6 & 0 & 3 & 2 & 3 & 1 & 1 & 3 & 1 & 1 \\
\hline $\begin{array}{l}\text { Jennifer } \\
\text { and } \\
\text { James }\end{array}$ & 3 & 4 & 0 & 1 & 1 & 0 & 1 & 2 & 1 & 3 \\
\hline
\end{tabular}




\section{Reflective PD: Teacher's Written Reflection.}

The table below presents the frequency data collected from teachers' written reflections. Donna and Linda, who participated in the same audio reflective conversation with the researchers, reflected about some different aspects of their practice. For example, while Linda reflected twice about targeting both content and cognitive skills (CCS bullet 1) in her unit for year 3 of implementation, Donna reflected on it just once. Further, Linda wrote about her desire to provide multiple opportunities for students to "show all they want to show" in more "well-crafted data sheets" (CCS bullet 2), when Donna did not write about it. Linda also wrote about her assessment practice and Donna did not (Table 15).

James and Jennifer also demonstrated discrepancy in their written reflections after participating in the audio conversation together. James addressed most of all bullet level categories in his written reflection when Jennifer concentrated in reflecting about targeting both content and cognitive skills in her practice. She also wrote about the pop rocket activity stating that she wanted students to practice the skill of finding surface area of the rockets (CCS bullet 2) (Table 15).

As for Mary and Susan, they also followed the same pattern found in the frequency of reflections of James and Jennifer. Mary reflected on four bullet level categories while Susan reflected just on one. For example, Susan wrote about her desire to revise her unit based on her interpretations of the assessment data (Table 15). 
Laura also reflected more than Nancy. Based on the frequencies provided in the table below, both teachers reflected on content and cognitive skills bullet 2 twice.

However, while Nancy addressed her intention to provide more opportunities for students to practice their higher-order thinking skills by answering "why questions" during the science inquiry, Laura wrote about providing opportunities for students to better organize the same data in different forms (Table 15).

In summary, most teachers reflected on four bullet level categories or on two bullet level categories. Only James reflected on seven out of the eight bullet level categories from the TIP rubric. From the two teachers who participated together in the reflective conversation with the researchers, one teacher always wrote more about different bullet level categories in the reflection than the other teacher (Table 15).

Table 15

Frequency of Teachers' Written Reflection Related to Each Bullet Level Category of the TIP Rubric for Year 2

\begin{tabular}{|c|c|c|c|c|c|c|c|c|c|}
\cline { 2 - 10 } \multicolumn{2}{c|}{} & Linda & Donna & Jennifer & James & Mary & Susan & Nancy & Laura \\
\hline \multirow{4}{*}{$\begin{array}{c}\text { Classroom } \\
\text { Roles }\end{array}$} & Bullet 1 & 0 & 0 & 0 & 0 & 0 & 0 & 0 & 0 \\
\cline { 2 - 11 } & Bullet 2 & 0 & 0 & 0 & 1 & 1 & 0 & 0 & 2 \\
\cline { 2 - 11 } & Bullet 3 & 1 & 1 & 0 & 1 & 1 & 0 & 0 & 1 \\
\hline $\begin{array}{c}\text { Content and } \\
\begin{array}{c}\text { Cognitive } \\
\text { Skills }\end{array}\end{array}$ & Bullet 1 & 2 & 1 & 3 & 1 & 1 & 0 & 1 & 0 \\
\cline { 2 - 11 } & Bullet 2 & 1 & 0 & 1 & 1 & 0 & 0 & 2 & 2 \\
\hline $\begin{array}{c}\text { Assessment } \\
\text { for Learning }\end{array}$ & Bullet 1 & 1 & 0 & 0 & 1 & 1 & 1 & 0 & 1 \\
\cline { 2 - 11 } & Bullet 3 & 0 & 0 & 0 & 1 & 0 & 0 & 0 & 0 \\
\hline
\end{tabular}




\section{Discussion}

The goal for this research study was to investigate the changes in elementary school teachers' instructional practices after participating in a reflective professional development (PD) experience. This discussion section is organized to present first the trends found in the first implementation of the integrated units and then the instructional changes between the two years of the unit implementations for science and mathematics. Finally, the last section summarizes the claims made in this study.

\section{Trends Found in the First Implementation of the Integrated Units}

By analyzing the TIP scores for year 2 for science (Tables 7) the first tendency observed is that most science scores represent a level 2 on the TIP rubric categories. As exceptions, Mary scored a 1 on content and cognitive skills and Nancy scored a 3 on assessment for learning. Since the TIP scores indicate the quality of instruction, it is possible to state that before the reflective PD teachers were not providing high quality science instruction to students when teaching these specific units.

The instructional practices represented by a score of 2 on the TIP rubric are described as teachers primarily being the content authority, students engaging in science inquiry by following a predetermined format and following procedures to complete activities they already knew how to accomplish. Further, the unit of instruction overemphasized content over cognitive skills and inconsistent opportunities were provided for students to construct meaning. As for assessments for learning, not all learning goals were linked to the assessments used prior, during and after instruction, 
students experienced infrequent opportunities to self-assess and at least a few assessments in these units were either not appropriate in terms of cognitive demand, not representative of learning progressions or misaligned with goals and standards.

In Laura's 3rd grade unit, for example, whole group instruction and reading characterized the most common locus of content authority with students having a few opportunities to be really engaged in hands-on learning (i.e.: Move It, Sir Issac! activity where students had to move a lump of clay, a paper clip and a marble by pushing it without picking it up). Overall, Laura's unit overemphasized content (i.e.: force) over skills that were brought into the unit only in the science inquiry (i.e.: "Why do you think that happened?" last question in the science inquiry worksheet asking students to reflect on their experiment). In addition, students had inconsistent opportunities to apply content and practice higher-order thinking skills. Students' work samples were very weak and some of the worksheets demonstrated that sometimes students had copied answers from Laura's model (i.e.: high, medium and low had the same answer on the word wall activity). The selection of assessments Laura used in her unit demonstrated that students' knowledge was assessed prior, during and after lessons (i.e.: pre and post-test, formative probes, and science inquiry) and that those assessments were aligned with the learning goal of her unit: "Describe how forces cause changes in an object's position, motion, and speed."

Further detailed examples of level 2 instructional practices characteristics were already presented in the case descriptions for year 2 of implementation (see results section). The characteristics of a level 2 TIP rubric description aligns well with the 
findings reported by Capps and Crawford (2013) when they describe science instruction at the elementary school level as:

...hands-on or activity-based lessons (which tended to be group or station work) and investigations. For the most part, these lessons were teacher-driven and highly structured. Common occurrences in these lessons were teachers explaining concepts to their students or telling their students what they should do or see. In general, these lessons provided little opportunity for student autonomy. Common instructional techniques included teacher demonstrations and group work. (p. 511)

In the TIPs analyzed in this research study, we also found that instruction was mainly teacher-centered as well as that the students' work sample showed a significant amount of copied work from the teacher, corroborating with Capps and Crawford description.

Considering mathematics instructional practices, the results were at a lower level of instruction, especially because math lessons were rather sparse when compared to science. Mathematics instructional practices scores from the TIP rubric ranged between 0 and 2, with four scores of a zero, nine scores of a one, and eleven scores of a two. The mathematics instructional practices represented in the eight instructional portfolios reflect the practice of mathematics that has been emphasized in schools (Hiebert et al., 1997; Stein et al., 2009). Those instructional practices are based on teacher's content authority, problem-solving tasks that have no connection with real life situations other than having the science content as the context for the math task, and students that are merely memorizing procedures to complete activity sheets. In addition, content was taught separately from higher-order thinking skills and students did not have opportunities to construct meaning. Students' conceptions were infrequently assessed and when students' knowledge was assessed, teachers used worksheets that were not appropriate in terms of 
cognitive demand. Because the math portion of those units were not well described, there was less opportunity to highlight what really happened instructionally for mathematics in the classrooms.

Most integrated units represented in this study had only two math lessons compared to an average of eight science lessons. Those math lessons were often disconnected from the whole scope of the unit and frequently only provided opportunities for students to practice measuring skills that were not tied to the unit goals originally articulated for math. In Mary's unit, for example, one math lesson focused on the skills students needed to name coordinate points. First, Mary taught students the procedures to name coordinate points and then they practiced naming it in the "Interpreting Sundial Data" worksheet. Another example was in Jennifer's unit where there was a problemsolving task, but no corresponding math lesson and the mathematics learning goals were not linked to the content of the task.

The findings from this research study regarding how mathematics is being taught in elementary schools corroborates Hiebert et al.'s (1997) argument that “the prevailing view of mathematics is one of rules and procedures, memorization and practice, and exactness in procedures and in answers" (p. xiv). In another study, Hiebert and Stigler (2000) compared US teachers' practices with German and Japanese teachers' instruction and also found that American teachers mainly "stated mathematical concepts rather than developing them [the math concepts]" (p. 5) when teaching. 
In general, another tendency observed in this study was that science was emphasized over mathematics when teachers planned their integrated units. One plausible explanation for teachers' focusing on science over mathematics could be that elementary school teachers usually do not have opportunities to teach science (Marx \& Harris, 2006). When they were invited to participate in the three-year long PD, they may have taken it as an opportunity to learn and teach science. Considering that the eight teachers from this study had a free choice over which summer courses to take before implementing their units for the first time and only Jennifer chose to take mathematics, it is evident that science largely represented teachers' perceived need for PD (Table 2).

However, when using an integrated approach to teach mathematics and science, the focus should be on achieving high quality of instruction in both areas. Douville, Pugalee and Wallace (2003) point out that currently "mathematics may too frequently be integrated in instances that merely reinforce basic skills related to measurement and analysis of data, thus limiting the potential of mathematics as a meaningful tool for understanding and conceptualizing science" (p. 394). In addition, mathematics needs to be taught not only to support science but also to foster students' understanding of logical reasoning and mathematical computation.

In summary, the main trend found for this study in year two was the lack of high quality science and mathematics instruction teachers were implementing in their classrooms when teaching these integrated units. Most science instruction was characterized by a level 2 of the TIP rubric. For math, most lessons illustrated a level 1 
on the TIP rubric or even a zero, representing a lack of evidence that math was taught in year two. Most teachers planned for an average of 8 science lessons to be implemented compared to two math lessons. Considering that the background foundation for this PD project was to generate and implement science and mathematics integrated units, teachers seemed unprepared to integrate both content areas without prioritizing science over mathematics.

\section{Instructional Changes Between Years 2 and 3}

\section{Data Sources: Explaining Teachers' Instructional Changes}

\section{Linda}

Linda improved her instructional practice related to the role of the students and the teacher in the classroom for science (score of a 2 in year 2 to a score of a 3 in year 3 ) as measured by her TIP rubric scores (Table 7). It is evident from the frequency Linda and Donna discussed about classroom roles for science in the audio (ten distinct times) that Linda's change might have been a result of the time spent reflecting on classroom roles for science (Table 13). When observing the other data sources for science, there is no strong correlation with her improvement on this specific instructional practice. She did rate her classroom roles instructional practices with higher scores in the self-assessment rubric in year 3. However, her self-assessment improved scores for classroom roles cannot be used alone to explain her more student-centered practice in year 3 . The reason for that is because Linda's self-assessments scores for year 3 were also improved for 
other instructional practices, but her TIP scores for those other practices did not change in year 3 .

Linda did not have an increase in her TIP scores for mathematics in year 3 even though she also reflected about classroom roles 9 times in the audio. It might be possible that to demonstrate instructional changes, teachers may have to concentrate in one discipline at a time. Since Linda improved her practice in science maybe she could not, at the same time, improve in mathematics. A change in instructional practice, as suggested by Guskey (2002), may require extra work from the teacher causing it to be a slow process most of the time.

\section{Donna}

Donna had an increase in her TIP scores in year 3 for science on classroom roles, the same as Linda (score of a 2 to a score of a 3 ). The same explanation can be applied here about the frequency of reflection that happened during the audio session between Linda, Donna and the researcher about this instructional practice.

Donna also had a positive change for mathematics related to assessment for learning. It is possible that Donna increased her teaching ability on assessment for learning based on her collaboration with Linda. Linda already scored a 2 on this category in year 2 and showed no improvement in year 3. On the other hand, Donna had scored a 1 in year 2. Maybe because Donna and Linda worked so closely together when planning, implementing, and reflecting on their units, Donna was able to notice the lack of assessments in her unit compared to Linda, and was able to provide better evidence of it 
or even really improve it in year 3. Linda and Donna spent a considerable amount of time discussing with the researchers about assessment for learning for mathematics (Table 14). The frequency of the assessment topic in their discussions could have prompted Donna to improve this instructional practice in year 3. Elmore and Burney (1997) argue that the effectiveness of PD is determined by "the level of commitment and mutual support among those responsible for instruction" (p. 271). Donna and Linda did collaborate a lot and that may be one reason why they both had changes in their instructional practices after the reflective PD (Anderson, 2002).

\section{Jennifer}

Jennifer showed no change in her instructional practices for science and mathematics. Her self-assessment scores were almost the same for both years with a few increases on assessment for learning (science) and content and cognitive skills for both disciplines. The frequency of her audio reflections for science on classroom roles and assessment for learning were not as high as Linda and Donna, but could have made her reflect more about those two practices. However, no change was demonstrated on her TIP scores for science in year 3 .

For mathematics, Jennifer's TIP scores moved from a zero to a 1 on classroom roles in year 3. That does not represent a change but an indication that no evidence or insufficient evidence was provided in year 2 to score this category. Jennifer and James discussed about classroom roles for mathematics seven times in the audio. The frequency of their discussion may have driven her to provide evidence of math lessons in year 3. 
The evidence provided was enough for her to score a 1 in year 3, but not enough to demonstrate an improvement on her classroom roles practice for mathematics.

James

James increased his practice for science on two categories: classroom roles and assessment for learning. The data that explains those changes is the frequency of reflective discussion about those two practices. James was the only participant of this study who demonstrated two positive changes for science. It is possible that his concentrated efforts on improving his instruction for science led to him falling short on improving his mathematics instruction.

For math, James had a negative change in classroom roles even though the frequency of time spent discussing this instructional practice on the audio was high when compared with the other practices. Further, there was a reported difference in what was documented in the unit and what was completed for math instruction. James also reported in his self-assessment scores that his classroom roles practice slightly decreased in year 3. These data reinforce, as already stated on Linda's section, that teachers may only concentrate and change their instructional practice in one discipline at a time. James had a high focus in science, having two improvements in this discipline in year 3. Considering that, it is reasonable to infer that he did not spend much effort in changing his practice for mathematics. 
Mary and Susan

Mary and Susan collaborated in planning and implementing their units. Both teachers had no change in instructional practices from year 2 to year 3. Susan was able to provide evidence on content and cognitive skills for mathematics so it was scored by the researchers in year 3 (moving her TIP score from a 0 to a 1 ). Both teachers also provided enough evidence of assessment for learning in mathematics for it to be scored, moving from a 0 in year 2 to a 1 in year 3 . Without having listened to their reflective conversations with the researchers, it is difficult to infer why those teachers did not change their instructional practices.

Nancy

Nancy had no change in her science instructional practices but had a decrease on content and cognitive skills for mathematics. Her self-assessment scores for science support the lack of change. Her written reflection also corroborates with her not having a change for all instructional practices with the exception of content and cognitive skills, which are discussed in details in the relevant findings section. As already stated, it is evident that change in instructional practice is not an easy task and that it may take extra time and reflection for some teachers to be able to demonstrate any change at all (Glenn, 2011; Gulamhussein, 2013; Guskey, 2002).

For mathematics, Nancy had a decrease on content and cognitive skills. That is once again aligned with her scores from the self-assessment rubric but was not related with the frequency presented on her written reflection. As for Mary and Susan, it is 
difficult to explain any change or lack of it without having more details about their practice. Capps and Crawford (2013) suggest:

It is certainly not enough to merely look at a teacher's self-reported views, or teacher-designed lesson plans, or even their classroom interactions, by themselves. Instead, it is necessary to take multiple factors into account when attempting to characterize one's teaching practice. (p. 503)

Our research study corroborates with Capps and Crawford idea since we have more evidence to explain changes in instructional practices when we analyzed the audio from the reflective conversation to write a case description of the teachers' unit implementation and participation in the reflective PD.

\section{Laura}

Laura had no change in instructional practices for science. Her lack of change corroborates with her scores from the self-assessment rubric but not with her written reflection or the questions posed by the researchers in her TIP. Based on those two data sources, one could predict that she would show a positive change. However, once again, without having more details about her practice or the frequency of reflection presented on her audio discussion with Nancy and the researchers, it is difficult to infer the reason behind a lack of change.

For mathematics, Laura showed improvement on classroom roles and on content and cognitive skills. It is possible that Nancy and Laura discussed those practices during their audio reflection but because this study did not include this data, this study cannot affirm this. 


\section{Case Descriptions: Teachers' Desire to Change Instructional Practices}

\section{Linda}

When using the qualitative data to analyze Linda's improvement in classroom roles for science, it is evident that Donna and her had a very strong discussion about this specific practice during the reflective conversation with the researcher. Even though there was only the question about the "Slide, Collide and Divide" activity posed by the researcher in reference to classroom roles, the two teachers spent a significant amount of time discussing about student roles. For example, they talked about the need for handson activities to be connected with students' reflections, as well as how important it was to build students' background knowledge prior to the science inquiry.

Linda's written reflection revealed how impactful the audio discussion was for her learning. She explicitly wrote about classroom roles in her reflection demonstrating evidence of her desire to change and better implement this instructional practice for science. She wrote she would like to provide students with science data sheets that were more "well-crafted to give students room/opportunities to show all they want[ed] to show." In addition, she also reflected on her job as the teacher by stating her desire to better scaffold language to prompt students' expression of complete scientific thoughts.

On the other hand, when analyzing the qualitative data for mathematics, it is evident that both teachers also had a significant reflective conversation about classroom roles, but that was not revealed in Linda's written reflection. In the audio, when Linda was talking about the journal writing activity, for example, she recognized the importance 
of it but did not voice her desire to improve implementation of this activity in year 3 . This example provides evidence that Linda acknowledged the value of improving her classroom roles practice for mathematics but did not demonstrate the intention to act on improving it in the following year.

For science and mathematics, when considering assessment for learning, Linda had frequent interactions with Donna about it in the reflective conversations but did not write about assessment in her reflection. Again, changing instructional practices is not an easy task and as stated by Gulamhussein (2013) it may take as many as 20 interactions to maintain and support an instructional change of a new skill. That may explain why we did not find explicit changes in assessment for learning on Linda's unit.

\section{Donna}

Donna had a very similar situation as Linda. She participated in the audio discussion for science with Linda and the researcher and had a strong reflective conversation about classroom roles. In addition, Donna demonstrated an improvement in her instructional practice the following year. The main difference between these two teachers was that Donna's written reflection was mainly about science, demonstrating a lack of intention to change her practice in relation to mathematics. Her only comment about mathematics stated "When integrating math within a content such as science, it has greater meaning and 'buy-in' for the students." For science, Donna wrote about the importance of developing students' scientific vocabulary so they could have access to scientific concepts. In addition, she also wrote "I would like to see a greater 
understanding of the 'why' behind the science in the students' processing" but she did not explain how she could do that in order to change her practice.

For math, she demonstrated an improvement in her assessment for learning practice. Her audio discussion with Linda and the researchers showed that they did have conversations about assessment, even though Linda was mainly the one talking about it. It is possible, since Donna did not write in her reflection about this topic, that she noticed the difference between her unit's assessments and Linda's unit's assessment when working closely together with Linda during year 3 to improve her assessment practice for mathematics. However, because this research study does not have data on collaborations the teachers had outside of structured PD time, it is very difficult to explain why Donna improved her assessment practice.

One way to explain Donna's change in assessment for mathematics is to consider that her collaboration with Linda was a main reason for her instructional change in year 3. Gulamhussein (2013) suggests when professional learning communities (PLCs), "where fellow teachers can serve as a network of coaches for each other" (p. 38), happen at schools, it is easier to observe changes in teachers' instructional practice. Since Linda and Donna worked so closely together there is a considerable possibility that they coached and influenced each other during the process of developing and implementing their units, especially because the larger three-year long PD project engaged teachers in PLCs. 


\section{Jennifer}

Jennifer showed no change on her TIP scores for science or mathematics. Her qualitative data indicates exactly the same. During her science audio discussion with James, she commented about her role as a teacher to model activities for students so they knew exactly what they had to do. She also discussed scaffolding scientific vocabulary so students could demonstrate the use of academic words in their writing. However, none of those topics showed up in her written reflection and there is no evidence in her case description that she changed her science instructional practices.

Most of her written reflections were about mathematics and especially about content and cognitive skills. In spite of this, there was no change in this practice for math in Jennifer's unit. This corroborates with the idea that content and cognitive skills are the most difficult instructional practice to change over time. Stanulis et al. (2012) argue that "teachers are often unaware that this is the pervasive pattern [teacher asks a lower-order recall question, students respond to it, and teacher evaluates the response] they use while teaching, and see this as the natural way to lead discussions" (p. 33). Jennifer's unit for year 2 did not even target HOTS. Stanulis et al. emphasize the importance of teachers learning how to facilitate and model the use of higher-order questions in the classroom as a way to foster students' deep understanding of the content they are learning, especially because it is so difficult for teachers to change their practice related to promoting higherorder thinking discussions. 
Even though she discussed with James other instructional practices for mathematics in the reflective conversation, there was no written evidence in her reflection that she planned to make changes. Jennifer spoke about how she implemented the math problem-solving task, based on the questions posed by the researcher. The frequency of their questions being about the problem-solving task indicated that more evidence on how it was implemented was necessary. The frequency of questions posed by the researcher may have been enough to bring her awareness of the importance of providing evidence of her math lessons for year 3. However, it was not enough to demonstrate change in her instructional practices because we had no evidence to score her math practices in year 2. Guskey (2002) comments that any relevant change in teachers' instructional practices is "likely to be slow and require extra work" (p. 388). Maybe Jennifer needs more time applying the new skills she learned in the PD to be able to better implement it in her unit.

\section{James}

James' instructional practices for science for year 2 were stronger than the instructional practices of most of the other participants in this study demonstrated in year 2 (see case descriptions). In addition, James written reflection was focused on science and not on mathematics. In the reflective conversation, he discussed with Jennifer and the researchers about the format of the science inquiry, explaining that he did it as a "guided inquiry or demonstration inquiry." On his written reflection he emphasized the format he would like to implement in year 3: collect and use group data and provide opportunities 
for students to analyze data for each experiment prior to the final inquiry. These two pieces of data combined make a strong case for James' improvement in classroom roles for science in year 3 .

A similar situation happened in assessment for learning for science. During the audio, more than once James demonstrated interest in providing opportunities for students to reflect on their learning, in having more time to assess students' knowledge and in providing performance criteria for students to meet the learning goals. In his written reflection he again emphasized a desire to have students keep a metacognitive journal as well as provide "criteria for meets, exceeds" especially when having an open ended question on the assessments. As far as assessment for learning in science, James also showed evidence of an improvement in this instructional practice collaborating with the idea that the reflective discussion with the researchers combined with the written reflection may be the source of James' instructional changes.

James had a decrease on his classroom roles instructional practice for mathematics. Even though, he and Jennifer discussed about it during the audio, he did not demonstrate in his written reflection an explicit desire to positively change it on his written reflection. There is a possibility that James was so focused on the science portion of his unit that he left math behind. This study cannot affirm this finding but may support the idea that when teachers concentrate their efforts in one subject area, it is difficult to demonstrate positive changes in another discipline, even when planning and implementing integrated units. 


\section{$\underline{\text { Summary of Claims }}$}

In summary, some teachers from this study demonstrated improvement in instructional practices and others did not. Possible reasons for the improved practices, as well as for the lack of change, are presented below.

The reflective PD had an impact on Linda and Donna positively changing their classroom roles practice in year 3. It is possible to state that their strong collaboration demonstrated in their similar TIPs as well as their reflective conversation with the researchers were the main reason behind their improvement. Other teachers, like Jennifer and James, for example, worked together but did not have a strong collaboration, as did Donna and Linda. Working closely together with a colleague seems to be one of the main reasons behind a positive change in instructional practice, corroborating with the literature about the impacts of a strong support system (Anderson, 2002, Elmore \& Burney, 1997 and Gulamhussein, 2013).

James also had positive changes in his practice, as well as did Laura. James changes can be attributed to the reflective discussions he had with Jennifer and the researchers as well as to his desire and intention to change his practice (as already reported). This finding corroborates with the suggestion that reflection may be an effective way to stimulate and foster teacher's change in instructional practice (Glenn, 2011; Gulamhussein, 2013; Guskey, 2002). Since we did not listen to Laura's reflective discussion, we cannot infer the reason behind her positive changes. 
Considering the teachers who did not have any change in their instructional practices as a result of the reflective PD, the literature suggests, as already stated, that many instances of practice are necessary for change to happen (Gulamhussein, 2013). Further, the lack of motivation to change may have also contributed to some teachers not improving their practice in year 3 (Ryan \& Deci, 2000). Guskey (2002) suggests that changes in instructional practices may be a slow process that requires extra work from the teachers, evidencing one more reason to justify the lack of change reported by this study.

It seems possible that each teacher may have distinct needs in relation to what triggers a desire and/or disposition to change instructional practices. Some teachers may need more time to practice the new skill; others may need to collaborate more with a colleague. Some teachers may need more time to reflect and intentionally plan the change to be made in their instruction; some may need to activate their intrinsic motivation to exhibit a change. It is difficult to exactly know the motives behind each teacher's lack of changes as a result of the reflective PD. We may only infer possible reasons for it that corroborate with the literature.

The results from this study suggest that this reflective PD had a flaw on not providing enough opportunities for those eight teachers to practice the new skills they were acquiring, to be able to demonstrate a positive change in their instruction. Further, the design of the reflective PD did not account for teachers' motivation to change. These could have had an impact on teachers not improving their practice and should be 
addressed when planning and designing professional development focused in changing instruction.

\section{Relevant Findings}

From all the quantitative and qualitative data presented in this study, some findings can be reported to contribute with the literature about professional development and change in teacher's instructional practices. The four main findings are summarized in the subsections below.

\section{Desire to Change Instruction versus Importance of Changing Instruction}

Of the eight teachers who participated in this study, three demonstrated improvement in classroom roles for science. As already described, those three teachers, Linda, Donna and James, had their positive change in this instructional practice associated with the reflective conversations they had with their teacher colleague as well as with the researcher during the reflective PD. James was the only teacher who also demonstrated a positive change in assessment for learning for science. It was possible to notice his enthusiasm and desire to understand and change when listening to his audio conversation. From all the eight teacher participants in this study, those three teachers could have been the most motivated to teach and learn about science based on their audio discussions, even though this study did not measure willingness to change. It is well known that motivation plays a significant role in improving teachers' instructional practices (Pop et al., 2010, Ryan \& Deci, 2000 and Schwartz et al., 2000). 
As for the two negative changes in mathematics instructional practices, James decrease could be explained based on his focus on improving the science portion of his unit. Even though he reflected about classroom roles for mathematics during the audio discussion, his written reflection did not show any desire to improve it. As for Nancy, this study cannot accurately explain her decrease on content and cognitive skills for mathematics, other than stating that her self-assessment scores corroborated with her negative change in year 3. Further, Nancy's written reflection was basically all about science. When she addressed mathematics, she wrote that the math content (numbers, multiplication, measuring, scale and fractions) could help "students see what the difference between a slow change, and a fast change [weathering and erosion - science content] would be." She reflected about the importance of mathematics content only in relation to the science content of her unit, not really demonstrating a desire to change her practice.

Linda's written reflection can provide a clear example of how we recognized teachers' desire to change their instruction versus acknowledging the importance to change. Linda wrote "as we move forward and begin planning of instruction and assessment for next year, I'd like to consider how the activities + experiences in the unit can carry students beyond one "right" method or answer." Then, she moved on writing about the specific changes she would like to do: "data sheets that are more well-crafted to give students room/opportunities to show all they want to show." If Linda had only written about the data sheets without clearly stating her intention to change and implement it the next year, like she did in the first quote, then we would consider that she 
recognized the importance of changing her data sheets but not demonstrated a desire to really change it.

Based on teachers' reflections, it became evident that some teachers struggled to reflect on their practices. Considering the difficulty of reflecting on her own practice, Glenn (2011) describes her journey into learning how to deeply reflect on her practice as a teacher. She states that she struggled to identify her educational values and battled to become more critical in her thinking. In trying to respond to the question: "How can I improve my practice?" She realized how difficult it was to think critically. Glenn (2011) also explains that she only was able to address the question about ways to improve her practice years later. Some teachers who participated in this study could have faced the same struggles when trying to reflect and implement instructional changes. Once again, improvement in instructional practices may take time and may need effort from teachers' to learn how to deeply reflect (Harnett, 2012; Marcos et al., 2008).

The results of this research study suggest that some teachers may have changed their instructional practices based on the reflective PD. Some of the increases and decreases in instructional practices may also be attributed to teachers' willingness to change or implement a change in their units. However, this research study did not measure teachers' motivation to change other than when explicitly stated in the written reflections or when teachers demonstrated with their voice tone and inflection their enthusiasm to change during the audio discussion session. Pop, Dixon and Grove (2010) argue that "what teachers believe about their abilities and teaching practices may also 
influence their expectancies of making change" (p. 130). It is possible that if teachers' motivation to change was assessed in the beginning of the PD, the researchers could better explain some of the changes observed.

We found a trend in teachers' reflections and the impact of it in their instructional changes. It appears that only when teachers explicitly demonstrated a desire to improve their practice by writing about it on their written reflections or by voicing it during the reflective discussion, did a change really occurred. Most teachers wrote about the importance of some instructional practices, acknowledging that a change could improve their practice. However, other than James, Linda and Donna, nobody else demonstrated a clear desire to intentionally change their instructional practice. More research about intention to change versus acknowledgment of the importance to change is necessary to confirm the findings from this study.

\section{$\underline{\text { The Specific Case of Content and Cognitive Skills for Science }}$}

When analyzing the possible changes between the implementations of the integrated units, the first result that is evident is the lack of change on the content and cognitive skills practices for science. None of the eight teachers had a change in the TIP rubric scores even though the researcher posed twelve questions about this specific classroom practice for science. Only Mary did not receive a question about it on her TIP. At the same time, Linda, Donna, Jennifer and James report on their self-assessment scores that their students were engaged in cognitively challenging activities and/or investigations (changing their self-assessment score from a 3 in year 2 to a 4 in year 3 ). 
Data from the reflective conversation (audio) with the researchers demonstrated that Linda and Donna discussed content and cognitive skills for science five times and Jennifer and James four times. Those four teachers spent a considerable amount of time discussing this practice, but did not change their units enough in year 3 to demonstrate an improvement. It is possible that teachers did not improve their instructional practice related to content and cognitive skills because they may need extra "instances of practice" (Gulamhussein, 2013) and this instructional practice may be very complex and something that teachers' are not familiar with.

One way to explain the finding about no change on content and cognitive skills for science is to comprehend that the TIP rubric requires evidence in the students' work sample. It was not enough for teachers to make small changes to the type of questions they ask in discussions and on assessment, for example, if students did not produce the deeper thinking. We needed to have evidence of HOTS in the students' work samples for this TIP rubric category to receive a higher score. For example, Laura's TIP received a score of a 2 for content and cognitive skills in both years. Her $3^{\text {rd }}$ grade unit about force and motion was very content heavy in year 2 with minimal opportunities for students to practice higher-order thinking skills. Even though content was still overemphasized in year 3, she was able to include new opportunities for students to practice their observations and data analysis skills as well as draw conclusions based on the activities they experienced. However, Laura's students' work sample demonstrated that they were able to apply content but some misconceptions were also brought in and did not receive Laura's attention. Thus, Laura's slight improvement was not enough to produce evidence 
on the students' learning consequently, the researchers could not rate a higher content and cognitive skills TIP score for her unit in year 3 .

\section{$\underline{\text { Comparison Between TIP Scores and Self-Assessment Scores }}$}

The self-assessment scores teachers provided for their own practice using the selfassessment rubric sometimes did not reflect the scores the researchers provided to the TIPs. Almost all teachers scored their instructional practices with higher scores than the researchers. Further, the teachers' scores on the self-assessment were often disconnected with the positive and negative changes evidenced in the quantitative and qualitative analysis.

A common example of the lack of correlation between the TIP scores and the selfassessment scores was demonstrated in the content and cognitive instructional practice, for science. Excluding Mary and Susan who did not self-assessed for year 3, for science, only Laura scored her cognitive demand instructional practice with the same score both years, representing her awareness that she did not change her cognitive demand practice. The remaining five teachers self-reported some perceived change with four teachers selfscoring themselves higher in cognitive demand in year 3 compared to year 2 for science and one self-scoring lower. There was no change on content and cognitive scores for science on the TIP rubric scores for year 3.

For mathematics, the situation was similar. Based on Linda, Donna and Jennifer's self-assessment scores, the cognitive demand of their units increased in year 3. However, their TIP scores demonstrated no change in this practice. Nancy's self-reported score for 
year 3 was the same as her score for year 2, but her TIP score was lower indicating a negative change for content and cognitive skills. Laura self-assessment also indicated no change but the researchers, through the TIP score, indicated an increase in her content and cognitive demand practice. James was the only teacher for mathematics who selfreported no change for cognitive demand between the two years and his TIP scores demonstrated the same.

There is indication in the literature that teachers' self-assessment scores tend to be higher than what teachers' instructional practices demonstrate (Capps \& Crawford, 2013, Harnett, 2012, Lakshmanan et al., 2011 and Ross \& Bruce, 2007). Capps and Crawford (2013) reported a similar situation as the one observed in this study where there was no change in instructional practice, but a positive change in teachers' self-assessment scores. The authors state "interview data suggested that many teachers who were not teaching science as inquiry believed that they were, since they involved their students in questioning, used student-centered approaches, and used hands-on teaching practices" (p. 519). Capps and Crawford explain this discrepancy in scores by calling attention to the fact that "teacher self-report alone fails to give an accurate picture of actual classroom practice" (p. 523).

This study took a closer look at teachers' self-assessment scores during the data analysis to verify possible relationships within other data sources, for example TIP scores, frequency of discussion about specific instructional practices in the audio, and written reflections. Our findings corroborate Capps and Crawford's (2013) findings that 
self-assessment scores should not be used as an indication of instructional practices changes in the classroom since self-report data alone fails to generate an accurate display of what is happening in the classrooms.

\section{External Factors that Could Have Contributed to Teachers' Instructional Change}

Some of the instructional changes observed in this study could not be explained by the analyzed data. There is possibility that external factors not measured by this study could have had an impact in teachers changing their instructional practices. We recommend that those factors need to be considered in future research studies to better understand the impacts of reflective PD in teachers' instructional practices.

Factors not measured by this study that could have contributed to teachers' positive change in instructional practices in science and mathematics are: working in collaboration (especially in the case of Donna and Linda) (Gulamhussein, 2013; Hoban et al., 2007), support from the schools' administrators (Ingvarson et al., 2005), motivation to change (Ryan \& Deci, 2000) and change in students' learning (Guskey, 2002). Adding those variables in future research about changes in teachers' instructional practices, may facilitate the analysis of the results of reflective PD.

Other factors that could have contributed to the negative changes a few teachers demonstrated in this study were: lack of support from their school administrators (Kazempour, 2009), too few instances of implementation of the unit for teachers to really master the new skill (Gulamhussein, 2013; Hoban et al., 2007), lack of motivation (Ryan \& Deci, 2000), not enough collaboration with colleagues (Hoban et al., 2007; 
Kazempour, 2009), and no evidence of change in students' learning (Guskey, 2002).

Those external factors not measured by this study combined with the difficulties

elementary school teachers have to deeply reflect on their practice (Marcos et al., 2008)

may have impacted teachers' ability to change in year 3.

\section{Limitations of the Study}

Although this study illustrated possible changes in elementary school teachers' instructional practices in relation to science and mathematics, we did not have a random sample of participants. The participating teachers were recruited to participate in the three-year long professional development based on their leadership position in their schools. Since the sample of teachers who participated in this study was not random, a claim that the results of this study were representative of all elementary school teachers is not possible.

During the data analysis, the researchers were not able to reach adequate level of inter-rater reliability on the TIP rubric scores. However, the research group was able to reach consensus on the TIP scores as well as on the frequency code developed to code the audio conversations between the teachers and the researchers. By coming to consensus on scores, it is possible that a researcher conducting the same investigation alone could produce different results; however, consensus is preferable than one researcher scoring and coding in isolation. In addition, there is a possibility that if we had reached consensus on the TIP rubric bullet level scores, we might have been able to articulate changes in teachers' instructional practices more clearly. 
Although the TIP provides detailed information about the integrated units and instructional practices for science and mathematics, the researchers did not have an opportunity to observe the teachers implementing their units. It is possible that classroom observations and interviews could have given the researchers a more complete picture of the nuances influencing implementation of the instructional practices and complement and support the data analysis. For example, classroom discussions could have fostered a deeper analysis or understanding of the content that the TIP rubric could not capture.

\section{Questions for Further Research}

Though this mixed methods study illustrated possible changes in teachers' mathematics and science instructional practices, it would be interesting to better understand what characteristics of reflective professional development impact those changes. It is not clear in these results or in the literature what aspects of reflective PD (i.e. teachers' self-assessment, teachers' reflection, teachers' collaboration, frequency of time spent discussing a specific practice) most impacted teachers' change. With this, it could be interesting to develop a study focused only on one factor at a time. By isolating the possible aspects of reflective PD that could have an impact on teachers' instructional practices change, a research study could better reveal which PD activity may foster high quality instruction in the classroom.

Further, because some of the changes represented in this study may be related to teachers' willingness to change their practice, a motivation to change survey/rubric could be an interesting instrument to be added to future studies of reflective PD. It is possible 
that with results from a motivational scale, researchers could better explain the increases, decreases and lack of change (i.e.: static score) in teachers' instructional practices demonstrated in this study.

Since, in the audio, it was observed that some extensive time was spent on discussing the integration of mathematics and science when planning and implementing teachers' integrated units, it could be interesting to investigate the TIP scores that each teacher received based on Lonning and DeFranco (1997) continuum model of integration for mathematics and science. For effective integration to happen both content areas need to be taught the best way possible (Lonning \& DeFranco, 1997).

The audio analysis also revealed an extensive amount of time spent on logistics. For example, James and Jennifer had a long discussion about the new mathematics curriculum adopted by their district and how difficult it was to learn and teach the new material at the same time. Considering this factor, logistics probably represents a relevant topic for teachers. Professional development designers need to be aware of the importance of logistics to teachers and include extra time on their PD agenda to discuss it. It is possible that the logistics theme reduced teachers' focus on the instructional practices discussion, may have had an impact on teachers' reflection and even had a cumulative effect on a teachers' practice and students' opportunities to learn.

Further research is also recommended on the impacts of reflective PD on students' learning. The literature suggests that teachers will only sustain changes in instructional practices over time when improvement in students' learning occurs (Elmore 
\& Burney, 1999; Gulamhusseim, 2013; Guskey, 2002). Even though this research study reported on science and mathematics teachers' instructional changes, the literature suggests that those changes will only be maintained if the students demonstrate learning progress within the concepts and higher-order thinking skills of those integrated units. An analysis of students' work samples from year 2 and year 3 of unit implementation may provide evidence of student progress and consequently indicate a better explanation for teachers' instructional change.

Finally, Gulamhussein (2013) emphasizes the need for effective professional development because to "internalize a practice and change their beliefs, teachers must see success with their students, but student success is very hard to come by initially, as learning new skills takes several attempts to master" (p. 12). To better serve our students, we need not only to enhance teachers' instructional practice through effective PD but also support the needs of those teachers after the PD experiences. 


\section{References}

Anderson, R. D. (2002). Reforming science teaching: What research says about inquiry. Journal of Science Teacher Education, 13(1), 1-12.

Black, P., \& Wiliam, D. (1998). Inside the black box - Raising standards through classroom assessment. Phi Delta Kappan, 80(2), 139-144.

Capps, D. K., \& Crawford, B. A. (2013). Inquiry-based instruction and teaching about nature of science: Are they happening? Journal of Science Teacher Education, 24(3), 497-526.

Common Core State Standards Initiative. (July, 2014). About the standards. Retrieved from: http://www.corestandards.org/about-the-standards/

Dougherty, C. (2013). College and career readiness: The importance of early learning. Retrieved from ACT Research and Policy: http://www.act.org/research/policymakers/pdf/ImportanceofEarlyLearning.pdf

Douville, P., Pugalee, D. K., \& Wallace, J. D. (2003). Examining instructional practices of elementary science teachers for mathematics and literacy integration. School of Science and Mathematics, 103(8), 388-396.

Elmore, R. F., \& Burney, D. (1999). Investing in teacher learning. In Darling-Hammond, L., \& Sykes, G. (Eds.), Teaching as the Learning Profession: Handbook of Policy and Practice (pp. 263-291). San Francisco: Jossey-Bass.

Ferraro, J. (2000). Reflective practice and professional development. Retrieved from ERIC database. (ED449120)

Glenn, M. (2011). Developing holistic practice through reflection, action and theorising. Educational Action Research, 19(4), 489-502.

Gulamhussein, A. (2013). Teaching the teachers: effective professional development in an era of high stakes accountability. Retrieved from Center for Public Education: http://www.centerforpubliceducation.org/Main-Menu/Staffingstudents/Teachingthe-Teachers-Effective-Professional-Development-in-an-Era-of-High-StakesAccountability/Teaching-the-Teachers-Full-Report.pdf

Guskey, T. R. (2002). Professional development and teacher change. Teachers and Teaching: theory and practice, 8(3/4), 381-391.

Harnett, J. (2012). Reducing discrepancies between teachers' espoused theories and theories-in-use: An action research model of reflective professional development. Educational Action Research, 20(3), 367-384. 
Hiebert, J., Carpenter, T. P., Fennema, E., Fuson, K. C., Wearne, D., Murray, H., Olivier, A., \& Human, P. (1997). Making sense - Teaching and learning mathematics with understanding. Portsmouth, NH: Heinemann.

Hiebert, J. \& Stigler, J. W. (2000). A proposal for improving classroom teaching: Lessons from the TIMSS Video Study. The Elementary School Journal, 101(1), 3-20.

Hoban, G. F., Butler, S., \& Lesslie, L. (2007). Facilitating self-study of professional development: Researching the dynamics of teacher learning. Studying Teacher Education, 3(1), 35-51.

Ingvarson, L., Meiers, M., \& Beavis, A. (2005). Factors affecting the impact of professional development programs on teachers' knowledge, practice, student outcomes \& efficacy. Education Policy Analysis Archives, 13(10), 1-26.

Kazempour, M. (2009). Impact of inquiry-based professional development on core conceptions and teaching practices: A case study. Science Educator, 18(2), 56-68.

Lakshmanan, A., Heath, B. P., Perlmutter, A., \& Elder, M. (2011). The impact of science content and professional learning communities on science teaching efficacy and standards-based instruction. Journal of Research in Science Teaching, 48(5), 534551.

Linn, M. C., Lee, H-S., Tinker, R., Husic, F., \& Chiu, J. L. (2006). Teaching and assessing knowledge integration in science. Science, 313, 1049-1050.

Lonning, R. A., \& DeFranco, T. C. (1997). Integration of science and mathematics: A theoretical model. School of Science and Mathematics, 97(4), 212-215.

Marcos, J. J. M., Sanchez, E., \& Tillema, H. H. (2008). Teachers reflecting on their work: articulating what is said about what is done. Teachers and Teaching: theory and practice, $14(2), 95-114$.

Marx, R. \& Harris, C. J. (2006). No child left behind and science education: Opportunities, challenges, and risks. The Elementary School Journal, 106(5), 467477.

Minner, D. D., Levy, A. J., \& Century, J. (2010). Inquiry-based science instruction What is it and does it matter? Results from a Research Synthesis Years 1984 to 2002. Journal of Research in Science Teaching, 47(4), 474-496.

National Research Council. (2012). A framework for K-12 science education: practices, crosscutting concepts, and core ideas. Washington, D.C.: The National Academies Press. 
Parise, L. M., \& Spillane, J. P. (2010). Teacher learning and instructional change: How formal and on-the-job learning opportunities predict change in elementary school teachers' practice. The Elementary School Journal, 110(3), 323-346.

Pop, M. M., Dixon, P., \& Grove, C. M. (2010). Research Experiences for Teachers (RET): Motivation, Expectations, and Changes to Teaching Practices due to Professional Program Involvement. Journal of Science Teacher Education, 21(2), 127-147.

Ross, J. A., \& Bruce, C. D. (2007). Teacher self-assessment: A mechanism for facilitating professional growth. Teaching and Teacher Education, 23, 146-159.

Ryan, R.M. \& Deci, E. L. (2000). Self-determination theory and the facilitation of intrinsic motivation, social development, and well-being. American Psychologist, 55(1), 68-78.

Schoenfeld, A. H. (1988). When good teaching leads to bad results: The disasters of "well-taught" mathematics courses. Educational Psychologist, 23(2), 145-166.

Schwartz, R. S., Lederman, N. G., \& Abd-El-Khalick, F. (2000). Achieving the reforms vision: The effectiveness of a specialists-led elementary science program. School of Science and Mathematics, 100(4), 181-193.

Shulman, L. S., \& Shulman, J. H. (2004). How and what teachers learn: A shifting perspective. Journal of Curriculum Studies, 36(2), 257-271.

Stanulis, R. N., Little, S., \& Wibbens, E. (2012). Intensive mentoring that contributes to change in beginning elementary teachers' learning to lead classroom discussion. Teaching and Teacher Education, 28, 32-43.

Stein, M., Smith, M., Henningsen, M. A., \& Silver, E. A. (2009). Implementing standards-based mathematics instruction: A casebook for professional development. Second Edition. Teachers College Press.

Weston, C., Gandell, T., Beauchamp, J., McAlpine, L., Wiseman, C., \& Beauchamp, C. (2001). Analysing Interview Data: The development and evolution of a coding system. Qualitative Sociology, 24(3), 381-400. 
Appendix A

Detailed TIP Instructions - Year 2

\section{Connect2MATH - Connect2SCIENCE Teacher Instructional Portfolio Year 2: Integrated Unit}

\section{Unit Title:}

This portfolio should document the implementation of the integrated unit you developed during the Connect2INTEGRATION course.

We ask you to review your instructional portfolio after the implementation of your unit. Please make sure to include an updated calendar, planning template and your completed reflections in your final instructional portfolio.

The portfolio contains the following sections:

I. Knowledge, Skills, and Experiences Outcomes

II. Assessments

III. Pedagogical Strategies 


\section{Knowledge, Skills, Experiences (K,S,E) Outcomes}

Please organize the unit materials in this section to represent the chronological order of implementation as best as possible.

1) Every teacher uses different strategies to plan and implement lessons. Please insert what you use for your lessons in this section of your portfolio. This includes, but is not limited to, the lesson planning template provided in the integrated workshop, copies of your lesson planning book, textbook lessons or pages, etc.

2) Use the 3 ring binder and the provided pockets to document artifacts from your unit that represent the knowledge, skills, and experiences outcomes for your unit.

Artifacts you might select for your portfolio include:

- Written lesson plans or planning notes (if generated ahead of time)

- Powerpoint slides or lecture notes

- Notes, problems, or questions you wrote on the white board or transparencies

- Description of any classroom activities relevant to the outcomes

- Notes written to yourself about the lesson

- Observation notes written to yourself about your students

- Handouts given that relate to the outcomes (ex. Notes, worksheets, laboratory instructions, problem descriptions, etc.)

3) Prior to turning in your instructional portfolio, please reflect on your original unit plan and mark it with notes/adjustments as appropriate. (i.e. 'did not do this activity - ran out of time', etc.) 


\section{Assessments}

Follow the Instructions below for this section of your Instructional portfolio.

Please organize the unit materials in this section to represent the chronological order of implementation as best as possible.

Use the 3 ring binder and the provided pockets to document the assessments used for your unit - be mindful of any formal and/or informal (questioning strategies, quick homework checks at the beginning of class, observations, etc.) assessment practices and try to document both.

\section{Artifacts you might select for your portfolio include:}

- Formative assessments given at the end of, or during, a class period to inform you of student progress

- Notes about questioning strategies used in your class (what questions were asked?)

- Homework

- Journal entries

- Summative assessments (unit exams, projects, etc.)

- Checklists

- Observation notes written to yourself about your students

- Rubrics used to score your students' assessments

- Integrated work sample

Please note:

1) full class sets of student work samples will also be collected, but in this portfolio section you should select low, medium, and high examples of student work. Please write ' $L$,' ' $M$,' or ' $H$ ' on it.

2) you should also clearly flag any assessments that you feel assesses both math and science outcomes (i.e. write ' $M$ \& $S$ ' on the assessment) 


\section{Pedagogical Strategies}

This section should contain your reflections of, and about, the instructional strategies you used while teaching the integrated unit. It may also contain artifacts that you feel are important to help you illustrate the strategies you use when teaching mathematics. Please make sure to fill out the attached reflection prompts during, or at the end of the unit.

Use the 3 ring binder and the provided pockets to document the pedagogical strategies used in your unit. Insert any artifacts in the order they are used so the sequence of events is clear.

Please make sure you include:

- Reflections about the pedagogical strategies used (see attached prompts)

- Any artifacts that demonstrate pedagogical strategies that were used (i.e. handouts you give students about group work, notes from class discussions, etc 
Integrated Unit

$\mathrm{C} 2 \mathrm{M}-\mathrm{C} 2 \mathrm{~S}$

\section{Pedagogical Strategies: Reflections}

There are many different pedagogical strategies and more than one strategy can be used in any given lesson.

1) Please list the pedagogical strategies you used while teaching your integrated unit.

2) Of the pedagogical strategies used while teaching your unit, please estimate the percentage of class time spent using each strategy for the unit as a whole. 
3a) Of the pedagogical strategies used, which strategies were most effective in helping students better understand the math content? Why?

3b) Of the pedagogical strategies used, which strategies were most effective in helping students better understand the science content? Why? 
4a) Of the pedagogical strategies used, which strategies were most effective in helping students develop problem solving skills? Why?

4b) Of the pedagogical strategies used, which strategies were most effective in helping students develop science inquiry skills? Why? 
5) Of the pedagogical strategies used, which strategies were most effective in helping students communicate their thinking in problem solving skills and science inquiry skills? Why?

6) Of the pedagogical strategies used, which strategies were most effective in helping you with classroom management? Why? 
7) What were the benefits and challenges of integrating math and science in your classroom? 
Detailed TIP Instructions - Year 3

\section{Knowledge, Skills, Experiences (K,S,E) Outcomes}

Please organize the unit materials in this section to represent the chronological order of implementation as best as possible.

1) Every teacher uses different strategies to plan and implement lessons. Please insert what you use for your lessons in this section of your portfolio. This includes, but is not limited to, the lesson planning template provided in the integrated workshop, copies of your lesson planning book, textbook lessons or pages, etc.

2) Use the 3 ring binder and the provided pockets to document artifacts from your unit that represent the knowledge, skills, and experiences outcomes for your unit.

Artifacts you might select for your portfolio include:

- Written lesson plans or planning notes (if generated ahead of time)

- Powerpoint slides or lecture notes

- Notes, problems, or questions you wrote on the white board or transparencies

- Description of any classroom activities relevant to the outcomes

- Notes written to yourself about the lesson

- Observation notes written to yourself about your students

- Handouts given that relate to the outcomes (ex. Notes, worksheets, laboratory instructions, problem descriptions, etc.)

3) Prior to turning in your instructional portfolio, please reflect on your original unit plan and mark it with notes/adjustments as appropriate. (i.e. 'did not do this activity - ran out of time', etc.). Portfolio's turned in without this step completed will be considered incomplete and will be returned for revision. 


\section{Pedagogical Strategies}

This section should contain your reflections of, and about, the instructional strategies you used while teaching the integrated unit. It may also contain artifacts that you feel are important to help you illustrate the strategies you use when teaching your integrated unit. Please make sure to fill out the attached reflection prompts during or at the end of the unit.

Use the 3 ring binder to document the pedagogical strategies used in your unit. Insert any artifacts in order they are used so the sequence of events is clear.

Please make sure you include:

- Reflections about the pedagogical strategies used (see attached prompts)

- Any artifacts that demonstrate pedagogical strategies that were used (i.e. handouts you give students about group work, notes from class discussions, etc) 
Integrated Unit

C2M-C2S Year 3

\section{Pedagogical Strategies: Reflections}

There are many different pedagogical strategies and more than one strategy can be used in any given lesson.

1) Please list the pedagogical strategies you used while teaching your integrated unit.

\begin{tabular}{|l|l|}
\hline $\begin{array}{l}\text { List the pedagogical strategies you used while teaching } \\
\text { your integrated unit. }\end{array}$ & $\begin{array}{l}\text { Please estimate the } \\
\text { percentage of class time } \\
\text { spent using each } \\
\text { strategy for the unit as a } \\
\text { whole. }\end{array}$ \\
\hline & \\
\hline & \\
\hline & \\
\hline & \\
\hline & \\
\hline & \\
\hline & \\
\hline & \\
\hline & \\
\hline & \\
\hline & \\
\hline & \\
\hline & \\
\hline & \\
\hline & \\
\hline
\end{tabular}


2) Of the pedagogical strategies used, which strategies were most effective in helping students better understand the math content? Please explain in detail and provide observations,examples, or specific data that leads you to this conclusion.

3) Of the pedagogical strategies used, which strategies were most effective in helping students develop problem solving skills (i.e. looking for patterns, making conjectures, justifying those conjectures)? Please explain in detail and provide observations, examples, or specific data that leads you to this conclusion. 
4) Of the pedagogical strategies you used, which strategies were most effective in helping students better understand the science content? Please explain in detail and provide observations, examples, or specific data that leads you to this conclusion.

5) Of the pedagogical strategies you used, which strategies were most effective in helping students develop science inquiry skills (i.e. asking questions, making observations, collecting data, drawing conclusions) or engineering design skills (i.e. defining the problem, generate possible solutions, testing solutions, analyzing and interpreting results)? Please explain in detail and provide observations, examples, or specific data that lead you to this conclusion. 
7) Please share an example from your unit that illustrates the roles that both you, as the teacher, and your students, as learners, took in this unit. Things that you might share include: what strategies you used to facilitate student learning in this example, who determined the accuracy of results or is the source for content knowledge (you, text, video, individual students, student groups, how are concepts explored or skills applied in the example, etc). 
8) Please share an example from your unit, where you feel you were able to use cooperative learning or grouping strategies to foster deeper learning or the development of problem solving, science inquiry, or engineering design skills. Be specific about the classroom context in your example, strategies you used to set up successful group dynamics, evidence or observations that lead you to believe this strategy was effective, etc. 
9) What were the benefits and challenges of integrating math and science in your classroom? 


\section{Appendix B}

\section{TIP Rubric}

\begin{tabular}{|c|c|c|c|}
\hline \multicolumn{4}{|c|}{ Ieacner Instructional rorctollio [IIIF/ Kuoric } \\
\hline Score & Classroom Roles & Content and Cognitive Sk & Score \\
\hline 4 & 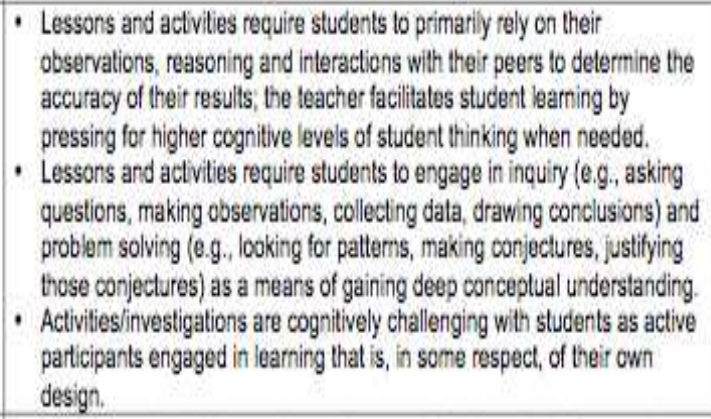 & $\begin{array}{l}\text { - The unit as implemented largets both content and higher- } \\
\text { order cognitive skils, frequently at the same time, } \\
\text { presenting students with opportunities to use both content } \\
\text { knowledge and cognitive skills in the same activities, } \\
\text { - lessons, or investigation(s). } \\
\text { - Lessons, activities, and investigation(s) in the unit, when } \\
\text { laken logether, represent multiple and diverse varieties of } \\
\text { opportunities for students to construct meaning, apply } \\
\text { content, and practice higher-order cognitive skills. }\end{array}$ & 4 \\
\hline 3 & 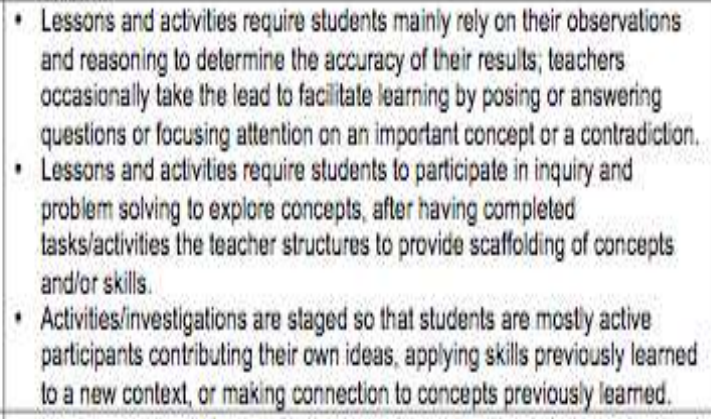 & $\begin{array}{l}\text { - The unit as implemented targets both content and higher- } \\
\text { order cognitive skills with frequent opportunities for } \\
\text { students to use both content knowledge and cognitive skills } \\
\text { in the same activites, lessons, or investigation(s). } \\
\text { - Lessons, activites, and investigation(s) in the unit, when } \\
\text { laken together, represent multiple opportunites for students } \\
\text { to construct meaning, apply content, and practice higher- } \\
\text { order cognilive skills. }\end{array}$ & 3 \\
\hline 2 & 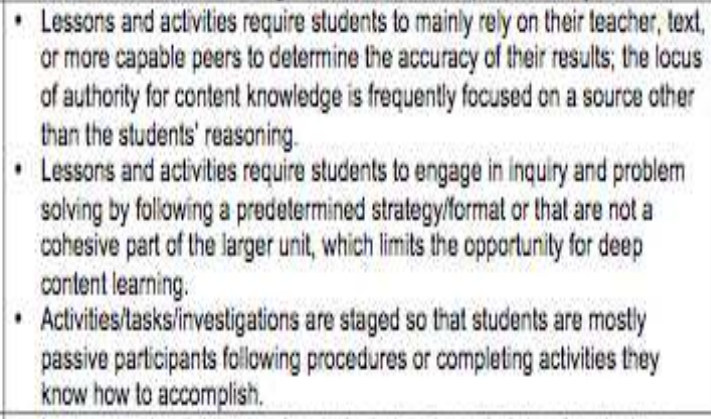 & $\begin{array}{l}\text { - The unil as implemtented largets both content and higher- } \\
\text { order cognilive skills, however, the lessons, activities, and } \\
\text { investigations overemphasize content or cognitve skills at } \\
\text { the expense of the other learning targets. } \\
\text { - Lessons, activities, and investigation(s) in the unit, when } \\
\text { laken logether, provide inconsistent opportunities for } \\
\text { students to construct meaning, apply content, and practice } \\
\text { higher-order cognitive skills. }\end{array}$ & 2 \\
\hline 1 & 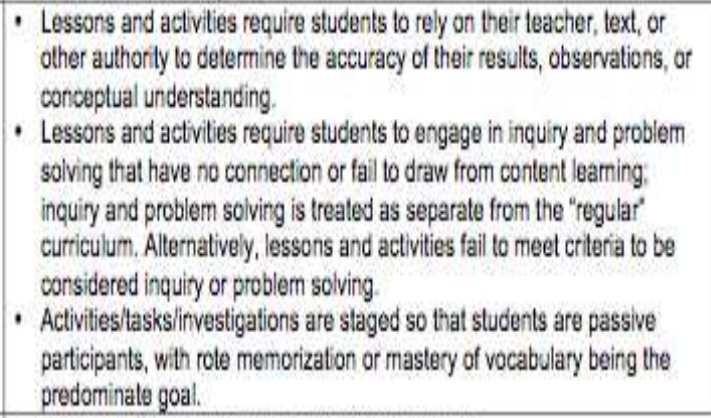 & $\begin{array}{l}\text { - The unit as implemented largets only content or higher- } \\
\text { order cognilive skills. } \\
\text { - Lessons, activities, and investigation(s) in the unit, when } \\
\text { laken logether, do not represent opportunities for stucentls } \\
\text { to construct mearing, apply content, and practice higher- } \\
\text { order cognilive skills. }\end{array}$ & 1 \\
\hline 0 & - Evidence either missing or to insufficient to score. & - Evidence either missing or to insufficient to score. & 0 \\
\hline
\end{tabular}


Teacher Instructional Portfolio (TIP) Rubric

\begin{tabular}{|c|c|c|}
\hline Score & Assessment for Learning & Score \\
\hline 4 & $\begin{array}{l}\text { - Student conceptions and skills are frequently assessed prior to, during, } \\
\text { and after lessons through intentional selection of formative and } \\
\text { summative assessments that link clearly to learning goals; } \\
\text { misconceptions or skill deficits are addressed through intentional teacher } \\
\text { moves. } \\
\text { - The unit is structured with frequent opportunities for students to self- } \\
\text { assess, reflect on their observations, understanding, or teacher/peer } \\
\text { feedback, and monitor their progress toward learning targets. } \\
\text { - The unit's assessments consistently have appropriate cognitive demand, } \\
\text { represent appropriate learning progressions, are aligned with designated } \\
\text { learning goals and standards, and generate evidence of performance } \\
\text { criteria for meeting those goais. }\end{array}$ & 4 \\
\hline 3 & $\begin{array}{l}\text { - Student conceptions are frequently assessed prior to, during, and after } \\
\text { lessons through intentional selection of formative and summative } \\
\text { assessments that link clearly to learning goals. } \\
\text { The unit is structured with periodic opportunities for students to self- } \\
\text { assess, reflect on their observations, understanding, or teacher/peer } \\
\text { feedback, and monitor their progress toward learning targets. } \\
\text { The unit's assessments primarily have developmentally appropriate } \\
\text { cognitive demand, represent appropriate learning progressions, are } \\
\text { aligned with designated learning goals and standards, and generate } \\
\text { evidence of performance criteria for meeting those goals. }\end{array}$ & 3 \\
\hline 2 & $\begin{array}{l}\text { - Student conceptions sometimes are assessed prior to, during, and after } \\
\text { lessons through intentional selection of formative and summative } \\
\text { assessments that link to some, but not all leaming goals. } \\
\text { - The unit is structured with opportunities for students to self-assess, or } \\
\text { monitor their progress toward learning targets, but these opportunities } \\
\text { are infrequent or superficial. } \\
\text { The majority of the unit's assessments are aligned with designated } \\
\text { learning goals and standards and generate evidence of performance } \\
\text { criteria for meeting those goals, however, a few assessments are either } \\
\text { not appropriate in terms of cognitive demand, not representative of } \\
\text { learning progressions, or misaligned with goals/standards. }\end{array}$ & 2 \\
\hline 1 & $\begin{array}{l}\text { Student conceptions are infrequently or not assessed prior to, during, } \\
\text { andior after lessons through intentional selection of formative and } \\
\text { summative assessments. } \\
\text { The unit not is structured with opportunities for students to self-assess, } \\
\text { or monitor their progress toward learning targets. } \\
\text { The unit's assessments primarily are either not aligned with designated } \\
\text { learning goals and standards, not representative of learning } \\
\text { progressions, fail to generate evidence of performance criteria for } \\
\text { meeting those goals, or are not developmentally appropriate in terms of } \\
\text { cognitive demand. }\end{array}$ & 1 \\
\hline 0 & - Evidence either missing or to insulficient to score. & 0 \\
\hline
\end{tabular}




\section{Appendix C}

\section{Teacher Self-Assessment Rubric - Science \\ Connect2Math/Connect2Science Math Science Partnership Teacher Self-Assessment Instructional Vision: Science}

1 select/adapt tasks and activities informed by

- my deep, rich, and well-connected understanding of science;

$\begin{array}{ccc}\text { Strongly Disagree } & \text { Disagree } & \text { Agre } \\ \square & \square & \square \\ \square & \square & \square \\ \square & \square & \square \\ \square & \square & \square\end{array}$

Teacher $\mathrm{Na}$

- my grade level content/core standards in science;

- my students' interests, questions, etc. and

- what 1 know about how students at this age learn.

\begin{tabular}{|c|c|c|c|c|}
\hline \multirow{2}{*}{ 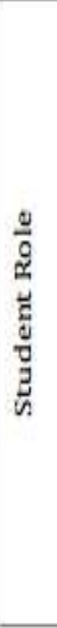 } & $\begin{array}{l}\text { Students look to me, the text, } \\
\text { or some authority beyond } \\
\text { themselves to determine the } \\
\text { accuracy of their conceptual } \\
\text { understanding or } \\
\text { observations. }\end{array}$ & $\begin{array}{l}\text { Students rely on me, the text, } \\
\text { or more capable peers to } \\
\text { provide the correct "answer" } \\
\text { or to verify that their } \\
\text { observation or conclusion } \\
\text { makes sense. }\end{array}$ & $\begin{array}{l}\text { Students mainly rely on their } \\
\text { observations and scientific } \\
\text { reasoning to determine the } \\
\text { accuracy of their results, though } \\
\text { occasionally I intervene to } \\
\text { answer a question or focus } \\
\text { attention on a contradiction. }\end{array}$ & $\begin{array}{l}\text { Students rely on their own } \\
\text { observations and scientific } \\
\text { reasoning and interactions with } \\
\text { their peers to determine the } \\
\text { accuracy of their results! I interject } \\
\text { by asking questions to encourage } \\
\text { student thinking at higher } \\
\text { cognitive levels when needed. }\end{array}$ \\
\hline & $\begin{array}{l}\text { Students engage in inquiry } \\
\text { devoid of other content } \\
\text { learning (e.g, science inquiry } \\
\text { is separate from the } \\
\text { "regular" curriculum)? }\end{array}$ & $\begin{array}{l}\text { Students participate in } \\
\text { activities that are not a } \\
\text { cohesive part of a larger unit } \\
\text { which limits the opportunity } \\
\text { for deep content learning? }\end{array}$ & $\begin{array}{l}\text { Students participate in inquiry } \\
\text { to explore concepts, but do so } \\
\text { by following steps or } \\
\text { procedures I purposefully } \\
\text { provide to allow for } \\
\text { confirmation of concepts. }\end{array}$ & $\begin{array}{l}\text { Students engage in inquiry (e.g." } \\
\text { asking questions, making } \\
\text { observations, collecting data, } \\
\text { drawing conclusions) as a means of } \\
\text { gaining deep conceptual } \\
\text { understanding. }\end{array}$ \\
\hline \multirow{2}{*}{ 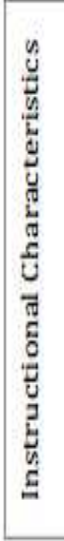 } & $\begin{array}{l}\text { Students' learning } \\
\text { opportunities are limited to } \\
\text { whole group instruction } \\
\text { sometimes followed by } \\
\text { individual work time. }\end{array}$ & $\begin{array}{l}\text { Students' learning } \\
\text { opportunities are generally } \\
\text { limited whole group } \\
\text { discussion and/or instruction } \\
\text { followed by individual or } \\
\text { partner work time. }\end{array}$ & $\begin{array}{l}\text { Students' learning } \\
\text { opportunities include } \\
\text { individual, partner, small and } \\
\text { whole group but these may not } \\
\text { be selected based on the } \\
\text { particular task. }\end{array}$ & $\begin{array}{l}\text { Students have opportunities to } \\
\text { work individually, then with a } \\
\text { partner or in a small group, and } \\
\text { finally summarize with a whole } \\
\text { class discussion for sense makings. }\end{array}$ \\
\hline & $\begin{array}{l}\text { Students regularly engage in } \\
\text { tasks/activities that rely on } \\
\text { rote memorization or } \\
\text { mastery of vocabularys. }\end{array}$ & $\begin{array}{l}\text { Students passively engage in } \\
\text { tasks/activities they know } \\
\text { how to complete (i.e. they } \\
\text { follow procedures) with } \\
\text { partial connection to science } \\
\text { concepts. }\end{array}$ & $\begin{array}{l}\text { Students are mostly active } \\
\text { participants in } \\
\text { activities/investigations } \\
\text { contributing their own ideas or } \\
\text { applying skills previously } \\
\text { learned to a new context. }\end{array}$ & $\begin{array}{l}\text { Students regularly engage in } \\
\text { cognitively challenging } \\
\text { activities/investigations that are, in } \\
\text { some aspect, of their own design } \\
\text { (question, data collection, display } \\
\text { of data, \&/or conclusions)?. }\end{array}$ \\
\hline
\end{tabular}

1Anderson, 2002; Narshall, 7009

: Marsiall. 2009

1Appletan, 2002:Aaderson, 2002

4 Banchi \& Bell, 2008; Marshill, 2000

'Banchi, \& Bell, 2006, National Resesarch C.euncil, 2003, Stein, \& Smith, 2011

- Marshall, 2009; Secher, 2005

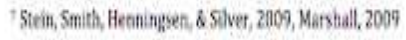

continued on reverse 


\section{Connect2Math/Connect2Science Math Science Partnership} Teacher Self-Assessment Instructional Vision: Science

\begin{tabular}{|c|c|c|c|c|}
\hline & $\begin{array}{l}\text { Student groups engage in } \\
\text { activities/ worksheets with } \\
\text { limited and sometimes } \\
\text { unbalanced interactions. }\end{array}$ & $\begin{array}{l}\text { Student groups occasionally } \\
\text { have the opportunity to engage } \\
\text { in tasks that have more than } \\
\text { one approach. I assign group } \\
\text { roles to encourage individual } \\
\text { accountabilitys. }\end{array}$ & $\begin{array}{l}\text { Student groups sometimes } \\
\text { engage in tasks that provide } \\
\text { opportunities for student with } \\
\text { different abilities to contribute. } \\
\text { The goals of the group work are } \\
\text { increased conceptual } \\
\text { understanding and social skills?. }\end{array}$ & $\begin{array}{l}\text { Students engage in } \\
\text { activities/discussions where } \\
\text { multiple abilities are relevant } \\
\text { which leads to balanced, open } \\
\text { interaction in the group. Students } \\
\text { are asked to reflect on group } \\
\text { process and interactions? }\end{array}$ \\
\hline & $\begin{array}{l}\text { Student discourse is limited to } \\
\text { one word or short } \\
\text { answers/explanations to } \\
\text { questions from the teacher. }\end{array}$ & $\begin{array}{l}\text { Students participate in } \\
\text { discourse with the teacher in } \\
\text { either individual, small group, } \\
\text { or whole group discussion. }\end{array}$ & $\begin{array}{l}\text { Students participate in } \\
\text { productive discourse but } \\
\text { interactions are consistently } \\
\text { mediated through the teacher. }\end{array}$ & $\begin{array}{l}\text { Students participate in productive } \\
\text { discourse with each other (and } \\
\text { myself, at times)- that is, social } \\
\text { exchange that provides the avenue } \\
\text { to construct and build on ideas } \\
\text { through interactions with } \\
\text { others }{ }^{\text {ti). }}\end{array}$ \\
\hline 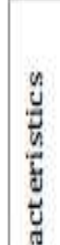 & $\begin{array}{l}\text { Student conceptions are nota } \\
\text { factor, rather the pacing } \\
\text { calendar or curriculum guide } \\
\text { is the strongest determinant } \\
\text { of next instructional steps. }\end{array}$ & $\begin{array}{l}\text { Student conceptions are } \\
\text { assessed and misconceptions } \\
\text { are partially addressed with } \\
\text { direct instruction. }\end{array}$ & $\begin{array}{l}\text { Student conceptions are } \\
\text { assessed prior to and during } \\
\text { lessons, misconceptions are } \\
\text { addressed through exploration } \\
\text { and discussion of the concept. }\end{array}$ & $\begin{array}{l}\text { Student conceptions, both correct } \\
\text { and incorrect, guide instructional } \\
\text { decisions }{ }^{11} \text { I I purposefully select } \\
\text { activities that will surface and/or } \\
\text { contradict misconceptions. }\end{array}$ \\
\hline 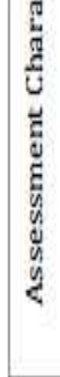 & $\begin{array}{l}\text { Students are not asked to self- } \\
\text { assess their work or monitor } \\
\text { their progress toward } \\
\text { learning targets. }\end{array}$ & $\begin{array}{l}\text { Students are occasionally } \\
\text { asked to reflect on what they } \\
\text { did or observed, but the } \\
\text { reflection remains superficial } \\
\text { with a focus on vocabulary or } \\
\text { steps in the } \\
\text { activity/investigation.'2 }\end{array}$ & $\begin{array}{l}\text { Students have periodic } \\
\text { opportunities to reflect on their } \\
\text { observation and draw } \\
\text { conclusions, but do not provide } \\
\text { explanations or use evidence. }\end{array}$ & $\begin{array}{l}\text { Students have ongoing } \\
\text { opportunities to self-assess their } \\
\text { work and monitor their progress } \\
\text { toward learning targets }{ }^{13} \text {.I } \\
\text { purposefully select self- } \\
\text { assessment tools that go beyond } \\
\text { checklists to facilitate student } \\
\text { reflection }{ }^{14} \text {. }\end{array}$ \\
\hline
\end{tabular}

Rindsdell, 2003

TRandsdell, 2003: Cohen, 19294

"Lampert, \& Blunk, 1999; Zohar \& Nere, 2002, |imenx-Alevandre, 2000; Nathan \& Knuth, 2009

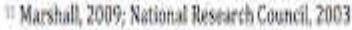

"Asdibactere \& Roth, 2002:5tectee, 2005

"Andersea, 2002; Marshall, 2009; Bladk and Wiliam, 1998, Stigins, 2005; fernande, \& Forana, 1996 w Bingham,Holbroak, and Meques, 2010 


\section{Teacher Self-Assessment Rubric - Mathematics}

\section{Connect2Math/Connect2Science Math Science Partnership Teacher Self-Assessment Instructional Vision: Mathematics}

I select/adapt tasks and activities informed by

- my deep, rich, and well-connected understanding of mathematics;

- my grade level content/core standards in mathematics;

- my students' interests, questions, etc. and

- what 1 know about how students at this age learn.
Teacher Nan

$\begin{array}{cccc}\text { Strongly Disagree } & \text { Disagree } & \text { Agree } & \text { Strongly Agree } \\ \square & \square & \square & \square \\ \square & \square & \square & \square \\ \square & \square & \square & \square \\ \square & \square & \square & \square\end{array}$

\begin{tabular}{|c|c|c|c|c|}
\hline \multirow{2}{*}{ 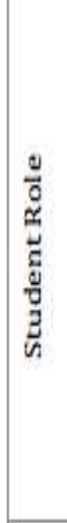 } & $\begin{array}{l}\text { Students look to me, the text, or } \\
\text { some authority beyond } \\
\text { themselves to determine the } \\
\text { accuracy of their results. }\end{array}$ & $\begin{array}{l}\text { Students rely on me, the text, or } \\
\text { more capable peers to provide } \\
\text { to confirm/verify that their } \\
\text { solution and/or solution path } \\
\text { makes sense. }\end{array}$ & $\begin{array}{l}\text { Students mainly rely on their own } \\
\text { mathematical reasoning to } \\
\text { determine the accuracy of their } \\
\text { results, though occasionally I } \\
\text { intervene to answer a question or } \\
\text { focus attention on a contradiction. }\end{array}$ & $\begin{array}{l}\text { Students rely on their } \\
\text { mathematical reasoning to } \\
\text { determine the accuracy of } \\
\text { their results! }\end{array}$ \\
\hline & $\begin{array}{l}\text { Students engage in inquiry and } \\
\text { problem solving separate from } \\
\text { other content learning. } \\
\text { Problem solving is treated as } \\
\text { separate from the "regular" } \\
\text { curriculum. }\end{array}$ & $\begin{array}{l}\text { Students engage in inquiry and } \\
\text { problem solving but do so by } \\
\text { following a particular strategy } \\
\text { or format. }\end{array}$ & $\begin{array}{l}\text { Students engage in inquiry and } \\
\text { problem solving after having } \\
\text { completed a similar task/activity } \\
\text { as a class. }\end{array}$ & $\begin{array}{l}\text { Students engage in inquiry } \\
\text { and problem solving (e.g," } \\
\text { looking for patterns, making } \\
\text { conjectures, justifying those } \\
\text { conjectures }{ }^{2} \text { ) as a means to } \\
\text { learn mathematics. }\end{array}$ \\
\hline \multirow{2}{*}{ 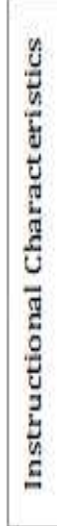 } & $\begin{array}{l}\text { Students' learning } \\
\text { opportunities are limited to } \\
\text { whole group instruction } \\
\text { followed by individual work } \\
\text { time. }\end{array}$ & $\begin{array}{l}\text { Students' learning } \\
\text { opportunities are generally } \\
\text { limited whole group discussion } \\
\text { and/or instruction followed by } \\
\text { individual or partner work } \\
\text { time. }\end{array}$ & $\begin{array}{l}\text { Students' learning opportunities } \\
\text { include individual, partner, small } \\
\text { and whole group but these may } \\
\text { not be selected based on the } \\
\text { particular task. }\end{array}$ & $\begin{array}{l}\text { Students have opportunities } \\
\text { to work individually, then } \\
\text { with a partner or in a small } \\
\text { group, and with finally } \\
\text { summarize with a whole } \\
\text { class a whole class } \\
\text { discussion? }\end{array}$ \\
\hline & $\begin{array}{l}\text { Students regularly engage in } \\
\text { tasks/activities that rely on } \\
\text { rote memorization. }\end{array}$ & $\begin{array}{l}\text { Students regularly engage in } \\
\text { procedural tasks/activities } \\
\text { they know how to complete. }\end{array}$ & $\begin{array}{l}\text { Students primarily engage in } \\
\text { tasks/activities they know how to } \\
\text { complete and periodically } \\
\text { complete more challenging } \\
\text { tasks/activities. }\end{array}$ & $\begin{array}{l}\text { Students regularly engage } \\
\text { in cognitively challenging } \\
\text { tasks/activities\}. }\end{array}$ \\
\hline
\end{tabular}

1 Secada \& Byrd. 1993

'Nattonal touncl ce Teachers of Mathematic, 2000

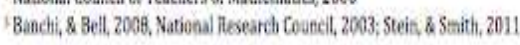

1Stein, Smith, Heaningsen, \& Siver, 2009 , Marshall, 2009 


\section{Connect2Math/Connect2Science Math Science Partnership Teacher Self-Assessment Instructional Vision: Mathematics}

\begin{tabular}{|l|l|l|l|l}
\hline & $\begin{array}{l}\text { Students engage in } \\
\text { tasks/activities that have a } \\
\text { particular approach/procedure } \\
\text { to follow. }\end{array}$ & $\begin{array}{l}\text { Students occasionally have the } \\
\text { opportunity to engage in tasks } \\
\text { that have more than one } \\
\text { approach. }\end{array}$ & $\begin{array}{l}\text { Students engage in tasks that } \\
\text { have multiple entry points or } \\
\text { provide opportunities for } \\
\text { multiple abilities (i.e, wide } \\
\text { range of intellectual abilities). }\end{array}$ & $\begin{array}{l}\text { Students engage in } \\
\text { tasks/activities that have } \\
\text { multiple entry points and/or } \\
\text { provide opportunities for } \\
\text { multiple abilities (i.e, wide } \\
\text { range of intellectual abilities) }\end{array}$ \\
\hline
\end{tabular}

'Boder, \& S Suples, 2008; Lotan, 2003; Coten, 1994; Vyatsky, 1979

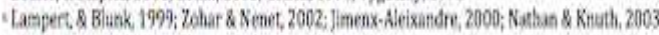

'Marshall, 2009; National Hesearch Council, 2003

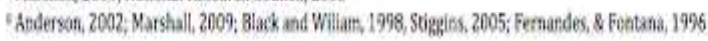




\section{Appendix D}

Reflection Day Agenda and Questions that Guided Teachers' Written Reflections

C2M-C2S: Year 2

Integrated Unit Data Reflection Day

\section{Goals:}

- Provide an opportunity for you to engage in reflective practice.

- Collaborate with your peers to revise the integrated units.

- Deepen your knowledge and skills for integration of disciplines.

- Help you move your instructional practice along the pathway.

\section{Agenda:}

Structure for Year 2 Data reflection days:

L. Self-assessment (20 min)

11. Goals of day \& review data analysis process (10 min)

111. Integrated Unit data: Math or Science Refiection First (40 min)

IV. Integrated Unit data: Math or Science Reflection Second (40 min)

V. Integrated Unit data: Integration Reflection ( 40 min)

V. Implications/reflection discussion focused on integration: (30 min)
a. Individual reflection
b. Whole group discussion 
$\mathrm{C} 2 \mathrm{M}-\mathrm{C} 2 \mathrm{~S}$

\section{Data analysis process:}

\section{Describing the Data}

- What do you see?

- How would you describe the data?

- Refrain from vocalizing judgments and interpretations at this point.

\section{Interpreting the Data}

- What does the data suggest?

- What are the assumptions we make about students and their learning?

- What are the assumptions we make about teachers and their practice?

- Try to find as many possible interpretations of the data as possible.

- As others express their interpretations, ask questions to better understand each other.

\section{Implications for Classroom Practice}

- What are the implications of this data for student learning and achievement?

- What are the implications of this data for teaching and assessment?

- Based on the interpretations of the data,

- What steps could be taken next?

- What strategies might be most effective?

- What else would you like to see happen?

- What kinds of assignments or assessments could provide this information?

- What does this conversation make you think about in term of your own practice?

- What does this conversation make you think about teaching and learning in general?

- Are there implications for equity?

4. Implications for your Professional Learning Community (PLC) next year

- What are the implications of this data for the goals of your PLC next year?

Based off the 'Critical Friends ATLAS: Looking at Data Protocol' 